\title{
Building and Fire Research Laboratory Publications, 1991
}

Nora H. Jason

QC

100

.056

4827

1992

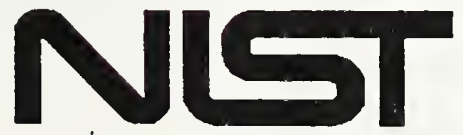

United States Department of Commerce

Technology Administration

National Institute of Standards and Technology 



\section{Building and Fire Research Laboratory Publications, 1991}

Nora H. Jason

\section{April 1992}

Building and Fire Research Laboratory

National Institute of Standards and Technology

Gaithersburg, MD 20899

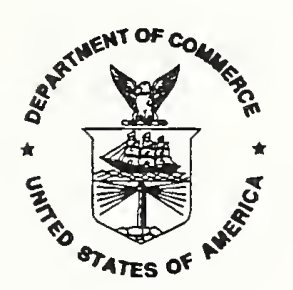

\section{U.S. Department of Commerce}

Barbara Hackman Franklin, Secretary

Technology Administration

Robert M. White, Under Secretary for Technology

National Institute of Standards and Technology

John W. Lyons, Director 


\section{CONTENTS}

Page

Abstract

iv

Literature Citations Arranged by First Author

1

Author Index

122

Keyword Index

126 
. 


\begin{abstract}
Building and Fire Research Publications, 1991 is the second edition to reflect the combined publications of the Building and Fire Research Laboratory (BFRL) for calendar year 1991. In 1991 the Center for Building Technology (CBT) and the Center for Fire Research (CFR) were combined to form BFRL. This publication is a supplement to Building and Fire Research Laboratory Publications, 1990 and previous editions of Fire Research Publications and the Building Technology Publications. Contact the author if you would like information about earlier editions. Only publications prepared by the members of the BFRL staff, by other National Institute of Standards and Technology (NIST) personnel for BFRL, or by external laboratories under contract or grant from BFRL are cited.
\end{abstract}

NIST Report series are available for purchase from either the Government Printing Office (GPO) or the National Technical Information Service (NTIS).

GPO documents, e.g., the NIST Technical Note series, are obtained by writing directly to the Superintendent of Documents, U. S. Government Printing Office, Washington, DC 20402. Orders must be payable to the "Superintendent of Documents, U. S. Government Printing Office". Major credit cards also may be used.

NTIS documents, i.e., the NISTIR and NIST-GCR series, are obtained by writing directly to the National Technical Information Service, Springfield, VA 22161. Microfiche copies of the documents also are available at a cost of approximately $\$ 12.00$ for domestic orders. Orders must be prepared by check or money order payable to "National Technical Information Service" or by utilizing your NTIS deposit account. Major credit cards also may be used. 

Alibe, B.

Alibe, B.; Cook, G. R.; Simiu, E.

Foias-Temam Approximations of Attractors for Galloping

Oscillators.

Morgan state Univ., Baltimore, MD

National Institute of Standards and Technology,

Gaithersburg, MD

ACE, EM Div. Mechanics Computing in 1990s and Beyond. May 20-21, 1991, Columbus, OH, 781-785 pp, 1991.

oscillators; equations; algebraic approximation; numerical integration

A method for the algebraic approximation of attractors recently developed by Foias and Temam is adapted for applicaton to autonomous galloping oscillators. We compare results obtained by algebraic approximation on the one hand and numerical integration on the other. We conclude with an assessment of the Iimitations of the method as applied to our systems.

Ames, $S$.

Ames, S. ; Parker, W. J.

Heat Release and Furniture.

Fire Research Station, Borehamwood, England

National Institute of Standards and Technology,

Gaithersburg, MD

Interscience Communications Limited. Heat Release and Fire Hazard. Ist U. S. Symposium. Abstracts. December 1991, San Diego, CA, 14 pp, 1991.

heat release; fire hazard; furniture; heat release rate;

rooms; furniture calorimeters; fire behavior; upholstery

over recent years there has been growing interest in the use

of rate of heat release measurement to provide meaningful

information about the burning characteristics of furniture.

studies are being actively undertaken in several countries and, research is now focusing on a small number of clearly defined techniques. In the United States, a full scale room fire test ( $\mathrm{Cal}$ 133) has been used to assess and to select upholstered seating for many years. Previously, in the last specification, heat release was not measured directly and air temperature measurements were used to indicate the deterioration of conditions in a room environment arising from the release of heat. Recent work at NIST has shown a correlation between these measurements and rate of heat release measurements obtained using a furniture calorimeter. The test specification has now been modified to include an option permitting the requirements to be met by furniture calorimeter measurements. In parallel with this, work in the UK at FRS has explored the use of a standard calorimeter test developed in sweden for furniture. Specimens, ignition source, apparatus design and test procedure were all similar to those used in the NIST studies. In addition, both programmes involved comparison between full scale rate of heat release measurements and those obtained from bench scale cone calorimetry. Particular attention was paid to peak rate of heat release comparison and the limiting condition where little or not fire growth was observed at full scale. 
Apte, V. B.

Apte, V. B. ; Bilger, R. W.: Green, A. R. ; Quintiere, J. G. Wind-Aided Turbulent Flame Spread and Burning over

Large-Scale Horizontal PMMA Surfaces.

Sydney Univ., Australia

Londonderry Occupational Safety Center, Australia

National Institute of Standards and Technology,

Gaithersburg, MD

Combustion and Flame, Vol. 85, No. 1-2, 169-184, 1991.

polymethylmethacrylate; turbulent flames; flame spread; heat

flux; flame length; pyrolysis; heat release; thickness;

flame velocity

Measurements of concurrent fire spread and burning over

horizontal polymethylmethacrylate (PMMA) surfaces exposed to

air flows ranging from 1 to $2.1 \mathrm{~m} / \mathrm{s}$ in a $2.4 \mathrm{~m} \times 5.4 \mathrm{~m}$ wind

tunnel are presented and analyzed. The fire propagation

occurs in two successive modes. In the first mode, when the flame is confined within a boundary layer, the pyrolysis mass loss flux is essentially constant. Transition to the second mode, occurring earlier at lower wind velocities, is accompanied by a rapid increase in the pyrolysis flux because the flame stands up into a plume. For the first boundary layer mode, the flame is an order of magnitude thicker than the theoretical turbulent boundary layer over a flat plate due to upward buoyancy and blowing effects. The measured flame spread rate in the first mode increases during propagation and is independent of the wind velocity [equation]. Over the whole range of data, the flame length [equation] is approximately 1.25 times the pyrolysis length. A correlation of [equation] in terms of the-energy release rate [equation] shows [equation] in the second mode. As the fire propagets, radiation increasingly becomes the dominant mode of heat transfer from the flame to the fuel surface. Predictions of the spread velocity using Quintiere's [ $J$. Res. Natl. Bur. Stand. 93:61-70 (1988)] model follow the trend in the measurements reasonably well, though the actual predictions are sensitive to the uncertain material property values.

Atreya, A.

Atreya, A.; Abu-Zaid, M.

Effect of Environmental Variables on Piloted Ignition. Michigan State Univ., East Lansing Mutah Univ., Jordan

International Association for Fire Safety Science. Fire Safety science. Proceedings. 3rd International symposium. July 8-12, 1991, Edinburgh, Scotland, Elsevier Applied Science, New York, Cox, G.; Langford, B., Editors, 177-186 pp, 1991.

fire research; fire safety; fire science; pilot ignition; environmental effects; wood; surface temperature; equations; heat flux; mass flux; thermal properties

In this paper the effect of environmental variables on piloted ignition of wood is investigated both experimentally and theoretically. The environmental variables considered are the moisture content of the solid, wind speed and its oxygen concentration and external radiation. Simultaneous measurements of weight loss rate, ignition time, sample 
surface temperature, oxygen depletion and production of $\mathrm{CO} 2$, co, total hydrocarbons, and water vapor were made. As expected, the presence of moisture delays the decomposition process and dilutes the decomposition products. The surface temperature and the evolved mass flux at ignition increased with increase in moisture content, decrease in oxygen concentration and increase in air velocity. All the ignition data are correlated according to an equation derived for surface temperature with convective and radiative heat losses. This equation reveals how the moisture content, air velocity, oxygen concentration and external radiation affect the ignition delay time. It also enables the determination of the critical incident heat flux below which piloted ignition does not occur.

Babrauskas, V.

Babrauskas, V.

Effective Measurement Techniques for Heat, Smoke, and Toxic Fire Gases.

National Institute for standards and Technology, Gaithersburg, MD

Fire Safety Journal, Vol. 17, No. 1, 13-26, 1991.

QMC Fire and Materials Centre in association with Fire

Research Station. Fire: Control the Heat... Reduce the

Hazard. International Conference. October 24-25, 1988, London, England, 4/1-10 pp, 1988.

fire hazards; fire gases; toxic gases; smoke; toxicity The latest techniques which have been developed for the measurement of heat, smoke, and toxic gas emissions from fires are reviewed. The current objective of minimizing apparatus dependence of the data is emphasized. Forms of data and their units are outlined. Differences between data obtained in large-scale and in bench-scale tests are discussed, and areas where further research is needed are indicated. Today the fire protection engineer has in his tool kit vastly more tools than were available only a few years ago. Yet, it is also clear, these do not represent an ultimate set. Fast and significant leaps forward are already visible in the area of quantitative methods for fire protection engineering. The focus of this conference is measurement of heat, smoke, and toxic fire gases. In this presentation, an attempt will be made to summarize, from an engineering point of view, the new tools available in each of these three inter-related areas. Data units will be discussed and the concept of apparatus-independent data will, especially, be emphasized.

Babrauskas, V.

Introduction to Mathematical Fire Modelling. [Book Review of An Introduction to Mathematical Fire Modeling by David $M$. Birk.]

National Institute of Standards and Technology, Gaithersburg, MD

Fire and Flammability Bulletin, 9-10, October 1991. mathematical models; fire models

This book, by David Birk, which is accompanied by a computer disk containing two models and ancillary programs, was 
developed out of Birk's master's degree project at worcester Polytechnic Institute, Massachusetts, USA. It is the first textbook being offered in the currently very important fire protection engineering area of room fire modelling. While a large number of very lengthy reports can be found on this topic, a textbook covering the area has long been awaited.

Babrauskas, V.

North American Experiences in the Use of Cone Calorimeter Data for Classification of Products.

National Institute of Standards and Technology,

Gaithersburg, MD

EUREFIC (European Reaction to Fire Classification). Performance Based Reaction to Fire Classification, International Seminar. September 11-12, 1991, Copenhagen, Denmark, Interscience Communications Ltd., London, England, 89-103 pp, 1991.

classifications; cone calorimeters; wall linings; ceilings; room fires; mathematical models; equations

North American building codes traditionally use the concept of 'non-combustible' required of products to be used in certain applications, plus other requirements, which can be considered 'degrees of combustibility' . Non-combustibility is intended to ensure a low heat release rate. However, these traditional concepts are not entirely in hamony with current fire protection engineering, where only a single, quantitative scale for heat release rate exists. This scale should be used to quantify the performance of products for any required applications. Nonetheless, as an intermediate step, it is shown that replacement of non-combustibility and various degree-of-combustibility requirements by heat release-based measurements may be fruitful. In recent years, the acceptance and widespread use of the cone Calorimeter (ISO DIS 5660) has prompted a number of exploratory studies. The goal of these studies has been to determine if a heat release-based substitute for these traditional measures could be established. Such a scheme would correct existing classification anomalies, but otherwide classify products into exactly the same categories as used by these building codes at the present. In this paper, the progress of these exploratory studies towards this goal is reviewed, and it is found that such a replacement is feasible and appropriate.

Babrauskas, V.; Damant, G.; Nubakhsh, S. Heat Release Rate Testing of Mattresses--Full-Scale Measurement.

National Institute of Standards and Technology, Gaithersburg, MD

Bureau of Home Furnishings and Thermal Insulation, North Highlands, CA

Interscience Communications Iimited. Heat Release and Fire Hazard. 1st U. S. Symposium. Abstracts. December 1991, San Diego, CA, 61-63 pp, 1991.

heat release; fire hazard; mattresses; heat release rate; upholstered furniture; test methods; flammability; cone calorimeters 
Upholstered furniture and mattress fires comprise the largest single factor in the Us fire fatality statistics. Heat release rate (HRR) has been identified as the single most important variable characterizing the hazard from furnishings fires. Over the past few years methods became available for large-scale HRR testing of upholstered furniture. Somewhat different standard test methods on this subject have been published by NORDTEST, Underwriters Laboratories and, most recently, the California Bureau of Home Furnishings and Thermal Insulation. For many applications, however, bench-scale testing is more appropriate than full-scale testing. Thus, efforts have been undertaken to predict the full-scale HRR performance of upholstered furniture from bench-scale data. The first such predictive method, for residential upholstered furniture, was developed at NIST in 1982. In recent years concern has been more focused on HRR performance of institutional and contract furniture. In a joint program between NIST and the state of California a predictive method for such furniture was developed in 1990. Many aspects of mattress construction and testing are similar to corresponding ones for upholstered seating. Yet there are enough differences to require separate test protocols and predictive methods to be developed. Original work on mattress flammability at both NIST and BHF predated the availability of modern HRR measuring instrumentation. During 1990-91 the opportunity arose to work on developing such procedures and data for mattresses. The California BHF test room was furnished with HRR-measuring instrumentation, while the cone Calorimeter (ASTM E1354) was available for use for bench-scale testing at NIST. Thus, the two organizations co-operated on jointly establishing such predictive capabilities. At BHF the studies were funded by the International sleep Products Association. At NIST work was conducted under funding from the Law Enforcement Standards Laboratory.

Babrauskas, V.; Harris, R. H., Jr.; Braun, E.; Levin, B. C.; Paabo, M.: Gann, R. G.

Large-Scale Validation of Bench-Scale Fire Toxicity Tests. National Institute of Standards and Technology, Gaithersburg, MD

Journal of Fire Sciences, Vol. 9, No. 2, 125-148, March/April 1991.

Interscience Communications Ltd.; National Institute of Standards and Technology; Building Research Establishment; and Society of Fire Protection Engineers. Interflam 190. Fire Safety. International Fire Conference, 5th. September 3-6, 1990, Canterbury, England, Interscience Communications Ltd., London, England, Franks, C. A., Editor, 3-12 pp, 1990. fire safety; toxicity test methods; validation; polyvinyl chloride; radiant heating; polyurethane foams; rigid foams; room fires; wood

A large number of bench-scale fire toxicity tests have been proposed over the last two decades. So far, none of them has reached acceptance by ISO, by ASTM, or by the majority of professionals in this area. The reasons are varied, but a major concern has been that none of the methods were seen to adequately predict the behavior of real, large-scale 
building fires. Such validation efforts have been held back both due to a shortage of good quality data, and because agreement had not been reached on the criteria for successful validation. NIST has now completed a pilot project to address both of these issues. In this study, systematic criteria for validation have been put forth. An initial data set has been compared against these criteria, comprising 2 bench-scale methods, 3 test materials, and a single real-scale fire scenario. The project results indicate that the course being pursued is appropriate, and provide illustrative performance data for the two bench-scale methods. The present project was a pilot study; further validation data will have to come from additional test materials and additional real-scale fire scenarios being examined. As a result of these studies, a factor-of-3 agreement between bench-scale and real-scale results was established as both useful and practical.

Babrauskas, V.; Harris, R. H., Jr.; Braun, E.; Levin, B. C.; Paabo, M. ; Gann, R. G.

Role of Bench-Scale Test Data in Assessing Real-Scale Fire Toxicity.

National Institute of Standards and Technology, Gaithersburg, MD

NIST TN 1284; $110 \mathrm{p}$. January 1991.

toxicity; polyvinyl chloride; fire tests; polyurethane

foams; rigid foams; room tests; wood

The need was seen for establishing a methodology by which bench-scale fire toxicity methods could be validated against real-scale room fires. The present study is the result of a pilot project in this area. Appropriate validation hypotheses have been put forth and examined in the context of some initial data. Three materials--Douglas fir, rigid polyurethane foam, and PVC--were examined in real-scale and bench-scale methods. The real-scale test environment was a post-flashover fire in a three-compartment (room, corridor, room) geometry, with the test specimens comprising wall lining materials. The bench-scale methods examined were the NBS cup furnace method and a new developmental protocol referred to as the "SwRI/NIST" method. The N-gas Model was applied to the analysis of the data and was found to be consistent with most of the data. The methods were compared for similarity of gas yields, of primary gases, and of types of death. Differences were found in individual cases, but most of those were readily explainable on the basis of an understanding of the test conditions. As a result of these studies, a factor-of-3 agreement between bench-scale and real-scale results was established as both useful and practical.

Babrauskas, V.; Levin, B. C. ; Gann, R. G.; Paabo, M. ; Harris, R. H., Jr.; Peacock, R. D.: Yusa, S. Toxic Potency Measurement for Fire Hazard Analysis. National Institute of Standards and Technology, Gaithersburg, MD

NIST SP 827; 119 p. December 1991. 
Available from Government Printing office

Available from National Technical Information Services

SN003-003-03129-1

PB92-137546

fire hazard analysis; toxicity test methods; building fires; computer models; fire models; death; $\mathrm{N}$-gas model; radiant heating: smoke toxicity

A comprehensive methodology has been developed for obtaining and using smoke toxicity data for fire hazard analysis. This description of the methodology comprises: determination that the post-flashover fire is the proper focus of smoke inhalation deaths; criteria for a useful bench-scale toxic potency (LC50) measurement method; a method which meets these criteria, especially validation against real-scale fires; a computational procedure for correcting the results for the $c o$ levels observed in real-scale post-flashover fires; procedures for reducing the usage of animals and broadening the applicability of data by interpreting gas measurement data using the N-Gas Model: and a procedure for identifying whether a product produces smoke within the ordinary range of toxic potency for post-flashover fires.

Babrauskas, V.; Peacock, R. D.; Braun, E.; Bukowski, R. W. ; Jones, W. W.

Fire Performance of Wire and Cable: Reaction-to-Fire

Tests--A Critical Review of the Existing Methods and of New Concepts.

National Institute of Standards and Technology, Gaithersburg, MD

NIST TN 1291: 130 p. December 1991.

Available from Government Printing office

Available from National Technical Information Services

SNOO3-003-03139-9

PB92-141563

cables; wires; flame spread; heat release rate; large scale

fire tests; small scale fire tests; standards; test methods

U. S. and Canadian reaction-to-fire tests for wire and cable are examined. The technical basis for their development is analyzed. The data requirements for engineering computations of fire hazard are examined. It is found that the current methods are primarily based on determining ignitability, speed of flame travel, or distance of flame propagation. The fire hazard to building occupants, however, is associated with the heat release rate of the fire, instead. Newer testing methods, which are not yet standards but which do measure the heat release rate of cables, are already under development. A limited comparison is made to British and international standards.

Recommendations are made for improved testing strategies. The document includes about 300 reference.

Babrauskas, V.; Richardson, L.

Determining Non-Combustibility Through Heat Release Rate Measurement.

National Institute of Standards and Technology,

Gaithersburg, MD

Forintek Canada Corp., Ottawa 
Interscience communications Limited. Heat Release and Fire Hazard. 1st U. S. Symposium. Abstracts. December 1991, San Diego, CA, 11-12 pp, 1991.

heat release; fire hazard; heat release rate; noncombustion;

tests; cone calorimeters; test methods; building codes Non-combustibility has typically been determined by procedures such as ISO 1182 and ASTM E136, and supplemented by additional building code provisions intended to pass some known-to-be safe materials which otherwise fail the standard test. These non-combustibility tests have been designed rather artitrarily, and their measurements do not correspond to any of the rational engineering variables used to describe fires. Thus, in Iso and in a number of individual countries the desire was expressed to progress on to a newer generation of test concepts for non-combustibility. For doing this, it became clear that demanding non-combustibility should be interpreted as a way of insisting on a low heat release rate (HRR). Thus, in the long term, the entire concept of non-combustibility could be appropriately discarded, just as "fireproof" is already deprecated. In the short term, however, it was considered appropriate to find a better measuring technique, while not yet demanding an immediate removal of the concept from regulatory documents. Thus in several laboratories as started to characterize non-combustibility by doing HRR tests and devising appropriate criteria for acceptance. goal of this work is to classify materials into the same classes as traditionally done, except that any materials which are currently known, from an engineering point of view, to be mis-classified should, if possible, be brought into line. Work is reported here that was done at NIST (US) and Forintek (Canada) using the cone Calorimeter. At NIST and BASF, the test conditions for all specimens involved an irradiance of $75 \mathrm{~kW} / \mathrm{m} 2$. A classification criterion was then sought which was based on either the peak HRR or the average HRR taken over a certain time period. The data obtained at NIST did not lead to definitive conclusions, but did suggest that the value at which the cut-off criterion could be based was uncomfortably tightly circumscribed. The work

undertaken at Forintek was more broadly based. The design was to amend the National Building Code of Canada not merely by re-defining non-combustibility, but rather, by defining "degrees of combustibility". Thus, for example, a logical HRR based category should emerge for rating fire-retardant treated woods (which are currently defined in the codes as a special use category). The work at Forintek involved an exposure level of $50 \mathrm{~kW} / \mathrm{m} 2$, although some other fluxes were also explored. More materials were included in this study than in the others, and it was possible to carry the conclusions further. The Forintek work showed that while it may be impossible to classify based on a single cut-off value, a satisfactory classification results by considering two variables. The two variables examined are the peak HRR and the total heat released over a $900 \mathrm{~s}$ period. Based on such a compound criterion, it was possible to establish classifications which were acceptably consistent with current building code practice. 
Baum, H. R.

Baum, H. R. : Rehm, R. G. ; Gore, J. P.

Transient Combustion in a Turbulent Eddy.

National Institute of Standards and Technology,

Gaithersburg, MD

Maryland Univ., College Park

Combustion Institute, symposium (International) on

Combustion, 23rd. July 22-27, 1990, Orleans, France,

Combustion Institute, Pittsburgh, PA, 715-722 pp, 1991.

combustion; turbulent combustion; diffusion flames;

formulations; combustion models; mathematical models

A mathematical model of a local transient diffusion flame

generated by mixing in a turbulent eddy is presented. It is intended ultimately as a computational "molecule" to be

imbedded in numerical simulations of large scale reacting

flows. The specific objective of the present analysis is to account explicitly for the modification of the local

velocity field induced by the heat generation process. An "idealized" single step irreversible reaction model and a

model treating the effects of real chemistry within the laminar flamelet approximation are considered. The

convection diffusion equation for the mixture fraction and the mass conservation equation are analyzed using the experimental observation that specific volume is a piecewise linear function of mixture fraction. A Cole-Hopf

transformation is used to reduce this equation to an incompressible form in terms of a new "pseudo mixture fraction" which can be related to all scalar properties using measured or idealized state relationships. Seven different fuels have been studied. Sample results for two of these are presented.

Benner, B. A., Jr.

Benner, B. A., Jr.; Bryner, N. P.; Wise, S. A.; Mulholland, G. W. ; Evans, D. D. ; Fingas, M. F.; Li, K.

Emissions of Polycyclic Aromatic Hydrocarbons From the

Combustion of Crude Oil on Water.

National Institute of standards and Technology,

Gaithersburg, MD

Environment Canada, ottawa

Spill Technology Newsletter, Vol. 16, No. 1, 1-16, March 1991.

crude oil; water; polycyclic aromatic hydrocarbons;

emissions; combustion; smoke; residues; cleaning; smoke yield

A study was performed of some of the factors necessary to assess the environmental impact of an in-situ burn: the fraction of an oil layer which can be burned, the quantity of smoke emitted, and the concentrations of 18 polycyclic aromatic hydrocarbons (PAHs) in the smoke, crude oil, and burn residue. Alberta Sweet Mixed-Blend crude in 2, 3, 5, 10 and $30 \mathrm{~mm}$ layers on water was burned and smoke samples were collected at elevated and ambient temperatures and analyzed by two independent laboratories. While burning the crude oil produced less total PAHs than was in the original crude oil, the concentrations of PAHs with five or more rings were 10 to 20 times greater in the smoke than in the oil. The organic carbon fraction of the smoke was in the 
range of 14 to $21 \%$. As the fuel layer thickness was increased from 2 to $10 \mathrm{~mm}$, the smoke yield increased from 0.035 to $0.080 \mathrm{~g}$-smoke/g-fuel; and the percentage of oil residue decreased from $46 \%$ to $17 \%$. By consuming much of the oil spill and reducing the amount of PAHs in the water, and by dispersing the combustion products over a larger area, in-situ burning can mitigate the local environmental impact of an oil spill. There appears to be a range of situations, such as in Arctic ice fields, where in-situ burning might be the most viable cleanup method.

Bentz, D. P.

Bentz, D. P.; Garboczi, E. J.

Digitized Simulation Model for Microstructural Development. National Institute of Standards and Technology, Gaithersburg, MD

National Institute of Standards and Technology and American Ceramic Society. Advances in Cementitious Materials.

Ceramic Transactions. Volume 16. July 22-26, 1990,

Gaithersburg, MD, Mindess, S., Editor, 211-226 pp, 1991.

cements; simulation; hydration; microstructures; random

dissolution; diffusion; nucleation; surface reaction

Characterization of the microstructure of hydrating cement

is difficult due to its complexity. Models of the hydration process provide one means of characterization as they

attempt to duplicate features of real microstructures. This paper presents a simple model for hydration consisting of steps which can be considered to represent random dissolution, diffusion, nucleation, and surface reaction. The model has been developed in a digitized format. Space is represented as an array of pixels, each of which is classified as a given material: reactant, dissolved species, hydrate, or water-filled pore. Having the model in digitized format allows for the visualization of the hydration as it occurs and for rapid subsequent quantification of the resultant microstructure. In addition, real images of cement particles can be digitized and used as the starting material for model execution. Algorithms for, and results of, the model are presented.

Bentz, D. P.; Garboczi, E. J.

Percolation of Phases in a Three-Dimensional Cement Paste

Microstructural Model.

National Institute of standards and Technology,

Gaithersburg, MD

Cement and Concrete Research, Vol. 21, 325-344, 1991. cements; neat paste; hydration; mineral admixtures; percolation theory; pore space percolation; silica fume; pore discontinuity; cement paste

A three-demensional digital-image-based simulation model of cement hydration is used to study the percolation or connectivity of phases as a function of hydration. Results from an investigation of the effects of water-to-cement ratio, degree of hydration, and the substitution of inert and pozzolanic mineral admixtures for cement, on the connectivity of the capillary porosity are presented. For all scenarios studied, plotting pore connectivity vs. total 
porosity results in a single universal curve. Based on this curve, the degree of hydration required to achieve pore discontinuity as a function of water-to-cement ratio and pozzolanic mineral admixture concentraion has been

determined. Similar universal curves have been obtained for the connectivity of the calcium silicate hydrate and calcium hydroxide phases in hydrated neat cement when plotted against the appropriate phase fraction. Simulation results are analyzed using percolation theory, and are applied to interpreting observed experimental results concerning cement properties as a function of hydration.

Bentz, D. P.; Garboczi, E. J. Simulation Studies of the Effects of Mineral Admixtures on the Cement Paste-Aggregate Interfacial Zone. National Institute of Standards and Technology, Gaithersburg, MD ACI Materials Journal, Vol. 88, No. 5, 518-529, September/October 1991. Title 88-M57;

cements; aggregates; concretes; fly ash; silica In concrete, the interfacial zone between cement paste and aggregate plays a critical role in determining mechanical performance. In recent years, high-performance concretes have been produced based on a low water-cement ratio cement paste containing a superplasticizer and silica fume. One of the key benefits of silica fume is its ability to improve the integrity of the interfacial zone in concrete. This paper presents a three-dimensional microstructural model for simulating the interfacial zone in concrete, including the incorporation of inert and pozzolanic mineral admixtures. The model is used to obtain the cementitious-material phase distributions as a function of distance from the aggregate surface to quantitatively characterize the interfacial zone. Pozzolanic admixtures, such as silica fume and fly ash, are found to increase the homogeneity of the interfacial region, with the most important enhancement proposed to be the improved homogeneity of the calcium-silicate-hydrate phase. The effects of mineral admixture particle size and reactivity are also computed via simulations. Simulation results are compared to conventional experimental measurements, such as compressive strength, and scanning electron micrographic investigations of the microstructure of actual cement-based materials.

Bentz, D. P.; Garboczi, E. J.; Gingold, D.; Lobb, C. J.; Jennings, H. M.

Diffusion studies in a Digital-Image-Based Cement Paste Microstructural Model.

National Institute of Standards and Technology,

Gaithersburg, MD

Thinking Machines Corp., Cambridge, MA

Maryland Univ., college Park

Northwestern Univ., Evanston, IL

National Institute of Standards and Technology and American

Ceramic Society. Advances in Cementitious Materials. 
Ceramic Transactions. Volume 16. July 22-26, 1990, Gaithersburg, MD, Mindess, S., Editor, 227-235 pp, 1991. cements; diffusion; microstructures; algorithms;

diffusivity; hydration; connected porosity fraction

A digital-image-based model of the microstructure of cement paste, coupled with a new, fast algorithm for computing the conductance of random conductor lattices, are used to study the diffusivity of the capillary pore space of cement paste. Degree of hydration and water:cement ratio are the principal variables. Computational methods and preliminary data are presented, and compared to experimental results. Model cement pastes with different values of water:cement ratio and degree of hydration are found to have diffusivities that lie on a single master curve when ploted as a function of the connected pore space fraction.

Bentz, D. P.; Martin, J. W. ; Batts, M. E. Characterization of Cylindrical Holes in Metallic substrates Via Their Infrared Emission Patterns.

National Institute of Standards and Technology, Gaithersburg, MD

Paratech Corp., Washington, DC

Wear, Vol. 143, 255-266, 1991.

substrates; cylindrical holes; infrared emission patterns; infrared detectors

IR emission patterns for a series of cylindrical holes milled into aluminum and steel plates were compared with those predicted form existing theory. The emission patterns were found to be influenced by the hole geometry, the substrate material and the IR camera system itself. For holes milled into an aluminum plate, the results were adequately explained by existing theory for diffuse materials. For holes milled into a steel plate, however, this theory was found not to apply and empirical calibration was required. It is concluded that the IR technique may have promise in characterizing the diameter and depth of milled holes at temperatures near ambient.

Braun, E.

Braun, E.; Klote, J. H.; Davis, S.; Levin, B. C.; Paabo, M.; Gann, R. G.

Assessment Methodology for the Fire Performance of School

Bus Interior Components.

National Institute of Standards and Technology,

Gaithersburg, MD

International Association for Fire safety science. Fire

Safety science. Proceedings. 3rd International symposium. July 8-12, 1991, Edinburgh, Scotland, Elsevier Applied Science, New York, Cox, G.; Langford, B., Editors, 855-864 pp, 1991.

fire research; fire safety; fire science; buses; combustion products; tenability limits; toxicity; seats; large scale fire tests; fire models; ignition source

A full-scale fire performance protocol for the evaluation of school bus seat assemblies was developed. This protocol is

based on the results of full-scale testing of end-use seat assemblies and computer fire modeling of the ignition source 
and burning item(s) in a single compartment enclosure. Tenability criteria were applied to the results of the full-scale tests and computer fire model calculations. The results showed that temperature is a suitable criterion for this application. Toxicity of the decomposition products plays a secondary role in determining occupant survivability. Occupant tenability limits are exceeded for ignition sources over $300 \mathrm{~kW}$, independent of the type of seat assembly. Based on the full-scale test data, computer simulations were conducted to determine which tenability criteria were exceeded in the full-scale tests.

Brown, J. E.

Brown, J.E.

Heat Release and Flammability of Composite Materials.

National Institute of Standards and Technology,

Gaithersburg, MD

Interscience Communications Limited. Heat Release and Fire

Hazard. 1st U. S. Symposium. Abstracts. December 1991,

San Diego, CA, $10 \mathrm{pp}, 1991$.

heat release; fire hazard; composite materials;

flammability; thermal radiation; cone calorimeters;

irradiance; parameters; pilot ignition; heat flux

A study was performed to evaluate the performance of

composite materials under external thermal radiation of fire environments. The cone Calorimeter was used as the bench-scale method of test to simulate the thermal irradiance from fires of various magnitudes. Parameters were derived from the calorimetry measurements to characterize the pilot ignitability and flammability of the composite materials. The parameters are, to some extent, empirical since radiative heat losses from the samples were not determined and are unknown. These parameters are: 1) minimum external radient flux (MERF) required to produce pilot ignition in a predetermined exposure time; 2) thermal sensitivity index (TSI) which indicates the burning intensity dependence on external heat flux; and 3 ) extinction sensitivity index (ESI) which indicates the propensity for continued flaming combustion without an external heat flux. MERF values at $300 \mathrm{~s}$ for $3 \mathrm{~mm}$ thick composite panels of a FR epoxy resin and of a poly (phenylene sulfide) (PPS) resin were about 19 and $28 \mathrm{~kW} / \mathrm{m} 2$, respectively. The TSI of the PPS resin composite revealed that it had the greatest dependency on external flux. Additionally, the ESI of the PPS composites was the only one to indicate an external flux requirement to sustain combustion during the first $60 \mathrm{~s}$ after ignition.

Bryner, N. P.

Bryner, N. P.; Mulholland, G. W.

Smoke Emission and Burning Rates for Urban structures.

National Institute of Standards and Technology,

Gaithersburg, MD

Atmospheric Environment, Vol. 25A, No. 11, 2553-2562, 1991. smoke emissions; burning rate; urban fires; nuclear winter; smoke generation; crib burning; scale effects; wood; ABS plastics; gypsum 
Cribs, ordered arrays of sticks, were burned to mimic post-nuclear building fires. As the packing density of the cribs was increased to simulate blast damage, the smoke yield increased and the smoke changed from strongly light absorbing to whitish in color. A ventilation parameter proportional to the ratio of the crib vent area to the total fuel surface area correlated the burning rate and smoke yield data for both large $(3.81 \mathrm{~cm}$ stick thickness) and small (0.64 cm stick thickness) scale cribs. The globally averaged smoke optical depth inferred from the burning of the wood cribs is in the low range of Penner's (1986, Nature $324,222-226)$ estimate. The smoke yield for freely burning cribs containing wood, gypsum, and plastic can be accounted for based on the high sooting yield of the plastic by itself.

Bukowski, R. W.

Bukowski, R. W.

Fire Models: The Future is Now!

National Institute of Standards and Technology, Gaithersburg, MD

NFPA Journal, Vol. 85, No. 6, 60-62,64,66-69, March/April

1991.

fire models; computer models

Computer fire models are turning up more and more in the everyday practice of fire protection. There are models that can be used to predict the development of fire, the performance of fire protection features and systems, the behavior of people during a fire, the effects of fire on victims, and more. Increasingly, expert judgment is no longer sufficient to win a court case unless it is backed up by calculations. In addition, code officials are more willing to accept innovative designs as long as detailed computer simulations show that the full intent of the code is being met. And manufacturers are having their products tested voluntarily to obtain the data neeed to produce models that will assess the performance of those products. To meet these varied needs, a large number of models have been developed. A recent international survey identified 36 actively supported models just to predict the development of fire. Of these, 20 predict the fire-generated

environment--mainly temperature--and 19 predict smoke movement in some way. Six calculate fire growth rate, nine predict fire endurance, four address detector or sprinkler response, and two calculate occupant evacuation times. But what are these models? How do they work? How accurate are they? How can we tell when--and when not--to believe them? These are just a few of the questions every fire protection professional must be prepared to answer when using, or encountering the results of, the models themselves.

Bukowski, R. W.

Improving the Fire Performance of Building Contents. National Institute of Standards and Technology,

Gaithersburg, MD

Construction Specifier, Vol. 44, No. 2, 42-46, February 1991. 
building materials; regulations; fire safety; inspections Fire codes traditionally have regulated only the structural and finish materials used in buildings. Such regulation was intended to limit the size of the fire, first to the building of origin and later to smaller and smaller portions of that building. In response to fires in which many lives were lost, codes eventually were designed to ensure protected paths of egress and sufficient structural integrity to keep the building standing, at least until the occupants were evacuated, and hopefully long enough to allow suppression activities. To a limited extent, these goals have been realized in modern buildings. Today, structure fires rarely spread beyond the floor of origin, much less result in total collapse of the building (through smoke and toxic gases still permeate most spaces of the building). But the fire problem has not been solved.

Bukowski, R. W. ; Jason, N. H. International Fire Detection Bibliography, 1975-1990. International Fire Detection Literature Review and Technical Analysis.

National Institute of Standards and Technology, Gaithersburg, MD

NISTIR 4661; 193 p. September 1991.

Available from National Technical Information Services PB92-109156

fire alarm systems; fire detectors; heat detectors; reliability; smoke detectors

This bibliography was collected from numerous international sources and represents as complete a compilation of publications from the 15 years covered as could be collected. Nearly 1000 references are included, separated into one of 20 topics such as aerosols and smoke, industrial occupancies, ships, smart detectors and systems, and system reliability studies. Each such section begins with a brief summary and cites the more important papers within. The bibliography ends with a commentary on what the overall literature shows, what research is needed to achieve more reliable detection system operation and reduced unwanted alarms. An author index and a key work index are provided.

Bukowski, R. W. ; Jason, N. H. International Fire Detection Bibliography, 1975-1990. International Fire Detection Literature Review and Technical Analysis.

National Institute of Standards and Technology, Gaithersburg, MD

NISTIR 4661; 193 p. September 1991.

Available from National Technical Information Services PB92-109156

fire alarm systems; fire detectors; heat detectors; reliability; smoke detectors

This bibliography was collected from numerous international sources and represents as complete a compilation of publications from the 15 years covered as could be collected. Nearly 1000 references are included, separated into one of 20 topics such as aerosols and smoke, industrial 
occupancies, ships, smart detectors and systems, and system reliability studies. Each such section begins with a brief summary and cites the more important papers within. The bibliography ends with a commentary on what the overall literature shows, what research is needed to achieve more reliable detection system operation and reduced unwanted alarms. An author index and a key work index are provided.

Bukowski, R. W. ; Peacock, R. D. ; Jones, W. W. ; Forney, C. L. Technical Reference Guide for the HAZARD I Fire Hazard

Assessment Method. Version 1.1. Volume 2.

National Institute of Standards and Technology,

Gaithersburg, MD

NIST HB-146/II; 283 p. June 1991.

Available from National Technical Information Services

computer models; computer programs; evacuation; fire models;

hazard assessment; human behavior; toxicity

This report describes the first version of a method for

predicting the hazards to occupants involved in a building

fire. To implement the method, a personal computer software package called HAZARD I is provided. The software consists of modules which can predict the time varying environment within a building resulting from a specified fire; the locations and actions of a specified group of occupants as they interact with the building, the fire, and each other; and the impact of the exposure of each of the occupants to the fire products in terms of whether the occupants successfully escape, are incapacitated, or are killed. NIST Handbook 146 consists of the Technical Reference Guide, the Software User's Guide, plus software supplied on six 5 1/4" and three 3 1/2" disks.

Burch, I; $\mathbf{M}$.

Burch, D. M.

Indoor Ventilation Requirements for Manufactured Housing.

National Institute of Standards and Technology,

Gaithersburg, MD

NISTIR 4574; 28 p. May 1991.

Available from National Technical Information Services

PB91-206698

fornaldehyde; indoor ventilation; manufactured housing; mobile homes; ventilation; ventilation standards; window condensation

In this study, a mathematical analysis is carried out to investigate the mechanical ventilation rates required in manufactured housing. The analysis reveals that the ventilation provided by natural infiltration is inadequate to comply with the ventilation requirements of ASHRAE Ventilation standard 62-1889 and to prevent double-pane window condensation. The study recommends that both single-wide and double-wide mobile homes be equipped with mechanical ventilation equipment having a minimum installed capacity of $0.026 \mathrm{~m}(3) / \mathrm{s}(55 \mathrm{ft}(3) / \mathrm{min})$. It was found that considerably larger ventilation rates are needed to prevent condensation on single-pane windows. Therefore, it is recommended that double-pane windows be required in all heating climates. 
Burch, D. M.; Thomas, W. C. Analysis of Moisture Accumulation in a Wood-Frame Cavity Wall Subjected to winter climate.

National Institute of Standards and Technology, Gaithersburg, MD

NISTIR $4674 ; \quad 36$ p. October 1991.

Available from National Technical Information Services

PB92-116334

moisture; capillary transfer; moisture control guidelines; moisture management in walls; moisture performance of walls; moisture transfer; water vapor diffusion

A transient, one-dimensional, finite-difference model is presented that predicts the coupled transfer of heat and moisture in a multilayer wall under nonisothermal

conditions. The model can predict moisture transfer in the diffusion through the capillary flow regimes. It has a provision to account for convective moisture transfer by including embedded cavities which may be coupled to indoor and outdoor air. The model is subsequently used to predict the time-varying average mositure content in the sheathing and siding of a wood frame wall as a function of time of year. Results are shown for a mild winter climate (Atlanta, $\mathrm{GA}$, an intermediate winter climate (Boston, $\mathrm{MA}$ ), and a cold winter climate (Madison, WI). The effect of several

construction parameters on the winter moisture accumulation are investigated. The parameters include the interior vapor retarder permeance, sheathing permeance, exterior paint permeance, indoor air leakage, and the amount of insulation.

Burch, D. M.; Zarr, R. R. Evaluation of the Heat Flux Transducer Technique for Measuring the Thermal Performance of Walls. National Institute of Standards and Technology, Gaithersburg, MD

In-Situ Heat Flux Measurements in Buildings Applications and Interpretations of Results. February 1991, 111-122 pp, 1991.

tranducers; evaluation; heat flux; walls; test methods Four wall specimens were instrumented with heat flux transducers and tested in a calibrated hot box to determine the accuracy of the heat flux transducers. The heat flux transducers were installed at the interior surface of the wall specimens and exposed to different steady and dynamic (i.e., time-dependent) temperature differences of homogeneous and monolithic material layers, which yielded virtually one-dimensional heat flux. The other two wall specimens were composed of conventional wall construction with wood structural members, which yielded a two-dimensional heat flux pattern. The heat flux transducers were previously calibrated by exposing them to a uniform heat flux in a guarded hot plate. The steady-state and transient heat flux transducer measurements agreed within $5 \%$ of the calibrated hot box measurements. These results indicate that, when heat flux transducers are carefully calibrated and installed, they provide accurate measurements of heat flux in walls. 
Bushby, S. T.

Bushby, S. T.

Draft Abstract Test Suite for Determining Conformance to the BACnet Protocol.

National Institute of Standards and Technology,

Gaithersburg, MD

NISTIR 4563; 118 p. April 1991.

Available from National Technical Information Services

PB91-187732

ASHRAE; BACnet; building automation; computer; conformance; control; EMCS; energy management; protocol

The BACnet communication protocol for building automation and control systems is in an advanced state of development and is expected to be released for public review in early 1991. When the review process is completed it will become an ASHRAE standard. One of the important outstanding issues to be resolved is conformance to the standard and how to test devices to determine if they meet the conformance requirements. This report is a draft Abastract Test suite based on working draft 3 of the proposed standard. This Abstract Test suite is a first step in developing the tests which will be used to certify conformance to BACnet. Its purpose is to provide a starting point from which a conformance certification program can be built and to focus discussions on the outstanding conformance issues that need to be resolved before the standard can be considered complete. The role of an abstract test suite in the conformance testing process is described, a proposed BACnet test system architecture is presented and individual abstract test cases are defined. Test cases to determine support for object types and application services defined in working draft 3 are included. A standard object configuration is also proposed to simplify the testing process.

Bushby, S. T.; Newman, H. M. BACnet Communication Protocol for Building Automation Systems.

National Institute of Standards and Technology, Gaithersburg, MD

Cornell Univ., Ithaca, New York

ASHRAE Journal, Vol. 33, No. 4, 14-21, April 1991. communication protocol; energy management and control systems

The building community in the United states and in several other countries has been carefully watching the efforts by ASHRAE to develop a communication protocol for building energy management and control systems (EMCS). In January, 1987, the ASHRAE Standards Committee formed a standards Project committee (SP-135P) to deliberate the creation of communication protocol that will become an industry standard. The name chosen for this protocol is "BACnet: Data Communication Protocol for Building Automation and Control Networks." 
Carino, N. J.

Carino, N. J.

Maturity Method. Chapter 5.

National Institute of Standards and Technology,

Gaithersburg, MD

CRC Handbook on Nondestructive Testing of Concrete. Chapter

5, CRC Press, Boca Raton, FL, Malhotra, V. M.; Carino, N.

J., Editors; 101-146 pp, 1991 .

concretes; temperature; curing agents; maturity; equivalent age; strength

This chapter reviews the history and technical basis of the maturity method, a technique for estimating the strength gain of concrete based upon the measured temperature history during curing. The combined effects of time and temperature on strength gain are quantified by means of a maturity function. The widely used maturity functions are reviewed critically. It is shown that the traditional maturity function is inadequate compared with the function based upon the Arrhenius equation. The concept of equivalent age, which is the most convenient measure of maturity, is explained. The strength gain of a specific concrete mixture is estimated using the measured maturity and the strength vs. maturity relationship for that mixture. Various proposed strength-maturity relationships are reviewed. It is also explained why the maturity method can only be used reliably to estimate relative strength. Examples are presented to illustrate how this technique can be used in combintion with other in-place tests of cocnrete strength. The ASTM standard dealing with the method is also summarized.

Carino, N. J.: Clifton, J. R. High-Performance Concrete: Research Needs to Enhance Its Use.

National Institute of Standards and Technology, Gaithersburg, MD

ACI Concrete International, 70-76, September 1991. concretes; curing agents; mechanical properties; test methods; durability; structural design; construction; structures

Historically, the development of concrete technology has been a slow, evolutionary process. Notable exceptions include the discoveries of the water-cement ratio law in 1919 and air entrainment in 1938. Today, we are at another revolutionary stage of concrete technology. The introduction of new admixtures and cementitious materials has allowed the production of highly workable concrete with superior mechanical properties and durability. This new class of concrete is being called high-performance concrete (HPC), and it is expected that its use will have a marked impact on concrete construction and the performance of concrete structures.

Celebi, M.

Celebi, M.; Phan, L. T.; Marshall, R. D.

Comparison of Responses of a select Number of Buildings to

the 10/17/1989 Loma Prieta (California) Earthquake and

Low-Level Amplitude Test Results. 
National Institute of Standards and Technology, Gaithersburg, MD

NIST SP 820: September 1991.

U. S./Japan Natural Resources Development Program (UJNR) .

Wind and Seismic Effects. Joint Meeting of the U. S./Japan Cooperative Program in Natural Resources Panel on Wind and Seismic Effects, 23rd. May 14-17, 1991, NIST SP 820,

Tsukuba, Japan, Raufaste, N. J., Editor, 475-481 pp, 1991.

Available from Government Printing office

earthquakes; vibration; testing; strong-motionte; buildings; damping; frequency; period

This paper summarizes dynamic characteristics of five buildings within the San Francisco Bay area. The dynamic characteristics are extracted from the october 17, 1989 Loma Prieta earthquake response records and from ambient tests conducted in November 1990. Dynamic characteristics determined for two of the five buildings prior to the Loma Prieta eqrthquake are also included for comparison. The results are to be used to draw conclusions related to the validity of small amplitude tests in assessing the dynamic characteristics of buildings and other structures. The preliminary results show, in some cases, that low-level tests are useful and, in other cases, they show considerable differences with those determined from strong-motion response records.

Chen, $\mathbf{Y}$.

Chen, Y.; Frendi, A.; Tewari, S. S.; Sibulkin, M.

Combustion Properties of Pure and Fire-Retarded Cellulose.

Brown Univ., Providence, RI

Combustion and Flame, Vol. 84, No. 1-2, 121-140, 1991. cellulose; combustion; fire retardants; char; heat of combustion; gasification; pyrolysis

Measurements are presented for the fuel-related properties of pure and fire-retarded cellulose used in diffusion flame calculations. The items measured are (1) heat of combustion of the volatile products of cellulose pyrolysis, (2) heat of gasification, (3) fuel and inert gas fractions in the pyrolysate and (4) stoichiometric ratio of the fuel

volatiles. Cellulose samples were subjected to a radiant heat flux in a special apparatus designed for this purpose, and the pyrolysate was analyzed using a gas chromatograph. Heats of combustion of cellulose and of the char produced by pyrolysis were measured by a bomb calorimeter. Results are given for pure cellulose and for cellulose that has been fire retarded by up to 3 wt. \% sodium hyroxide. For heat fluxes simulating those in diffusion flames, the char yield is found to increase from 9 wt. \% percent for pure cellulose to $30 \mathrm{wt}$. \% for retarded cellulose. The effect of retardant addition is to decrease the heat of combustion per unit mass of (total) volatiles, but to increase the heat of combustion per unit mass of combustible volatiles. The heat of gasification (defined as the energy input required to generate a unit mass of volatiles) is determined from measurements of mass loss, surface temperature, and surface emissivity. For pure cellulose, the mass loss rate and surface temperature increase for higher applied heat fluxes while the heat of gasification decreases. At a fixed heat 
flux, retardant addition increases both the mass loss rate and surface temperature, which results in a decease in the heat of gasification. Analysis of the volatiles shows that retardant addition increases the fraction of inert gases (carbon dioxide and water) in the pyrolysate, which reduces the fuel fraction from 69 wt. $\%$ for pure cellulose to 35 wt. $\%$ for retarded cellulose. The corresponding change in stoichiometric oxyen/fuel ratio is from 1.6 for pure cellulose to a maximum value of 2.3 for retarded cellulose.

Chen, Y.; Frendi, A.; Tewari, S. S.; Sibulkin, M. Effects of Fire Retardant Addition on the Combustion Properties of a Charring Fuel.

Brown Univ., Providence, RI

International Association for Fire safety Science. Fire Safety science. Proceedings. 3rd International symposium. July 8-12, 1991, Edinburgh, Scotland, Elsevier Applied Science, New York, Cox, G.; Langford, B., Editors, 527-536 $\mathrm{pp}, 1991$.

fire research; fire safety; fire science; gasification; heat of combustion; fire retardants; combustion; charring; fuels; sodium hydroxides; cellulose; wood; plastics; pyrolysis Results are presented which show the effect of fire retardant addition on the fuel related properties used in diffusion flame calculations. Samples of cellulose retarded with up to 3 wt. percent of sodium hydroxide were subjected to a radiant heat flux of $40 \mathrm{~kW} / \mathrm{m} 2$ in a special apparatus designed for this purpose. The volatile products of pyrolysis were analyzed using a gas chromatograph to determine the concentration of inert gases (carbon dioxide and water). Retardant addition was found to increase both the char yield and the production of inert gases. This results in a decrease in the fuel fraction in the pyrolysate from 69 wt. percent for pure cellulose to 35 wt. percent for retarded cellulose. The corresponding change in the stoichiometric oxygen/fuel ratio is from 1.6 for pure cellulose to a maximum of 2.3 for retarded cellulose. Retardant addition also causes a decrease in the heat of gasification (defined as the energy input to generate a unit mass of volatiles) and an increase in the heat of combustion of the combustible gases in the pyrolysate.

Cheok, G. S.

Cheok, G. S.; Lew, H. S.

Performance of 1/-3-Scale Model Precast Concrete Beam-column Connections subjected to Cyclic Inelastic Loads. Report No.

2 .

National Institute of Standards and Technology,

Gaithersburg, MD

NISTIR 4589; 84 p. June 1991.

Available from National Technical Information Services

PB91-222570

beam-columns; concretes; connections; cyclic loading; ductility; energy absorption; joints; moment resistant; post-tensioning; precast concretes

Results are presented from the experimental test program on precast beam-column connections subjected to inelastic 
cyclic loads being conducted at the the National Institute of Standards and Technology. This report is the second in a series and covers the test results from Phase 2 of a three phase program. The objective of the test program is to develop an economical moment resistant precast beam-column joint for high seismic zones. Test specimens are 1/3-scale models of a prototype interior concrete beam-column connection. The 1985 UBC design criteria for seismic zone 2 and 4 were used. Six specimens were tested. The experimental variables include the location of the post-tensioning force and the type of post-tensioning tendons used. Comparisons of the performance among these specimens are made. Comparisons with the monolithic specimens (Phase 1 [Ref. 1]) are also presented. These comparisons are made based on the failure mode, energy absorption characteristics, strength and ductility of the connenction.

Cheok, G. S.; Lew, H. S. Performance of Precast Concrete Beam-to-column Connections subject to Cyclic Loading. National Institute of Standards and Technology, Gaithersburg, MD

PCI Journal, Vol. 36, No. 3, 56-67, May/June 1991. concretes; beams; columns; cyclic loading; literature reviews; specimen design; tests

An experimental study of the behavior of precast concrete beam-to-column connections subjected to cyclic inelastic loading conducted at the National Institute of standards and Technology is presented. The study was initiated to provide data for the development of a rational design procedure for such connections in seismically active regions. The objective of the study is to develop a moment resistant precase concrete connection that is economical and can be easily constructed. Four one-third scale monolithic concrete beam-to-column connections were tested: two were designed according to the 1985 Uniform Building Code (UBC) Seismic Zone 2 criteria and two to UBC Zone 4 criteria. In addition, two precast, post-tensioned concrete beam-to-column connections similar in design to the monolithic Zone 4 specimens were tested. These tests constitute the first phase of a multi-year test program.

\section{Chwalowski, M.}

Chwalowski, M.

Evaporator Performance Investigation for Residential

Air-Conditioning Applications Using Mixed Refrigerants. National Institute of Standards and Technology, Gaithersburg, MD NISTIR 4723; 147 p. November 1991. Available from National Technical Information Services PB92-126432

refrigerants; air-conditioning; effectiveness; evaporator; mixture; nonazeotropic; NTU; profile

The design of the heat exchanger utilizing nonazeotropic refrigerant in an air conditioning application presents unique problems due to the phase change of the moist air and 
the variable specific heat of the evaporating refrigerant mixture. This study discusses the performance analysis and the design procedure of a cross counterflow heat exchanger working as an evaporator in an experimental system which simulated a residential air conditioning application. The effect of the change of the mixture composition on heat exchanger performance was evaluated. The focus of the theoretical study was the development of the effectiveness/NTU (epsilon/NTU) relationships with the use of the experimentally derived quantities for moist air flowing across the heat exchanger. Variable mixture specific heat, air and heat profiels obtained from the experimental results were utilized to obtain the expresion for epsilon/NTU. The derived epsilon/NTV relations were verified and found to be in good agreement with test results.

\section{Cleary, T. G.}

Cleary, T. G.; Quintiere, J. G.

Flammability Characterization of Foam Plastics.

National Institute of Standards and Technology, Gaithersburg, MD

NISTIR 4664; 142 p. October 1991.

Available from National Technical Information Services PB92-123033

flammability; rigid foams; cellular plastics;

combustibility; fire growth; fire hazard assessment; fire spread; flammability testing; heat release rate; low density foams

The results of a study to identify an alternative test protocol to the steiner Tunnel Test as a measure of flammability for foamed plastic are presented. New fire test apparatuses namely the cone Calorimeter and Lateral Ignition and Flame spread apparatus were used to more completely characterize foamed plastic flammability. Key flammability properties obtained from these apparatuses describe ignitability, flame spread rate, rate of heat release and smoke obscuration. An extensive data set of these flammability properties for 10 selected foamed plastics was generated. The tested materials included melting foams (polystyrene foams) and charring foams (polyurethanes, polyisocyanurate and phenolic foams). The effects of melting and dripping was limited by testing the materials in the horizontal orientation. In addition, an integrated approach to material flammability

characterization is presented that uses these parameters to predict fire growth potential.

Cleary, T. G.; Quintiere, J. G.

Framework for Utilizing Fire Property Tests.

National Institute of Standards and Technology, Gaithersburg, MD

Maryland Univ., College Park NISTIR 4619; $36 \mathrm{p}$. August 1991.

International Association for Fire Safety Science. Fire Safety science. Proceedings. 3rd International symposium. July 8-12, 1991, NISTIR 4619, Edinburgh, Scotland, Elsevier 
Applied Science, New York, Cox, G.; Langford, B., Editors, 647-656 pp, 1991 .

Available from National Technical Information Services PB91-240788

fire research; fire safety; fire science; energy transfer; linings; room fires

A complete approximate set of equations is developed to describe fire spread over a surface and its resultant energy release. Wall, floor, and ceiling orientations are considered. The needed model data are couched in terms of available test method results, e.g., Cone Calorimeter and LIFT apparatuses. Several applications are presented to show how energy release rates can be predicted and how well they represent real data from full scale and model room lining experiments.

Clifton, J. R.

Clifton, J. R.

Predicting the Remaining Service Life of Concrete.

National Institute of standards and Technology,

Gaithersburg, MD

NISTIR 4712; 84 p. November 1991.

Available from National Technical Information Services PB92-126598

concretes; accelerated testing; alkali-aggregate reactions; corrosion; modeling; nuclear power plants; service life; sulfate attach

Nuclear power plants are providing, currently, about 17 percent of the U. S. electricity and many of these plants are approaching their licensed life of 40 years. The U. S. Nuclear Regulatory Commission and the Department of Energy's Oak Ridge National Laboratory are carrying out a program to develop a methodology for assessing the remaining safe-life of the concrete components and structures in nuclear power plants for continued service. The National Institute of Standards and Technology (NIST) is contributing to this program by identifying and analyzing methods for predicting the remaining life of in-service concrete materials. This report examines the basis for predicting the remaining service lives of concrete materials of nuclear power facilities. Methods for predicting the service life of new and in-service concrete materials are analyzed. These methods include 1) estimates based on experience, 2) comparison of performance, 3) accelerated testing, 4) stochastic methods, and 5) mathematical modeling. New approaches for predicting the remaining service lives of concrete materials are proposed and recommendations for their further development given. Degradation processes are discussed based on considerations of their mechanisms, likelihood of occurrence, manifestations, and detection. They include corrosion, sulfate attack, alkali-aggregate reactions, frost attack, leaching, radiation, salt crystallization, and microbiological attack.

Clifton, J. R.; Knab, L. I.; Garboczi, E. J.; Xiong, L. X. Chloride Ion Diffusion in Low Water-To-Solid Cement Pastes. 
National Institute of Standards and Technology, Gaithersburg, MD

NISTIR 4549; 30 p. April 1991.

Available from National Technical Information Services

PB91-187690

cements; chloride ion; concretes; corrosion; diffusion

coefficient; service life

Diffusion coefficients of 0.3 water to solids ratio (w/s)

hydrated portland cement paste specimens were measured using

a conventional diffusion cell. Specimens were made from

both ASTM Type I and Type II portland cements and blends containing mineral admixtures (fly ash, granulated blast furnace slag, or silica fume). The average diffusion coefficient for the portland cement paste specimens was $14 \times 10(-13) \mathrm{m}(2) / \mathrm{s}$. The diffusion coefficients for the specimens containing mineral admixtures were much more variable than those for the portland cement paste specimens. A probable cause of the variability in the test results was the presence of cracks observed in the test specimens. The effects of the depth of concrete cover over reinforcing steel and of the chloride ion diffusion coefficient on the service life of reinforced concrete exposed to chloride ions were predicted based on a diffusion model. Based on the model, the effect of the cover was shown to be proportional to the square of the cover depth. A 10-fold decrease in the diffusion coefficient of concrete was predicted to result in a 10-fold increase in the predicted service life. Based on the results of the present study, it is recommended that a new chloride diffusivity test should be developed which is applicable to concrete. A candidate test method is proposed.

Collins, B. L.

Collins, B. L.

Evaluation of the Characteristics of Effective Exit signs.

National Institute of standrds and Technology, Gaithersburg,

MD

Commission Internationale de l'Echiage (CIE). CIE 22nd

Session. Division 3. July 1991, 55-58 pp, 1991.

color; contrast; egress; emergency lighting; exit;

luminance; sign; smoke; optical density; uniformity;

visibility

Data on factors that can determine the visibility and

effectiveness of exit signs are reported from four studies.

The visibility of different types of internally and

externally lit exit signs was assessed for both clear and smokey conditions. The role of luminance, contrast, color, size and position of the directional indicator in

determining exit sign effectiveness is discussed and suggestions for further research are given.

Collins, B. L.

Visibility of Exit Signs and Directional Indicators.

National Institute of Standards and Technology, Gaithersburg Journal of the Illuminating Engineering Society, Vol. 20, No. 1, 117-133, Winter 1991. 
Not Available from National Technical Information Service PB91-161984

exit signs; arrows; chevrons; color; contrast; directional indicators; exit; egress; emergency lighting; sign;

visibility

The purpose of the presented research was to determine the size at which arrows and words are visible for and exit sigr. at a specified distance. The National Fire Protection Association (NFPA) is currently revising the life safety Code (NFPA 101) to standardize the inclusion of a directional indicator (i.e., arrow) in conjunction with the word Exit. The current version of NFPA 101 (1988) specifies the use of an arrow located outside the exit legend "of such size, character and location that is plainly visible and identifiable as a directional indicator" . This wording allows arrows of any shape and size to be located below, above, and to the side of the legend-provisions that are not very specific. A proposed revision suggests the use of a 2.25 inch chevron, an arrow-type shape with no tail as shown in Table 1, located to the left and/or right of the 6-inch exit legend. Yet, it is not known whether the chevron is the best shape or whether 2.25 inches is the best size for adequate visibility at $100 \mathrm{ft}$, the maximum distance allowed by NFPA for locating exit signs from a means of egress.

Furthermore, it is also not known whether the arrow needs to be visible at $100 \mathrm{ft}$, or at what distance an arrow is visible enough to ensure proper directional movement.

\section{Collins, B. L. : Goodin, P. J.}

Visibility of Exit Directional Indicators.

National Institute of Standards and Technology, Gaithersburg NISTIR 4532; 43 p. March 1991.

Available from National Technical Information Services PB91-184762

exit signs; arrows; chevrons; color; contrast; directional indicators; exit; egress; emergency lighting; sign;

visibility

A three-phase experiment assessed the effectiveness of different configurations for exit signs and directional indicators. Two phases involved visibility assessments, while a third phase was a behavioral assessment. In the experiment, sign effectiveness was determined in terms of distance to detection, correct identification, and rated effectiveness, as well as speed through a corridor. The results indicated that a chevron in grey on white with a contrast of about 0.4 to 0.5 (to meet minimum

specifications) was identified correctly at the greatest mean distance and receives the highest mean ratings of effectiveness, as compared to other directional indicators. The combination of a 2.25-in chevron with a 6-in EXIT sign was identified correctly at a mean distance of about $100 \mathrm{ft}$. Use of color, either red or green, increased this distance by about 15 to $20 \mathrm{ft}$. Reducing width to height ratio reduced identification distance by about 35-40 ft for chevrons of comparable height, although chevrons of 2.6 to 3.75-in. in height, with a width to height ratio of 0.29 to 0.43 , were identified correctly at about $100 \mathrm{ft}$. These data suggest that chevron width could be reduced if height were 
increased above 2.6-in, and still maintain adequate visibility at $100 \mathrm{ft}$. However, visibility is best predicted by total chevron area, with chevrons with larger total areas seen at greater distances. Analysis of the movement data from the behavioral phase indicated that chevrons of 2.25 -in provided adequate visibility at about $100 \mathrm{ft}$ but that speed of movement is not a sensitivie indicator for sign visibility. Finally, the data from all three phases indicate the importance of chevron size and configuration as well as sign color and contrast in determining visibility.

Cook, G. R.

Cook, G. R.: Simiu, E.

Experimental and Numerical chaos in Continuous systems: Two Case studies.

National Institute of Standards and Technology,

Gaithersburg, MD

ACE, EM Div. Mechanics Computing in 1990s and Beyond. May 20-21, 1991, Columbus, OH, 786-790 pp, 1991.

offshore platforms; chaotic motion; columns; galloping

square bars; numerical simulations

Motivated by recent numerical investigations according to

which certain types of deep-water compliant offshore

structures may experience undesirable chaotic motions, two

types of experimental structural systems capable of

exhibiting chaotic or apparently chaotic behavior were

studied. The first type of system is a harmonically forced

buckled column with a concentrated mass at midspan and with pretensioned continuous springs. For this system a model with acceptable predictive capabilities can be constructed if the continuous springs are represented by a sufficient number of lumped mases with discrete stiffnesses. The second type of system consists either of a galloping square bar or of a pair of parallel, elastically coupled galloping square bars. Our results suggest that the behavior of this type of system, including apparently chaotic behavior, can be described at least to a first approximation by conventional fluidelastic models. However, the predictive capabilities of such models are poor, i.e., in the present state of the art the existence of certain types of hydroelastic behavior may be altogether missed at the design stage. The incorporation of stochastic excitations in the models to account for small flow irregularities may result in improved prediction capabilities.

Cook, G. R. i Simiu, E.

Periodic and Chaotic Oscillations of Modified stoker column. National Institute of Standards and Technology,

Gaithersburg, MD

Journal of Engineering Mechanics, Vol. 117, No. 9, 2049-2064, September 1991.

stoker column; periodic motion; periodic snap-through

motion; chaotic motion; equations

Records are presented of typical measured motions of a modified forced stoker column, including periodic motion around a stable fixed point of the unforced column; periodic snap-through motion around the unstable fixed point; and 
chaotic motion. Characterizations of the recorded chaotic motion include the autocorrelation function; the spectral density plot; capacity dimensions; and the Lyapounov exponent. Numerical simulations were performed in which spring stiffnesses measured under static conditions and dissipative forces based on the viscous damping model were used. The experimental device was represented as a multidegree-of-freedom system that approximated the distributed mass and stiffness of the springs. The simulations yielded chaotic motions comparble qualitatively to, though different quantitatively from, those recorded in the laboratory. As evidenced by the estimated fractal dimension, the influence of the spring mass distribution was not sufficiently strong to affect the dimension of the embedding phase space for the attractor of the chaotic motion.

Cooper, I. $\mathbf{Y}$. Cooper, I. Y.

Applications of the Generalized Global Equivalence Ratio Model (GGERM) for Predicting the Generation Rate and Distribution of Products of Combustion in Two-Layer Fire Environments: Methane and Hexanes.

National Institute of standards and Technology,

Gaithersburg, MD

NISTIR 4590; 76 p. June 1991.

Available from National Technical Information Services PB91-216689

building fires; combustion; compartment fires; computer models; fire models; mathematical models; zone models

The Generalized Global Equivalence Ratio Model (GGERM) was developed to predict the generation rates of oxygen, fuel, and other products of combustion in rooms containing fires. The GGERM extends to general transient conditions the global equivalence ratio model established during times of steady-state in experimental studies involving two-layer compartment fires. The present work uses the GGERM to predict upper layer mass fractions of products of combustion (fuel, oxygen, $C O$ and others) in these two-layer fire experiments, but during times of transient response. All predicted results are found to be plausible and, where transient data are available, predicted and measured results compare favorably. However, available data are limited and additional validation of the GGERM under more varied fire conditions is required before it can be used with confidence in two-layer zone-type compartment fire models.

Cooper, I. Y.

Fire-Plume-Generated Ceiling Jet Characteristics and

Convective Heat Transfer to Ceiling and Wall Surfaces in a Two-Layer Zone-Type Fire Environment: Uniform Temperature Ceiling and Walls.

National Institute of Standards and Technology,

Gaithersburg, MD

NISTIR 4705; 57 p. November 1991.

Available from National Technical Information services 
PB92-123074

ceiling jets; building fires; compartment fires; computer models; fire models; heat transfer; mathematical models; zone models

It has been determined by Sandia National Laboratories and the U. S. Nuclear Regulatory Commission that the use of deterministic, multi-room, zone-type fire modeling technology could enhance the reliability of their recent reactor safety risk studies. These studies are confined to the relatively early detection times of fire development when fire-driven ceiling jets and gas-to-ceiling convective heat transfer are expected to play a particularly important role in room-to-room smoke spread and in the response of near-ceiling mounted detection hardware. A parameter of concern in these risk analyses is the location of the fire within the space of fire origin. One goal of the analyses is to determine the significance to risk of this

fire-position parameter. This work presents a model to predict the instantaneous rate of convective heat transfer from fire plume gases to the overhead ceiling surface in a room of fire origin. The room is assumed to be a rectangular parallelopiped and, at times of interest, ceiling temperatures are simulated as being uniform. Also presented is an estimate of the convective heat transfer, due to ceiling-jet-driven wall flows, to both the upper and lower portions of the walls. The effect on the heat transfer of the location of the fire within the room is taken into account. Finally presented is a model of the velocity and temperature distributions in the ceiling jet. The model equations were used to develop an algorithm and associated modular computer subroutine to carry out the indicated heat transfer calculations. The subroutine is written in FORTRAN 77 and called CEILHT. The algorithm and subroutine are suitable for use in two-layer zone-type compartment fire model computer codes. The subroutine was tested for a variety of fire environments involving a $10(7) \mathrm{W}$ fire in a $8 \mathrm{~m}$ $\mathrm{x} 8 \mathrm{~m} \times 4 \mathrm{~m}$ high enclosure. While the calculated results were plausible, it is important to point out that CEILHT simulations have not been experimentally validated.

Cooper, L. Y.

Interaction of an Isolated Sprinkler Spray and a Two-Layer Compartment Fire Environment.

National Institute of Standards and Technology, Gaithersburg, MD

NISTIR 4587; 48 p. May 1991.

Available from National Technical Information Services PB91-216804

building fires; compartment fires; computer models; fire models; mathematical models; vents; sprinklers; sprinkler response; zone models

A mathematical model is developed to simulate the interaction of an isolated operating sprinkler and a two-layer fire environments under arbitrary conditions of sprinkler-nozzle evaluation, and upper- and lower-layer thickness and temperature. The sprinkler is characterized by water flow rate, nozzle diameter, and three other device parameters. The model takes account of all effects of the 
sprinkler spray as it entrains, drives downward (by aerodynamic drag on the spray drops), humidified, and cools (by drop evaporation) gases from both the high temperature upper layer and the relatively cooler lower layer. The model provides a means of predicting the rates of flow of mass, enthalpy, products of combustion, and evaporated water to each of the two layers as a result of sprinkler operation. An algorithm for such predictions is presented in a manner that is suitable for general use in two-layer zone-type compartment fire models. The model is exercised ir example calculations which simulate the interaction between the spray of a real sprinkler device and both fire and non-fire environments. The calculations revealed an important generic interaction phenomenon, namely, an abrupt and large change in the growth rate of an upper layer that would accompany an increase in upper layer thickness beyond a critical thickness (for a given upper layer temperature) or an increase in upper layer temperature beyond a critical temperature (for a given upper layer thickness). Exceeding critical values would lead to very large rate of growth of upper layer thickness, a growth that would likely lead to rapid and complete smoke filling of even the largest compartments of fire origin.

Cooper, L. Y.

Model for Predicting the Generation Rate and Distribution of Products of Combustion in Two-Layer Fire Environments.

National Institute of Standards and Technology, Gaithersburg, MD

NISTIR 4403; 53 p. September 1990.

American Society of Mechanical Engineers (ASME). Heat and Mass Transfer in Fire and combustion systems. ASME HTD Vol. 176. 1991, NISTIR 4403, ASME, New York, Yao, S. C.; Chung, J. N., Editors, 9-22 pp, 1990.

Available from National Technical Information Services

PB91-107151

combustion; building fires; compartment fires; computer models; fire models; mathematical models; zone models

A model is developed for predicting the generation rates of oxygen, fuel, and any other products of combustion in rooms containing fires. The model is called the generalized

global equivalence ratio model. It extends the steady state global equivalence ratio model established from steady-state data of several previous experimental studies. After describing the model in detail, a concise algorithm is outlined for implementing it in two-layer zone-type compartment fire model computer codes. With the algorithm in place, such codes could be used to simulate the distribution of combustion products in single or multi-room fire environments. In an example application, the model simulates the time-dependent environment, including that of steady-state, in conditions and under the assumption of complete stoichiometric combustion, solutions for concentrations of products of combustion are obtained and presented. The solutions are used to predict the time-to-extinguishment of a burning methane fuel source embedded in an initially ambient-atmosphere upper layer. 
Damasceno, G. S.

Damasceno, G. S.; Domanski, P. A. ; Rooke, S.; Goldschmidt,

V. W.

Refrigerant Charge Effects on Heat Pump Performance.

University Federal of Vicosa, Brazil

National Institute of Standards and Technology,

Gaithersburg, MD

Purdue Univ., West Lafayette, IN

ASHRAE Transactions, Vol. 97, No. 1, [pages unknown], 1991.

3474 ;

refrigerants; pumps; heat pumps; computer models

The capability of predicting the effects of refrigerant charge on the steady-state performance of a heat pump is addressed. Rather extensive test data for one particular residential air-to-air heat pump are compared with the predictions of HPSIM, a computer model with the capability of tracking refrigerant mass distribution within the various components. The need to properly account for parasitic volumes and all internal volumes of the heat pump is underscored.

Danner, W. F.

Danner, W. F.; Sanford, D. T.; Yang, Y.

STEP (Standard for the Exchange of Product Model Data)

Resource Integration: Semantic and Syntactic Rules.

National Institute of Standards and Technology,

Gaithersburg, MD

NISTIR 4528; 20 p. March 1991.

Available from National Technical Information Services

PB91-184788

conceptual model; integration; PDES; product data exchange;

STEP

STEP (Standard for the Exchange of Product Model Data)

Resource Integration: Semantic and Syntactic Rules, documents the rules that are used in the integration of STEP draft resource models. The rules are applied in the development of the STEP Integrated Resource that satisfies application requirements for STEP.

Davis, W. D.

Davis, W. D. : Cooper, L. Y.

Computer Model for Estimating the Response of Sprinkler

Links to compartment Fires with Draft Curtains and Fusible

Link-Actuated Ceiling Vents.

National Institute of Standards and Technology,

Gaithersburg, MD

Fire Technology, Vol. 27, No. 2, 113-127, May 1991. computer models; sprinklers; compartment fires; curtains; vents; ceiling jets

A computer program, LAVENT, is now available which computes the heating of fusible links due to the presence of a ceiling jet imbedded in an upper layer. An important new feature in this program is that the two-dimensional

structure of the ceiling jet is taken into account such that the location of the link beneath the ceiling plays a role in the response of the link. The links can be used to activate ceiling vents such that the effect of venting the upper 
layer on the ceiling jet may be studied. Additional applications would include the study of upper layer containment through the use of a combination of draft curtains and ceiling vents. The geometry modeled by the program is that of a large compartment enclosed by a combination of walls and draft curtains.

Davis, W. D. : Forney, G. P.: Klote, J. H. Field Modeling of Room Fires.

National Institute of Standards and Technology, Gaithersburg, MD

NISTIR 4673; 45 p. November 1991.

Available from National Technical Information Services PB92-156751

field models; room fires; compartment fires; computational

fluid dynamics; validation; zone models

The application of the Harwell field model, FLow3D, to model compartment fires is investigated. Two experiments are chosen to model numerically. The first experiment is a single room fire where the vertical structure of the ceiling jet produced by the fire is measured and the tempeature response of simulated fusible links to the ceiling jet is availble. The second experiment consists of three rooms with a fire. Temperature measurements using thermocouples are available in each of the three rooms as well as in the corridors connecting the rooms. These two experiments provide an opportunity to investigate both two and three dimensional field modeling of fires. It is found that the numerical results using the field model are in reasonable agreement with the experimental data. FLOW3D has been enhanced by the addition of a simple fusible link algorithm previously used in the zone fire model LAVENT. This algorithm used in conjunction with the field model produces good agreement with the measured fusible link temperatures found in the single room experiment.

Dietenberger, M. A.

Dietenberger, M. A.

Technical Reference and User's Guide for FAST/FFM Version 3. Dayton Univ., $\mathrm{OH}$ NIST-GCR-91-589; 152 p. May 1991. Available from National Technical Information Services PB91-206664

compartment fires; computer models; fire spread; furniture; room fires: smoke; smoke transport; toxic gases

The FAST/FFM computer model provides dynamic, quasi-three-dimensional predictions of furniture fire growth and burnout in a room as well as of the spread of both nontoxic and toxic gases, smoke, and fire to other rooms. This reference guide provides a detailed description of the furniture fire model (FFM) equations, the program structure of FFM and its insertion into FAST, the FFM data input requirements, and the output produced by version 3 of the model. 
Dikkers, R. D.

Dikkers, R. D.

Standards for the Physical Protection of National Resources

and Facilities.

National Institute of Standards and Technology,

Gaithersburg, MD

NISTIR 4618; 88 p. July 1991.

Available from National Technical Information Services

PB91-222695

assets; emergency preparedness; essential resources and

facilities: Federal government; physical security; security engineering: standards; threats

In regard to a Federal Emergency Management Agency (FEMA) responsibility for the protection of essential resources and facilities, NIST conducted a study whose objectives are: to identify and compile existing standards and guidelines pertaining to the protection of facilities and resources; and (2) to prepare a plan and strategies for developing national standards which may be needed to assist Federal departments and agencies in the protection of their facilities and resources. A review of factors and considerations involved in the planning and design of physical protection for facilities and resources is discussed along with a description of physical security activities of selected Federal departments and agencies, and non-government organizations. General information on

standards and brief descriptions of 110 standards pertaining to physical security and protection are included in Appendices. Recommendations are made for: (1) the conduct of a comprehensive study to identify and describe Federal agency physical security activities and resource information; and (2) the development of national voluntary standards which would cover the planning and design phases of the security engineering design process as well as various physical security equipment and systems.

dimarzo, M.

diMarzo, M.; Liao, Y.; Tartarini, P.; Evans, D. D.; Baum, H. $\mathrm{R}$.

Dropwise Evaporative Cooling of a Low Thermal Conductivity Solid.

Maryland Univ., College Park

National Institute of Standards and Technology,

Gaithersburg, MD

International Association for Fire Safety science. Fire

Safety science. Proceedings. 3rd International symposium. July 8-12, 1991, Edinburgh, Scotland, Elsevier Applied

Science, New York, Cox, G.; Langford, B., Editors, 987-996 pp, 1991.

fire research; fire safety; fire science; evaporation: cooling; droplets; thermal conductivity; solid fuels;

equations; formulations

Insight on extinguishment of a solid fuel fire by sprinkler generated droplets is obtained by detailed modelling of a single droplet evaporative cooling on a hot low thermal conductivity solid. The assumption of constant and uniform temperature at the solid-liquid interface, which decouples the solid and the liquid modelling, cannot be applied to this case because strong local cooling of the solid requires 
the solutions of both regions (liquid and solid) to be coupled. The large thermal gradients observed at the edge of the droplet preclude the application of finite difference techniques for the integration of the transient conduction governing equation. A mixed technique that uses a control volume method for the liquid and a boundary element formulation for the solid is proposed. Both methods are briefly outlined and the computed predictions are validated with experimental measurements which encompass high resolution thermography of the solid surface subjected to evaporative cooling. Insight on the temperature distribuiton at the solid-liquid interface is obtained deduced from the model and the deviation from the constant and uniform temperature at the liquid-solid interface is assessed. The radial versus axial conduciton in the liquid droplet is also quantified.

Dobbins, R. A.

Dobbins, R. A.; Santoro, R. J.; Semerjian, H. G. Analysis of Light Scattering From Soot Using optical Cross Sections for Aggregates.

Brown Univ., Providence, RI

Pennsylvania State Univ., Unviersity Park

National Institute of Standards and Technology,

Gaithersburg, MD

Combustion Institute, symposium (International) on

Combustion, 23rd. July 22-27, 1990, Orleans, France, Combustion Institute, Pittsburgh, PA, 1525-1532 pp, 1991. combustion; soot; light scattering; aggregates; optical properties; diffusion flames; data analysis

soot formed in flames usually consists of aggregates (clusters or agglomerates) of a variable number of nearly spherical, monodisperse primary particles (monomers or spherules). In this work, the optical properties of polydisperse aggregates are used to analyze light scattering data from a coannular ethene diffusion flame. In previously reported studies, data have been obtained on the local extinction and volumetric scattering cross sections from laser scattering experiments, on the flame velocity field from laser velocimetry, and on the primary particle sizes determined by electron microscopy. The present analysis yields the average number of primary particles per aggregate, the mean-square radius of gyration, the soot volume fraction and the aggregtion rate. It is found that sustained collisional growth of the aggregates occurs while their primary particles grow through heterogeneous reactions low in the flame, and contract through surface oxidation in the upper half of the flame. A recent value of the refractive index gives internally consistent moment ratios of the aggregate size distribution function. This method of analysis provides a more detailed and complete description of the formation, growth and oxidation of soot aggregates in a diffusion flame.

Domanski, P. A.

Domanski, P. A. 
Rating of Mixed, Split, Residential Heat Pumps Operating in the Heating Mode.

National Institute of Standards and Technology,

Gaithersburg, MD

ASHRAE Transactions, Vol. 97, No. 2, [pages unknown], 1991. 3525 ;

heat pumps; heating equipment; methodology; cooling

An analysis and methodology are presented for rating the performance of mixed, single-speed, split, residential heat pumps operating in the heating mode. The method allows for calculation of the capacity at the DOE $8.3 \mathrm{deg} C$ (47 deg F) rating point and the heating seasonal performance factor for the minimum design heating requirement in Region 4 without performing laboratory testing of a complete system. The analysis included evaluation of the impact of the indoor coil, expansion device, and fan on system performance. Verification and applicablility limits of the procedure are also discussed.

Domanski, P. A.

Simulation of an Evaporator With Nonuniform one-Dimensional Air Distribution.

National Institute of Standards and Technology,

Gaithersburg, MD

ASHRAE Transactions, Vol. 97, No. 1, [pages unknown], 1991. NY-91-13-1;

simulation; evaporator; heat exchanger; air conditioning;

refrigerants; equations

This paper presents a simulation model of a plate-fin, air-to-refrigerant heat exchanger used as an evaporator in residential air conditioning. The model can account for nonuniform air distribution between coil tubes and simulates refrigerant distribution for coil circuits and individual tubes. The model is based on a tube-by-tube approach. Performance of each tube is analyzed separately by considering the cross-flow heat transfer with the external air-stream and the appropriate heat and mass transfer relationships. Each tube is associated with individual refrigerant parameters and mass flow rate, and air mass flow rate, inlet temperature, and humidity. A comparison of the model's predictions and laboratory test data is provided. Simulation results indicate that air maldistribution may induce maldistribution of a refrigerant, which contributes to the performance degradation of the evaporator.

Evans, D. D.

Evans, D. D.; Mulholland, G. W.; Lawson, J. R.; Tennyson, E. J.; Tebeau, P. A.; Fingas, M. F.; Gould, J. R.

Burning of oil spills.

National Institute of Standards and Technology,

Gaithersburg, MD

Materials Management Service, Herndon, VA

Coast Guard Research and Development Branch, Groton, CT

Environment Canada, ottawa, ontario

American Petroleum Institute, Washington, DC

U. S. Coast Guard, American Petroleum Institute, and U. S.

Environmental Protection Agency. International oil spill 
Conference: Prevention, Behavior, Control, Cleanup, 1991 Proceedings. March 4-7, 1991, San Diego, CA, 677-680 pp, 1991.

oil spills; combustion; offshore drilling; pollution; crude

oil; water

The Center for Fire Research (CFR) at the National Institute of Standards and Technology (NIST) is conducting research related to safety in offshore drilling and oil spill pollution under joint funding from Minerals Management Service (MMS), U. S. Coast Guard, and the American Petroleum Institute. Technical assistance in measurement has been donated by Environment Canada. This research has focused on examining the phenomena associated with crude oil combustion and the impact of using burning as a spill response method. The process of burning crude oil on water as a means to mitigate oil spills has been investigated with a research effort combining both small-scale experiments and calculations. As a result of these studies, there has been increased understanding of the burning process, including burning rate, heat radiation, smoke emission, smoke composition, and smoke dispersion in the atmosphere. to gaining acceptance of burning as a spill response technique is the demonstration that favorable results obtained at laboratory scale can be shown to continue in test burns representing the size of fires expected in actual operations. Field-scale burn tests are being planned and coordinated jointly by MMS, API, USCG, and Environment Canada to document the use of burning technology under conditions simulating actual oil spill cleanup operations. The purpose of this project is to measure the effects of oil spill burning in laboratory and field tests.

Evans, D. D.; Tennyson, E. J.

In-Situ Burning: A Promising Oil spill Response strategy. National Institute of Standards and Technology,

Gaithersburg, MD

Minerals Management Service, Herndon, VA

Coastal and Ocean Management, 7th Symposium. July 8-12,

1991, Long Beach, CA, 1-18 pp, 1991.

oil spills; in situ combustion; response time

In 1984 the Minerals Management Service began to investigate limiting conditions for burning spilled oil in-situ on the open ocean through a multiphase research program to

understand the important aspects of in-situ burning as a response strategy. The first phase of this research program was an investigation to quantify the airborne pollutants resulting from the burning of various oils and to model the major features of the smoke plume flow. This laboratory study was conducted by the National Institute of standards and Technology. Scaling of the results from the NIST laboratory results was examined in meso-scale spill burns up to $15 \mathrm{~m}$ square. Although in-situ burning has limitations, as do other oil spill response strategies, it shows promise for many of the conditions occurring in accidential spills.

Evans, D. D. ; Walton, W. D. ; Baum, H. R.; Mullholland, G. W. ; Lawson, J. R.; Koseki, H.; Ghoniem, A. 
Smoke Emission From Burning crude oil.

National Institute of Standards and Technology,

Gaithersburg, MD

Fire Research Institute, Tokyo, Japan

Massachusetts Institute of Technology, Cambridge

Enviornment Canada. Arctic and Marine Oilspill Program

Technical Seminar, 14th. June 12-14, 1991, Vancouver, B.C.,

Enviornment Canada, ottawa, Ontario, $421-449$ pp, 1991.

oil spills; crude oil; smoke emissions; burning rate; smoke

yield; fire spread; pool fires; combustion products

Research has shown that burning can be an effective means to remove oil from the surface of the water after a spill.

Previous research has focused on laboratory studies of

combustion products from oil pool fires less than 1 meter in

diameter. This paper describes instrument packages

developed to determine the amount of various combustion products emitted from large $(15 \mathrm{~m} \times 15 \mathrm{~m})$ crude oil pool

fires. Based on samples drawn directly from the smoke plume immediately downstream of the flame, burning a mixture of Arabian light and Murban crude oils in a $2.7 \mathrm{~m} \times 2.7 \mathrm{~m}$ pan produces a smoke yield of 0.15. Preliminary results from burning Louisiana crude in a $6 \mathrm{~m} \times 6 \mathrm{~m}$ pan indicate a similar 0.14 of the crude oil is converted to smoke in the combustion process. The increase in burning rate and smoke production with increasing fire size is discussed. Progress is reported on new calculation methods for smoke dispersion and downwind deposition of particulate. Results of example calculations are presented.

Fanney, A. H.

Fanney, A. H.; Thomas, W. C.; Burch, D. M.; Mathens, L. R.,

Jr.

Measurements of Moisture Diffusion in Building Materials.

National Institute of Standards and Technology,

Gaithersburg, MD

Virginia Polytechnic Institute and State Univ., Blacksburg

ASHRAE Transactions, Vol. 97, No. 2, 99-113, 1991.

3498 ;

American society of Heating, Refrigerating, and

Air-Conditioning Engineers, Inc. (ASHRAE). Summer Annual

Meeting. June 23, 1991, 3498, Indianapolis, IN, 99-113 pp,

1991.

building materials; moisture; diffusion; gypsum board;

paints; latex; coatings; moisture content

Experimental techniques were developed for measuring moisture diffusion coefficients of building materials.

Results were obtained for white pine, gypsum board, and a latex paint coating at nominal ambient temperatures of 76 $\operatorname{deg} F$ and $44 \mathrm{deg} F$. Moisture transfer rates were measured using a modified ASTM permeance cup procedure. The modifications were implemented to investigate the dependence of moisture diffusivity on moisture content and to take into account the effects of external transfer resistance.

Diffusivities were correlated with moisture content using an exponential relationship. The measured diffusivities for both materials depended strongly on moisture content and temperature. At $76 \mathrm{deg} F$, the diffusivity for white pine increased almost an order of magnitude, for a $20 \%$ increase 
in moisture content (dry basis). The diffusivity of gypsum board decreased by approximately two orders of magnitude, for a $2 \%$ increase in moisture content at $75 \mathrm{deg} F$. At the same moisture content, the diffusivity for white pine was about three times greater at 76 deg $F$ than at 44 deg $F$. For gypsum board, the diffusivity was from two to six times greater at 75 deg $F$ than at 44 deg F. Moisture transfer rates were also measured for gypsum board specimens with two coats of latex paint on one surface. The data were analyzed to determine the permeance of the paint layer. Permeance was also found to depend strongly on ambient relative humidity. At $75 \mathrm{deg} F$, the permeance increases by approximately a factor of $\mathrm{six}$ as the average ambient relative humidity increased from $20 \%$ to $90 \%$.

Fattal, S. G.

Fattal, S. G.; Todd, D. R.

Ultimate Strength of Masonry Shear Walls: Predictions VS

Test Results.

National Institute of Standards and Technology, Gaithersburg, MD

NISTIR 4633; 46 p. October 1991.

Available from National Technical Information Services

PB92-116342

masonry; predicted strength; walls; reinforced walls; shear strength; shear walls; test strewngth; ultimate load

This study compares the ability of four different equations to predict the ultimate shear stress in masonry walls failing in shear. Experimental data on fully-grouted reinforced shear walls from four different sources are compared with the predictions from the four equations. Wall characteristics from 62 test specimens were used as input to the four predictive equations. The ultimate strength predictions were then compared to the actual measured strength of the 62 test walls. Two of the equations (the existing Uniform Building Code equation for shear strength of masonry walls and the Architectural Institute of Japan's equation for predicting the shear strength of reinforced concrete shear walls) were found to be inadequate for the prediction of ultimate shear strength of masonry walls. An equation proposed by shing et al. was found to predict shear strength well for only limited ranges of variables, primarily because excessive weight is given to the contributions of horizontal reinforcement to strength. An equation proposed by Matsumura was found to be the best predictor of the four equations examined, but it lacks the consistency needed to use it as a basis for design. The conclusions drawn from the present study indicate the possibility of developing reliable predictive formulations using both rational analysis and an empirical approach.

Fields, B. A.

Fields, B. A.; Fields, R. J.

Prediction of Elevated Temperature Deformation of structural

Steel Under Anisothermal Conditions.

National Institute of Standards and Technology,

Gaithersburg, MD 
NISTIR 4497; 45 p. January 1991.

Available from National Technical Information Services

PB91-184838

steel structures; anisothermal tests; creep; deformation; elevated temperatures; linear heating; non-linear heating; plastics; plasticity; stress

Using a previously formulated equation which calculates the elastic, plastic and creep strains during loading at a constant elevated temperature, a method and a computer program have been developed that will predict the strain due to creep during anisothermal tests at constant load. Comparisons were made with results from anisothermal tests for the Australian Steel AS A149, a steel close to the specification for ASTM A36. Agreement with experimental results is excellent for several linear heating rate and one non-linear heating rate.

\section{Forney, G. P.}

Forney, G. P.

Computing Radiative Heat Transfer Occurring in a Zone Fire Model.

National Institute of Standards and Technology,

Gaithersburg, MD

NISTIR 4709; 49 p. November 1991.

Available from National Technical Information Services PB92-156777

radiative heat transfer; zone models; numerical analysis

Radiation, convection and conduction are the three

mechanisms which a zone fire model must consider when calculating the heat transfer between fires, wall surfaces and room gases. Radiation dominates the other two modes of heat transfer in rooms where there are fires or hot smoke layers. The computational requirements of a radiation model can also easily dominate the work required to calculate other physical sub-models in a zone fire model. This report presents algorithms for efficiently computing the radiative heat exchange between four-wall surfaces, several fires and two interior gases. A two-wall and a ten-wall radiation model are also discussed. The structure of this radiation model is exploited to show that only a few configuration factors need to be calculated directly (two rather than 16 for the four-wall model and eight rather than 100 for the ten-wall model) and matrices needed to solve for the net radiative flux striking each surface are shown, after the appropriate transformation is taken, to be diagonally dominant. Iterative methods may then be used to solve the linear equations more efficiently than direct methods such as Gaussian elimination. The radiation exchange algorithms are implemented as FORTRAN subroutines named RAD2, RAD4 and RAD10. These subroutines along with a test driver are available from the author.

\section{Frohnsdorff, G.}

Frohnsdorff, G.; Masters, L. W.

Suggestions for a Logically-Consistent structure for service Life Prediction standards. 
National Institute of Standards and Technology, Gaithersburg, MD

American Society for Testing and Materials; Building

Research Establishment; International Council for Building

Research Studies and Documentation; National Institute of

Standards and Technology; National Research Council of

Canada; and International Union of Testing and Research

Laboratories for Materials and structures. Durability of

Building Materials and Components. International

Conference, 5th. Chapter 11. November November 7-9, 1990,

Brighton, UK, E. \& F. N. Spon, New York, Baker, J. M. :

Nixon, P. J.: Majumdar, A. J.; Davies, H., Editors, 113-126

pp, 1991 .

building materials; durability; standards; methodology; life

prediction; kinetics; degradation; mathematical models

Ability to predict the service life of building materials, components, and systems is needed to improve the selection process. Evaluation of durability using existing standards does not give adequate service life information. Because service life prediction is more complex than current durability evaluations, its standardization will require a new body of standards to be put in place. The standards must define a general methodology, and essential components of the methodology. These are enviornmental

characterization, characterization of the item whose service life is to be predicted, identification of the mechanisms and kinetics of the degradation processes, development of mathematical models of degradation, application of the models in service life prediction, and reporting of the results. It is proposed that the needed standards must comprise a hierarchy with the highest level being the general methodology, the second level defining the essential components of the methodology, and the third and lower levels describing the application of the generic standards to specific materials, components, or systems. The development of the proposed hierarachy will require a well-coordinated activity which cuts across the interests of many different standards committees.

Fuller, S. K.

Fuller, S. K.

Evaluating Fire Protection Investment Decisions for

Homeowners.

National Institute of Standards and Technology,

Gaithersburg, MD

Socio-Economic Planning Science, Vol. 25, No. 2, 143-154, 1991.

fire protection; decision making; risks; smoke detectors; sprinkler systems; life safety; insurance; costs:

maintenance

This paper examines the use of the Analytic Hierarchy Process (AHP) for evaluating fire protection systems for homeowners. It explores how to include in the decision-making process information on an individual's risk exposure and risk attitude. The AHP is applied to the choice of purchasing smoke detectors, a sprinkler system, or a combination of the two. Two hypothetical cases are assumed, one in which the homeowner is risk-taking and has 
lower-than-average risk exposure, and one in which the homeowner is risk-averse and has higher-than-average risk exposure. Probabilities of fire, death, injury, and property loss, subjectively derived from national fire statistics, are used in combinaton with more easily quantifiable benefit and cost criteria such as system price, property tax increase, and insurance savings. The study focuses on the decision making of homeowners, but the results are also of interest to builders of residential homes, fire chiefs, policy makers, and others who make decisions about fire protection investments.

\section{Garboczi, E. J.}

Garboczi, E. J.; Bentz, D. P.

Digital Simulation of the Aggregate-Cement Paste Interfacial Zone in Concrete.

National Institute of Standards and Technology, Gaithersburg, MD

Journal of Materials Research, Vol. 6, No. 1, 196-201, January 1991.

\section{aggregates; cements; concretes}

Researchers using backscattered scanning electron microscopy, along with quantitative image analysis techniques, have clearly demonstrated the existence of a highly porous interfacial region between aggregate particles and the cement paste matrix in ordinary portland cement concrete. This paper presents the results of a digital-image-based simulation model of this interfacial zone. A dissolution-diffusion-reaction-like cycle of hydrating cement particles is directly simulated using cement particles packed around a simple nonreactive aggregate particle. The model is two-dimensional, as we are comparing to experimental results obtained on

two-dimensional images of polished sections. The qualitative features seen experimentally, such as large amounts of porosity and calcium hydroxide in the interfacial zone, are accurately reproduced. A new mechanism, one-sided growth, is proposed, along with the more usual particle-packing ideas, as an explanation of the origin of the characteristic features of the interfacial zone.

Garboczi, E. J.; Bentz, D. P. Digitized Simulation of Mercury Intrusion Porosimetry. National Institute of Standards and Technology, Gaithersburg, MD

National Institute of Standards and Technology and American Ceramic Society. Advances in Cementitious Materials. Ceramic Transactions. Volume 16. July 22-26, 1990, Gaithersburg, MD, Mindess, S., Editor, 365-379 pp, 1991. mercury intrusion porosimetry; porous materials; algorithms; simulation

Mercury intrusion porosimetry is a widely used method for measuring the pore-size distribution of porous materials. This paper describes an algorithm that has been developed that simulates mercury intrusion into a two-dimensional porous material. The simulation can be implemented on model sturctures or on micrographs of real porous materials. Using 
a burning algorithm, the critical pore diameter for mercury connectivity can be directly computed and studied as a function of microstructure. The point at which the intruding mercury becomes continuous is found to occur at the inflection point of the cumulative intrusion curve, in agreement with recent experimental results.

Garboczi, E. J. ; Day, A. R. Universal Conductivity Curve for a Plane Containing Random Holes.

National Institute of Standards and Technology,

Gaithersburg, MD

Michigan State Univ., East Lansing

Marquette Univ., Milwaukee, WI

Physical Review A: Statistical Physics, Plasmas, Fluids, and Related Interdisciplinary Topics, Third Series, Vol. 43 , No. 12, 6473-6482, June 15, 1991.

random holes; conductivity; conductance

This paper examines the general percolation problem of cutting randomly centered insulating holes in a two-dimensional conducting sheet, and explores how the electrical conductivity decreases with the remaining area fraction. This problem has been studied in the past for circular, square, and needlelike holes, using both computer simulations and analog experiments. In this paper, we extend these studies by examining cases where the insulating hole is of arbitrary shape, using digital-image-based numerical techniques in conjunction with the [symbol] algorithm. We find that, within computational uncertainty, the scaled percolation threshold [equation] is a universal quantity for all the cases studied, where [symbol] is the critical value at percolation of the number of holes per unit area [symbol] and [equation] is a measure of [symbol], the initial slope of the [symbol] curve, calculated in the few-hold limit and averaged over the different shapes and sizes of the holes used. For elliptical holes [equation], where [symbol] and [symbol] are the semimajor and semiminor axes, respectively. All results are well described by the universal conductivity curve: [equation], where [equation] and [symbol] is the conductivity of the sheet before any holes are introduced.

Gore, J. P.

Gore, J. P. ; Evans, D. D.; McCaffrey, B. J.

Temperature and Radiation of Diffusion Flames with

Suppression.

Maryland Univ., College Park

National Institute of Standards and Technology,

Gaithersburg, MD

Maryland Univ., Catonsville, MD

Combustion Science and Technology, Vol. 77, No. 4-6, 189-202, 1991 .

diffusion flames; temperature; heat release rate; jet

flames; water

Temperature and radiation properties of 1-8 MW heat release rate methane/air jet diffusion flames without and with the addition of liquid water suppressant to the fuel stream are 
studied. The analysis includes an existing parabolic flow solver, in conjunction with the locally homogeneous flow approximation and the laminar flamelet concept. State reltionships for methane + liquid water mixtures are calculated from species concentration measurements for methane flames without water added. The analyses are compared with previously published data. Tests for flames without water addition show the applicability of the analyses to the present flame scales. The results for flames with water addition indicate that finite rates of evaporation and separated flow effects need to be considered for accurate predictions at high water loading.

Gore, J. P. ; Klassen, M. E. Study of structure and Radiation Properties of Pool Fires. Annual Report. July 1, 1989-June 30, 1990. Maryland Univ., College Park Annual Report; 37 p. 1991.

pool fires; flame height; burning rate; radiative heat loss; fuels; luminous flames; soot; absorption; data analysis Measurements of flame heights, burning rates and radiative heat loss fractions for pool flames burning a variety of fuels in pools of three sizes are reported. The data show significant effects of fuel type on burning rates. The radiative heat loss fractions of luminous flames are found to be relatively independent of sooting tendency.

Measurements of monochromatic absorption and two-line emission intensities indicate that this insensitivity is due to the presence of large quantities of cold soot in heavily sooting flames.

Gore, J. P. ; Klassen, M. E. Study of structure and Radiation Properties of Pool Fires. Annual Report. July 1, 1990-August 30, 1991. Maryland Univ., College Park Annual Report; 31 p. 1991.

pool fires; tolune; soot; radiative heat transfer; temperature; absorption; emissions

Measurements of in situ radiative feedback, temperatures based on emission and soot volume fractions based on absorption and emission in a variety of pool fires were completed. The present report focusses on the results from $30 \mathrm{~cm}$ toluene fired pool fires as an example. The effects of turbulent fluctuations on the radiative heat feedback are treated using the transient soot volume fraction and temperature data. The results show large fluctuations in soot volume fractions and temperatures in all regions of the $30 \mathrm{~cm}$ pool fires. A layer of cold soot is found near the surface of the fire. The present treatment of radiative heat transfer accounts for the blockage of energy by the cold soot particles. The results also show the presence of large quantities of relatively cold soot in the fires. Treatment of turbulence radiation interactions using the present method was adequate for the calculation of directional and hemispherical heat feedback to the pool surface. 
Gore, J. P.; Klassen, M.; Hamins, A. ; Kashiwagi, T. Fuel Property Effects on Burning Rate and Radiative Transfer From Liquid Pool Flames.

Maryland Univ., College Park

National Institute of Standards and Technology,

Gaithersburg, MD

International Association for Fire Safety Science. Fire Safety science. Proceedings. 3rd International symposium. July 8-12, 1991, Edinburgh, Scotland, Elsevier Applied Science, New York, Cox, G.; Langford, B., Editors, 395-404 pp, 1991.

fire research; fire safety; fire science; pool fires; radiation; burning rate; radiative heat loss; fuels; luminious flames; soot

Measurements of burning rates and radiative heat loss fractions for pool flames burning a variety of fuels in pools of three sizes are reported. The data show significant effects of fuel type on burning rates. The radiative heat loss fractions of luminious flames are found to be relatively independent of sooting tendency. Measurements of monochromatic absorption and two-line emission intensities indicate that this insensitivity is due to the presence of large quantities of cold soot in heavily sooting flames.

Gore, J. P.: Skinner, S. M.

Mixing Rules for State Relationships of Methane and

Acetylene/Air Diffusion Flames.

Purdue Univ., West Lafayette, IN

Maryland Univ., College Park

Combustion and Flame, Vol. 87, No. 3-4, 357-364, December 1991.

mixing; methane; acetylene; diffusion flames; laminar

flames; sampling; fuels

Measurements of concentrations of major gas species in laminar diffusion flames burning mixtures of $\mathrm{CH} 4$ and $\mathrm{C} 2 \mathrm{H} 2$ in air are reported. The results are interpreted in terms of the laminar flamelet concept. Two methods of estimating the state relationships of fuel mixtures were evaluated. overall, a mixing rule that utilizes the information concerning the state relationships of the individual fuels provides better estimates of species concentrations in flames burning fuel mixtures than the generalized state relationships.

Graves, R. S.

Graves, R. S.; McElroy, D. L.; Miller, R. G.; Yarbrough, D. W. ; Zarr, R. R.

Interlaboratory Comparison of Four Heat Flow Meter

Apparatuses on Planed Polyisocyanurate Boards Foamed With CFC-11.

Oak Ridge National Lab., TN

Jim Walter Research Corp., st. Petersburg, FL

Tennessee Technological Univ., Cookeville, TN

National Institute of Standards and Technology, Gaithersburg, MD 
ORNL/TM-11720; 36 p. June 1991.

polyisocyanurate foam; measuring instruments; heat

transmission; tests

This report describes an interlaboratory comparison of apparent thermal conductivity (k) results on planned polyisocyanurate (PIR) boards foamed with chlorofluorcarbon 11 (CFC-11). Sequential tests were conducted at 75 deg F (24 deg C) at four facilities on two rigid (PIR) boards, individually and as a pair, using four comparative heat flow meter apparatuses that meet American Society for Testing and Materials (ASTM) C 518. The specimens were shipped from lab to $1 \mathrm{ab}$, and the testing sequence ( $\operatorname{Lab} 1,2,3,4$, and 1 ) yielded $15 \mathrm{k}$-values that have a two standard devition

[symbol] value of $2.2 \%$ when describes by: [equation] where $t$ is the elapsed time in days after planing of the boards. The [symbol] value for five tests on Board 1 was $2.1 \%$ and the [symbol] value for five tests on Boards $1+2$ was $2.2 \%$; but the [symbol] value for five tests on Board 2 was $2.8 \%$. This may be associated with a larger variation in measured specimen thickness ( $4.1 \%$ ) for Board 2 than for Board 1

$(1.7 \%)$ and Boards $1+2(1.6 \%)$. The 15 thermal conductance (C) values have a [symbol] value of $3.2 \%$ when described by: [equation]. Thus, the [symbol] (k-values) of the interlaboratory comparison is not reduced by comparing $c$ values.

Griffiths, P. R.

Griffiths, P. R.

Expert Systems Approach for Spectra-Structure Correlation

for Vapor Phase Infrared Spectra.

Idaho Univ., Moscow

NIST-GCR-91-587; 82 p. March 1991.

Available from National Technical Information Services

PB92-156736

expert systems; infrared spectrometers; FT-IR

Identification of unknown gas species can be done-at lease approximately-by infrared spectrometric measurements alone, without separtion (that is, without gas chromatography) if a sufficiently robust set of algorithms can be developed for automatic search and identification procedures. The PAIRS computer program is an example of such an automated approach. Existing programs, such as PAIRS, however, do not have the ability of identifying a sufficiently large number of gas species to find regular use in areas such as toxicity of fire gases. For such purposes, it was necessary to develop a more comprehensive approach, one which could include every commonly exptecte functionality. The present report describes the first stage of such development. The solution taken is based on principal components analysis. The report documents the initial development done on this topic.

Gross, D.

Gross, D.

Estimating Air Leakage Through Doors for Smoke Control.

National Institute of Standards and Technology,

Gaithersburg, MD 
Fire Technology, Vol. 26, No. 1, 75-81, February 1990 AND Fire Safety Journal, Vol. 17, No. 2, 171-177, 1991, 1991. Lund University. Science of Building Fire Safety. Symposium to Honor Professor ove Pettersson on His Retirement. May 2-4, 1989, Lund, Sweden, 1-3 pp, 1989.

fire safety; building safety; air leakage; doors; smoke control; seals; air flow

A generalized, nondimensional relationship for flow through defined narrow gaps is used to predict leakage flow past closed door assemblies. Typical gap shapes considered include straight-thorugh; single or double sharp (90 deg) bends; baffle at leading edge; comb-type labyrinth; and filament brush seal. Applications for prediction and desigr appropriate to smoke control systems are indicated. One of the most difficult design problems in maintaining the fire-safety integrity of separating elements deals with joint and penetration details. Doors within walls represent a major challenge, in terms of both flame penetration and the passage of smoke and gases. With the increased attention now being given to the design of buildings to control smoke movement and to maintain smoke-free areas of refuge, better information on the flow of air and smoke-air mixtures through closed door assemblies is needed.

Gross, D.

Fire Research at NBS: The First 75 Years.

National Institute of Standards and Technology,

Gaithersburg, MD

International Association for Fire Safety Science. Fire Safety Science. Proceedings. 3rd International Symposium. July 8-12, 1991, Edinburgh, Scotland, Elsevier Applied

Science, New York, Cox, G.; Langford, B., Editors, 119-133 $\mathrm{pp}, 1991$.

fire research; fire safety; fire science; detection;

extinguishment; fire resistance; flammable fabrics; history; spontaneous combustion

A short history is presented of fire research and testing activities at the National Bureau of standards from its beginnings in 1914 to 1989. Many of the principal technical projects undertaken to provide information needed by Government agencies, practicing architects and engineers, code officials and the general public are noted. Brief mention is made of organizational, staff and budget changes through the years. References to selected staff publications and source materials are cited.

Gross, J. G.

Gross, J. G.

Codes, Standards, and Institutions--Pressures for Change. National Institute of Standards and Technology,

Gaithersburg, MD

Journal of Professional Issues in Engineering Education and

Practice, Vol. 117, No. 2, 75-87, April 1991.

standards; regulations; building codes; certification

Understanding the U. S. building regulatory system and the roles of standards and their development organizations is essential to the introduction of new products or practices 
and to the improvement of the building regulatory system. U. S. practices for development and enforcement of building standards and codes are described for the guidance of those who seek to develop or apply improved building products or practices. The paper reviews current and near-future expected changes in the international construction market for products and services. The importance of standards as a basis for regulations, contracts, and quality-assurance systems is discussed. A review of building and construction standards and their development and use in the United States is covered, including product approval systems that are supported by laboratory accrediation and certification. The European EC 92 programs, the development and use of international standards, and the related certification and testing programs are reviewed.

Gross, J. G.

Meeting the Challenges of a Global Market--Construction Standards, Testing and Certification. National Institute of Standards and Technology, Gaithersburg, MD

Construction Business Review, 31-34, March/April 1991. construction; standards; certification; regulations; competitiveness; EC 92; product approval; testing

This article provides information on the rapidly changing global market for construction products and services. Particularly, the unification of the European Community and activities in the development of the EC 92 internal market are discussed. Standards development processes in the United States and internatonally are reviewed. The importance of standards as the basis for regulation and commerce makes these activities extremely important for the U. S. design profession and building product producers. Related testing, certification and product approval requirements are reviewed. Recommendations for the U. S. construction community are provided.

Gross, J. G.

NIST Labs Research Assures Building Safety, Reduces Fire Loss.

National Institute of Standards and Technology,

Gaithersburg, MD

NCSBC News, Vol. 16, No. 5, 4-5, October/December 1991.

safety; fire losses; research facilities

The National Institute of Standards and Technology (NIST) is recognized as the nation's science and engineering measurement laboratory. NIST develops measurement technology, testing procedures, quality assurance methods, and innovations that help build the infrastructure upon which much of the U. S. economy rests.

Gross, J. G.

United states Standards and Building Regulations: Problems and opportunities for International Trade. National Institute of Standards and Technology, Gaithersburg, MD 
Progetto Finalizzato Edilizia. International Workshop: The Change the Single European Market Shall Introduce Into the Building Sector. December 5, 1990, Milan, Italy, 61-72 pp, 1991.

regulations; standards; building codes; certification; building construction

This paper will outline the United states building standard: and regulatory system including testing and certification. Comparisons with the European community 92 developments will be drawn. The paper will address the consensus proces: for the development of standards, organizations involved in the building standards development, and their relationship to regulating building construction. The methods and participants in enforcement of building regulations will be reviewed. Actions which the United States should take to accommodate international commerce will be shared.

\section{Grot, R. A. \\ Grot, R. A. \\ User Manual NBSAVIS CONTAM88. \\ National Institute of Standards and Technology, \\ Gaithersburg, MD \\ NISTIR 4585i 149 p. June 1991. \\ Available from National Technical Information services \\ PB91-206722 \\ indoor air quality; air flow analysis; contaminant \\ dispersal; user interface; multizone analysis \\ This manual describes the use of three computer programs for analyzing the air movement and indoor air quality in \\ multizone buildings. The first program NBSAVIS creates and edits a building description and generates the leakage, fan and contaminant data necessary to predict the air \\ infiltration and internal air movement in a building and perform an incoor air quality analysis. These data are used by the program CONTAM88 which calculates the air flows and both dynamic and steady state levels of indoor contaminants. CONTAMEZ also produces an output file which can serve as the input for the NIST programs CONTAM86 and CONTAM87 developed by Dr. James Axley.}

Grot, R. A.; Hodgson, A. T.; Daisey, J. M.; Persily, A. K. Indoor Air Quality Evaluation of a New office Building. Lagus Applied Technology, Olney, MD

Lawrence Livermore Lab., CA

National Institute of Standards and Technology, Gaithersburg, MD ASHRAE Transactions, 16-18,20,23-25, 1991.

office buildings; air quality; building design; building construction

An evaluation of the thermal and environmental performance of a new federal office building in Portland, Oregon, was performed by the Center for Building Technology, National Institute of standards and Technology (NIST). This evaluation is part of a research effort to develop methods for evaluating buildings with advanced technology during the pre-occupancy and early occupancy stages. The procedure used for this evaluation was to install in the new office 
building a diagnostic center capable of monitoring important environmental parameters. The measurements included: air infiltration and ventilation rates; building envelope tightness; interzone air movement; detection of envelope thermal deficiencies; envelope thermal resistance; and the levels of indoor contaminants. The indoor contaminants measured include carbon dioxide ( $\mathrm{CO} 2)$, carbon monoxide ( $\mathrm{CO}$ ), respirable particulates in the 0.3-10 micron range, formaldehyde radon and volatile organic compounds (Vocs) that could be emitted either by the new building materials and furnishings or the activities of the building occupants. There were more than 100 monitoring points installed in the building's interior space, HVAC systems and underground parking garage. Many measurements were made in real-time.

Hagen, D. E.

Hagen, D. E.

Study on the Scavenging and In-cloud Processing of Combustion Aerosols.

Missouri Univ.

i 15 p. 1991.

combustion aerosols; crude oil; humidity; haze; fog

Work performed under this effort can be broken down into seven parts: (1) Combustion aerosol scavenging experiments in the UMR cloud simulation chamber, (2) Crude oil Combustion Aerosols, (3) Optical particle fluorescence spectrometer, (4) Electron microscope studies of JP-4 combustion aerosol samples, (5) Environmental chamber for the aerosol humidity effects experiemnt, (6) combustion aerosol scavenging rate measurements, (7) Experiments on the influence of scavenged combustion aerosols on the condensation behavior of $\mathrm{CCN}$, and (8) Deposition of insoluble fine particles (combustion and other aerosols) on fog (haze) elements.

Hamins, $\mathbf{A}$.

Hamins, A.; Klassen, M. E.; Gore, J. P. ; Kashiwagi, T.

Estimate of Flame Radiance via a Single Location Measurement in Liquid Pool Fires.

National Institute of Standards and Technology, Gaithersburg, MD

Combustion and Flame, Vol. 86, No. 3, 223-228, August 1991. pool fires; liquid fires; radiative heat loss; heat release; fuels

A method for estimating the radiative heat loss fraction, the ratio of the flame energy radiated to the surroundings to the idealized combustion heat release, is developed for pool fires. Experimental investigtion of small to medium sized pool fires shows that a radiance measurement made at a single location and corrected for anisotropic effects yields an estimate of [symbol] that is within $13 \%$ of the multilocation measurement of [symbol]. Eight fuels were tested, with heat release rates of $0.6-120 \mathrm{~kW}$ and values of [symbol] from 0.16 to 0.35 . A previously proposed rule for finding [symbol] from one-location radiance measurements was also tested and works reasonably well for nonluminious alcohol flames. 
Harris, R. H., Jr.

Harris, R. H., Jr.; Babrauskas, V.; Levin, B. C.; Paabo, M. Data for Fire Hazard Assessment of Selected Non-Halogenated and Halogenated Fire Retardants; Report of Test FR 3983. National Institute of Standards and Technology, Gaithersburg, MD

NISTIR 4649; 55 p. October 1991.

Available from National Technical Information Services PB92-112473

cone calorimeters; flame retardant treatments; halogenated compounds; plastics; polyethylenes; polypropylene; polyvinyl chloride; toxic hazards; toxicity

Five plastic materials, with and without fire retardants, were studied to compare the fire hazards of non-halogenated fire retardant additives with halogenated flame retardants. The plastic materials were identified by the sponsors as unsaturated polyesters, thermoplastic high density, low density and cross-linked low density polyethylenes, polypropylene, flexible and rigid poly (vinyl chlorides), anc cross-linked and thermoplastic ethylene-vinyl acetate copolymers. The non-halogenated fire retardants tested were aluminum hydroxide $(\mathrm{Al}(\mathrm{OH}) 3)$, also known as alumina trihydrate $(\mathrm{ATH})$, sodium alumino-carbonate, and magnesium hydroxide. The halogenated flame retardants were chlorine or bromine/antimony oxides. The plastics were studied usinc the cone calorimeter and the cup furnace smoke toxicity method (high density polyethylene only). The cone Calorimeter provided data on mass consumed, time to ignition, peak rate and peak time of heat release, total heat released, effective heat of combustion, average yields of $\mathrm{CO}, \mathrm{CO} 2, \mathrm{HCl}$, and $\mathrm{HBr}$, and average smoke obscuration. The concentrations of toxic gases generated in the cup furnace smoke toxicty method were used to predict the toxic potency of the mixed thermal decomposition products. The data from the cone calorimeter indicate that the non-halogenated fire retardants were, in most of the tested plastic formulations, more effective than the halogenated flame retardants in increasing the time to ignition. The non-halogenated fire retardants were also more effective in reducing the mass consumed, peak rate of heat release, total heat released, and effective heat of combustion, and in reducing the amount of smoke produced. The use of halogenated flame retardants increased smoke production and $\mathrm{CO}$ yields and, additionally, produced the known acid gases and toxic irritants, $\mathrm{HCl}$ and HBr, in measurable quantities. The chemical analytical data for the high density polyethylene samples decomposed via the cup furnace smoke toxicity method in the non-flaming mode indicated that the levels of $\mathrm{CO}$ and $\mathrm{CO} 2$ were insufficient to cause death of the test animals (rats), but deaths did occur with all samples except the one containing the halogenated flame retardant. In the flaming mode deaths occurred during exposure to the combustion products from the non-fire retarded control and from the halogenated sample; only in the latter case were the $\mathrm{CO}$ and $\mathrm{CO} 2$ concentrations high enough to cause the within exposure deaths. These toxicity results are unusual, but do not indicate a need for concern, since the LC50 values are in the range typical of many common materials. 
Harris, R. H., Jr.; Navarro, M.; Gann, R. G.; Eberhardt, K. R.

Reevaluation of Experimental Cigarettes Used in the

Cigarette Safety Act of 1984. Report of Test.

National Institute of Standards and Technology,

Gaithersburg, MD

Report of Test FR 3984; 7 p. May 1991.

cigarettes; ignition; statistics

Experimental cigarettes which had been stored for several

years in freezers were reevaluated on mockups constructed

from the same materials in the original study and

statistically analyzed for differences in their ignition propensity.

Heskestad, G.

Heskestad, G.

Sprinkler/Hot Layer Interaction.

Factory Mutual Research Corp., Norwood, MA

NIST-GCR-91-590; 55 p. May 1991.

Available from National Technical Information Services

PB91-206680

sprinklers; fire models; heat transfer; water sprays; zone models

A model has been developed for the cooling of a quiescent hot layer by a sprinkler spray in a two-layer zone model

(with no direct interaction of the spray with a fire plume), based on existing models of spray-induced flow and heat

transfer to evaporating drops. In addition, existing models have been adapted to predict the penetration of the spray-induced flow below the layer interface and associated entrainment of lower-layer fluid into the upper layer. The cooling model is in good agreement with published results from sprinklered room-fire experiments, for which penetration of spray-induced flow into the lower lajer and associated entrainment were calculated to be neligible. No published results have been found to test the validity of the adapted models of penetration and associated entrainment, which do not account for possible effects of the spray below the layer interface.

Jason, N. H.

Jason, N. H.

Building and Fire Research Laboratory Publications, 1990.

National Institute of Standards and Technology,

Gaithersburg, MD

NISTIR 4562; 68 p. April 1991.

Available from National Technical Information Services

PB91-187807

building research; building technology; concretes;

earthquakes; fire research; flame research; halons; fire models; building fires; refrigerants; roofs

Building and Fire Research Publications, 1990 is the first edition to reflect the combined publictions of the Building and Fire Research Laboratory (BFRL) for calendar year 1990. In 1991 the center for Building Technology (CBT) and the Center for Fire Research (CFR) combined to form BFRL. This publication is a supplement to previous editions of Fire 
Research Publications and the Building Technology Publications. Contact the author if you would like information about the earlier editions. Only publications prepared by the members of the BFRL staff, by other Nationa] Institute of standards and Technology (NIST) personnel for BFRL, or by external laboratories under contractor grant from the BFRL are cited.

Jason, N. H.

FIREDOC Users Manual. 2nd Edition.

National Institute of standards and Technology,

Gaithersburg, MD

NISTIR 4526; 35 p. March 1991.

Available from National Technical Information Services PB91-178830

databases; fire research; information retrieval; information dissemination; manuals

FIREDOC is the on-line bibliographic database which reflects the holdings (published reports, articles, books, and audivisual items) of the Fire Research Information Services (FRIS), at the Building and Fire Research Laboratory, National Institute of Standards and Technology. This manual provides a step-by-step technique for entering and exiting the database via telecommunication lines, as well as a number of techniques for searching the database and processing the results of the searches. This Second Edition incorporates changes from a recent STAR software upgrade, a section of Advanced Techniques and procedures for using FIREDOC with an IBM PB, XT, AT and compatible computers and with a Macintosh computer.

Jason, N. H.

Summaries of BFRL Fire Research In-House Projects and Grants, 1991.

National Institute of Standards and Technology, Gaithersburg, MD

NISTIR 4686; 194 p. October 1991.

Available from National Technical Information Services

PB92-112218

charring; combustion; fire models; blowout fires; hazards;

ignition; polymers; smoke; soot; toxicity

This report describes the research projects performed in the Building and Fire Research Laboraotry (BFRL) Fire Research Program and under its grants program from october 1 , 1990-September 30, 1991.

Joshi, A. A.

Joshi, A. A. : Pagni, P. J.

Users' Guide to BREAKI, The Berkeley Algorithm for Breaking Window Glass in a Compartment Fire.

California Univ., Berkeley NIST-GCR-91-596; 27 p. October 1991.

Available from National Technical Information Services PB92-112556

computer models; fire models; glass; mathematical models; radiation; thermal stresses; vents 
This is an instructional manual for the computer program BREAK1, the Berkeley Alogorithm for Breaking Window Glass in a compartment Fire, version 1.0. The thermal response of window glass exposed to a compartment fire and its time to breakage are calculated. The following glass properties, treated here as constant, are required as input: thermal conductivity, thermal diffusivity, absorption length, breaking stress, Young's modulus, coefficient of linear thermal expansion and emissivity. In addition, the ambient temperature, the hot layer temperature, heat transfer coefficients and emissivities and the direct flame radiation histories are needed as input. The window geometry is also required. The output describes the evolution of the window temperature field, $T(x, t)$, where $x$ is the direction normal to the glass pane, culminating in the window breakage time. This manual contains a summary of the mathematical model, sample thermophysical and mechanical data tables, some worked examples and advice on using the program.

Kaetzel, L. J.

Kaetzel, L. J.; Clifton, J. R. ; Struble, L. J.

Guidelines for the Development of Computer Based Models in a Cementitious Materials Modeling Laboratory.

National Institute of standards and Technology,

Gaithersburg, MD

Illinois Univ., Urbana

NISTIR 4650; 34 p. August 1991.

Available from National Technical Information Services PB91-240804

computer models; computer platforms; software languages;

software tools; software engineering; software documentation

This paper presents guidelines and considerations for the development, archiving, and distribution of computer models for a centralized cementitious materials modeling

laboratory. An analysis of the approach used by cement researchers to develop large complex computer models revedals the need for guidelines in selecting computer platforms, software languages and tools, software engineeirng and documentation. A modeling laboratory established at NIST associated with the NSF Center for Science and Technology of Advanced Cement-Based Materials is discussed and the important of such a facility in promoting the exchange of information (i.e., ideas, models, data). The computer models currently archived in the modeling

laboratory are use as test cases to describe the facility. Institute of Standards and Technology, Building Materials Division, for exchanging and disseminating information related to cement and concrete research. The computer is accessible, remotely, through telephone lines. Messages, and computer stored files in many formats can be exchanged among cement researchers. Also, information can be retrieved and/or viewed that describes: scheduled symposia, archived computer based models, project summaries, and published papers. This document describes how to use the computer system. 
Rao, J. Y.

Kao, J.Y.

Direct Digital Control Based Building Automation System Design Criteria.

National Institute of standards and Technology, Gaithersburg, MD

NISTIR 4604; 39 p. June 1991.

Available from National Technical Information Services

PB91-216614

automatic control; building automation system; building control; building design; design criteria; direct digital control

This document serves to provide design guidance for Direct

Digital Control (DDC) based Building Automation systems

(BAS). It also provides instructions to design engineers

for the BAS design. Explanations of general design

philosophy, current unresolved problems confronting the application of DDC in BAS, and considerations for choosing alternative control strategies in specifying application programs are given. This guide is intended for use by GSA and contract designers as a means of identifying major aspects in DDC based BAS design where new construction or major renovations of control systems are included.

Kao, J. Y.

Guide Specification for Direct Digital Based Building

Automation system.

National Institute of standards and Technology,

Gaithersburg, MD

NISTIR 4606; 74 p. June 1991.

Available from National Technical Information Services

PB9 1-26697

automatic control; building automation system; building control; building design; construction specification; direct digital control; guide specification

This publication is intended for building system designers' use in specifying direct digital control (DDC) based building automation systems (BAS) for construction of Federal buildings. This guide specification conforms with the format of guide specifications used by the General Services Administration (GSA) and its professional services contractors.

Kao, J. Y.

Variable Air Volume System Design Guide.

National Institute of standards and Technology,

Gaithersburg, MD

NISTIR 4605; 53 p. June 1991.

Available from National Technical Information Services

PB91-216655

air conditioning; air handling system; automatic control;

building design; design practice; variable air volume system

Variable air volume (VAV) systems have been used extensively in office buildings during recent years. However, there are persistent complaints by building occupants about the air quality and environmental conditions of these buildings. This guide has been developed to give guidelines on VAV system design to alleviate possible design-caused problems. 
This guide provides general discussion of VAV systems, air handling system design, system control, and commissioning. This guide has been developed for the General services Administration to be used by GSA personnel and GSA's contract designers. It includes design check lists as a means of identifying major aspects in VAV system design where new construction and alteration of air systems are involved.

Rashiwagi, T.

Kashiwagi, T.; Cleary, T. G.

Effects of Sample Mounting on Flammability Properties of

Intumescent Polymers.

National Institute of Standards and Technology,

Gaithersburg, MD

Interscience Communications Limited. Heat Release and Fire

Hazard. 1st U. S. Symposium. Abstracts. December 1991,

San Diego, CA, 4 pp, 1991.

heat release; fire hazard; sampling; flammability;

polycarbonates; cone calorimeters; char; heat release rate;

heat of combustion; soot; flame spread; flame spread rate

Various flammability properties of polycarbonate samples

were measured with the cone Calorimeter and Lateral Ignition

and Flame Spread, LIFT, devices at various external fluxes.

Four different sample mountings were used with the cone

Calorimeter to investigate the effects of sampling mounting

on the flammability properties of these samples. One sample mounting configuration employed the standard metal edge frame and a grid to retain intumesced char. The other three samples mounting configurations allowed the intumesced char to rise free. The results show that peak heat release rates and heat release rate curves were significantly affected by the sample mounting configuration but total heat released, effective heat of combustion, and soot yield were not significantly affected. Flame spread characteristics were measured with the LIFT. Two sample mounting configurations were used, the standard method and the standard method with the addition of wire grid to retain intumesced char.

significant differences in flame spread rates were observed between the two sample mounting configurations with and without the grid. This was caused by difference in flame spread rates versus rising rates of char.

\section{Kedzierski, M. A.}

Kedzierski, M. A.; Didion, D. A.

Comparison of Experimental Measurements of Local Flow

Boiling Heat Transfer Coefficients for RII and R123.

National Institute of Standards and Technology,

Gaithersburg, MD

ASME/JSME Thermal Engineering Proceedings. Vol. 3. 1991, 243-250 pp, 1991 .

refrigerants; heat transfer; ozone; trichloroethylene; dichlorotrifluoroethane; flow boiling heat transfer; tests; thermodynamics

This paper presents a comparison of the measured horizontal, smooth-tube, flow boiling heat transfer coefficient of R11 to that of its proposed ozone safe replacement $R 123$. The 
fluid properties of R11 and R123 are similar. The flow boiling data for the two fluids are similar for the convective region. However, the heat transfer coefficient for RII in the nucleate flow boiling region was consistentl observed to be, on average, $8.5 \%$ to $33 \%$ larger than that fo R123. The influence of Reynolds number and heat flux on th heat transfer-thermodynamic quality relationship is also presented. Predictions of the heat transfer coefficient with two open literature flow boiling correlations were compared to the measured data. The heat transfer coefficients predicted with the correlations were, on average, from 13\% to $57 \%$ greater than the measured heat transfer coefficients. Not until recently has there been sufficient thermodynamic or transport data for R123 to perform an accurate heat transfer analysis for that fluid. Great care was taken to ensure that the most carefully measured property data were used for this analysis. For the convenience of the reader, both the R123 and RII property data used in this study are presented.

Kelly, G. E.

Kelly, G. E.; Park, C.; Barnett, J.P.

Using Emulators/Testers for Commissioning EMCS Software, operator Training, Algorithm Development, and Tuning Local Control Loops.

National Institute of Standards and Technology, Gaithersburg, MD

ASHRAE Transactions, Vol. 97, No. 1, [pages unknown], 1991. NY-91-9-1;

computers; simulation; computer programs; case histories; training; algorithms

Unlike a building simulation program, which is normally run on a single computer as quickly as the computer can process the instructions, a building emulator/EMCs tester

(emulator/tester) emulates a building and its mechanical systems in real time. The emulator/tester is connected to the energymanagement and control system (EMCS) in place of the EMCS's sensors and actuators. The EMCS then controls the simulated building as it would a real building, while the emulator/tester can be used to evaluate the performance of the EMCS. As a part of a joint research effort conducted by participants of the International Energy Agency (IEA)

Annex 17 committee, the National Institute of Standards and Technology (NIST) has developed a second-generation emulator/tester. To validate the emulator/tester, two studies using a small office building were performed that compared the results obtained using both simulation and emulation. Both studies showed good agreement between the simulation and emulation results. In addition, an exercise using the emulator/tester to tune a cooling-coil control loop was carried out using two different tuning methods. Information is also presented on how the emulator/tester can be used for training, commissioning EMCS software, and developing new control algorithms. These and other applications should encourage the widespread use of these versatile tools in future. 
Kinney, P. D.

Kinney, P. D.; Pui, D. Y. H.; Mulholland, G. W.; Bryner, N. P.

Use of Electrostatic Classification Method to Size 0.1 mum

SRM Particles. A Feasibility study.

Minnesota Univ., Minneapolis

National Institute of standards and Technology,

Gaithersburg, MD

Journal of Research of the National Institute of Standards

and Technology, Vol. 96, No. 2, 147-176, March/April 1991.

The use of the electrostatic classification method for

sizing monodisperse 0.1 mum polystyrene latex (PSL) spheres

has been investigated experimentally. The objective was to

determine the feasibility of using electrostatic

classification as a standard method of particle sizing in

the development of a 0.1 mum particle diameter standard

Reference Material (SRM). The mean particle diameter was

calculated from a measurement of the mean electrical

mobility of the PSI spheres as an aerosol using an

electrostatic classifier. The performance of the classifier

was investigated by measuring its transfer funciton,

conducting a sensitivity analysis to verify the governing

theoretical relationships, measuring the repeatability of

particle sizing, and sizing NIST SRM 1691, 0.269 mum and

NIST SRM 1690, 0.895 mum particles. Investigations of the

aerosol generator's performance focused on the effect of

impurities in the particle-suspending liquid on the

resulting particle diameter. The uncertainity in particle

diameter determined by electrical mobility measurements is

found to be $-3.3 \%$ to $+3.0 \%$. The major sources of

uncertainty include the flow measurement, the slip

correction, and a dependence of particle size on the aersol

flow rate. It was found that the classifier could be

calibrated to indicate the correct size to within $0.1 \%$ for

both SRM particle sizes if the defined classification length is decreased by $1.9 \%$.

Klote, J. H.

Klote, J. H.

Design Manual for Smoke Control systems.

National Institute of Standards and Technology,

Gaithersburg, MD

NISTIR 4551; $381 \mathrm{p}$. October 1991.

Available from ASHRAE, Atlanta, GA

This manual consolidates and systematically presents data and calculation procedures for use by smoke control system designers, and design criteria is discussed. Fundamental issues of smoke control include reliability, activation, smoke obscuraton, toxicity, and the driving forces of smoke movement. The mechanisms of compartmentation, dilution, air flow, pressurization, and buoyancy are used by themselves or in combination to manage smoke conditions in fire

situations. A computer program for analysis of smoke 
control systems is presented. Systems for stairwell pressurization, elevator smoke control, and zoned smoke control are presented. Numerous example calculations are included.

Klote, J. H.

General Routine for Analysis of Stack Effect.

National Institute of Standards and Technology,

Gaithersburg, MD

NISTIR 4588; 33 p. July 1991.

Available from National Technical Information Services

PB91-231589

stack effect; building fires; computer models; mathematical models; smoke movement

stack effect is a major driving force of smoke movement in

buildings. This paper presents a general method for

evaluation of the location of the neutral plane for a space

connected to its surroundings by any number of openings. A

computer program, STACK, for analysis of the location of the neutral plane and resulting flows is presented along with example analyses. The examples show that the location of the neutral plane between a space and its surroundings is a weak function of temperature and a strong function of the size of openings. Further, the mass flow rate leaving a space due to stack effect is a strong funciton of temperature.

Klote, J. H. ; Tamura, G. T.

Design of Elevator Smoke Control systems for Fire

Evacuation.

National Institute of Standards and Technology,

Gaithersburg, MD

National Research Council of Canada, ottawa, Ontario

ASHRAE Transactions, Vol. 97, No. 2, 634-642, 1991.

elevators (lifts); smoke control; evacuation; elevator

shafts; piston effect; pressurization; pressure differential

A joint U. S./Canadian project was undertaken to evaluate

the feasibility of using elevators for the evacuation of the handicapped during a fire. This project consisted of conceptual studies, full-scale fire experiments, and theoretical analysis. This paper summarizes the findings that are relevant to the design of smoke control systems for elevators. A method of dealing with elevator piston effect is discussed. Elevator piston effect is the transient pressures produced by elevator car motion, and this effect depends on air temperature, building leakage areas, elevator car velocity, and hoistway size. All other things being equal, piston effect is considerably greater for single-car hoistways than for multiple-car hoistways. Different approaches for dealing with the pressure fluctuations due to the opening and closing of building doors are presented. An approach for design analysis is presented with example analyses of two different elevator smoke control systems. Results indicate that many types of elevator smoke control systems can be designed to provide acceptable levels of pressurization even under severe conditions of doors opening and closing. 
Klote, J. H.: Tamura, G. T.

Smoke Control Systems for Elevator Fire Evacuation.

National Institute of Standards and Technology,

Gaithersburg, MD

National Research Council of Canada, Ottawa, Ontario

American Society of Mechanical Engineers; Council of

American Building Officials and National Fire Protection

Association. Elevators and Fire. February 19-20, 1991,

Baltimore, MD, 83-94 pp, 1991.

elevators (lifts); smoke control; evacuation; handicapped;

piston effect; doors; pressure differental; computers

Some people cannot use stairwells because of physical

disabilities, and for these people fire evacuation is a serious problem. A potential solution to this problem is the use of elevators for fire evacuation. A joint project of the U. S. National Institute of Standards and Technolgoy (NIST) and the National Research Council of Canada (NRCC) was formed to evaluate the feasibility of using elevators for the evacuation of the handicapped during a fire. This project consisted of conceptual studies, full scale fire experiments, and theoretical analysis. This paper summarizes the findings of the joint project that are relevant to the design of smoke control systems for elevators. A method of dealing with elevator piston effect is discussed. All other things being equal, piston effect is considerably greater for single car hoistways than for multiple car hoistways. Different approaches to deal with the pressure fluctuations due to opening and closing of building doors are presented. A method of design analysis is presented with an example analysis. Results indicate that many types of elevator smoke control systems can be designed to provide acceptable levels of pressurization even under severe conditions of doors opening and closing.

Koseki, H.

Koseki, H.; Kokkala, M.; Mulholland, G. W.

Experimental study of Boilover in Crude Oil Fires.

Fire Research Institute, Tokyo, Japan

VTT, Espoo, Finland

National Institute of standards and Technology,

Gaithersburg, MD

International Association for Fire Safety Science. Fire Safety Science. Proceedings. 3rd International symposium. July 8-12, 1991, Edinburgh, Scotland, Elsevier Applied Science, New York, Cox, G.; Langford, B., Editors, 865-874 pp, 1991.

fire research; fire safety; fire science; crude oil;

kerosene; boilover; thermal radiation; burning rate

An experimental study of boilover phenomena in connection with crude oil and kerosene pool fires was carried out in the large scale test facilities of the Fire Research Institute of Japan. Arabian light crude oil was burned in steel pans ranging from a circular one with a diameter of $0.3 \mathrm{~m}$ to a square one with a $2.7 \mathrm{~m}$ side. An oil layer of 10 $\mathrm{mm}$ to $100 \mathrm{~mm}$ was floating on water in the pans. The intensity of boilover was found to increase with increasing fuel thickness. An almost tnefold increase in the amount of unburned residue was found to occur as the layer thickness 
was increased from $40 \mathrm{~mm}$ to $50 \mathrm{~mm}$. Results of measurements of 1 iquid and gas temperatures, burning rates and radiative heat outputs are reported.

Koseki, H.; Mulholland, G. W. Effect of Diameter on the Burning of Crude oil Pool Fires. Fire Research Institute, Tokyo, Japan

National Institute of Standards and Technology, Gaithersburg, MD

Fire Technology, Vol. 27, No. 1, 54-65, February 1991 AND Report of Fire Research Institute of Japan, No. 72, 95-106, September 1991,

crude oil; smoke emissions; thermal radiation; burning rate; pool fires

In order to understand the combustion characteristics of crude oil pool fires, an experimental study was carried out at the Fire Research Institute (FRI) large scale test facility. The radiative output, burning rate, and the concentrations of $\mathrm{CO}, \mathrm{CO} 2$, and smoke (above the flame tip) were measured during the burning of Arabian light crude oil, heptane, toluene, and kerosene floating on water. The effect of scale was studied by using steel pans ranging from 0.6 to 3 meters in diameter. Crude oil burned less rapidly and gave off less thermal radiation compared with heptane, but when water boiling, i.e., boilover, ocurred, the burning rate increased by a factor of two or more. The intensity of boilover is related to pan diameter and initial fuel layer thickness.

\section{Rostreva, M. M.}

Kostreva, M. M. ; Wiecek, M. M.; Getachew, T. Optimization Models in Fire Egress Analysis for Residential Buildings.

Clemson Univ., sc

International Association for Fire Safety science. Fire Safety science. Proceedings. 3rd International symposium. July 8-12, 1991, Edinburgh, Scotland, Elsevier Applied Science, New York, Cox, G.; Langford, B., Editors, 805-814 pp, 1991.

fire research; fire safety; fire science; residential buildings; egress; mathematical models; case histories; evacuation

Fire hazard analysis often includes the use of mathematical models of the egress of the individual occupants of a structure which is involved in a fire. In this paper, we introduce some mathematical optimization models which produce as output at least one path for each occupant which is optimal with respect to some measurement. Network based models of increasing levels of complexity and realism are demonstrated by means of a sequence of examples. The examples include single attribute constant costs, single attribute time-imposed on network links. Dynamic programming functional equations which are based on the principle of optimality are presented. A multi-attribute analysis is proposed to evaluate a building design with respect to evacuation paths. 
Kounalakis, M. E.

Kounalakis, M. E.; Sivathanu, Y. R.; Faeth, G. M.

Infrared Radiation Statistics of Nonluminous Turbulent

Diffusion Flames.

Michigan Univ., Ann Arbor

Journal of Heat Transfer, Vol. 113, No. 2, 437-445, May

1991.

turbulent flames; diffusion flames; infrared radiation

Mixture fraction and radiation statistics were studied for radiation paths through turbulent carbon monoxide/hydrogen diffusion flames burning in still air. Measurements included Mie scattering for mixture fraction statistics and fast-response infrared spectroscopy for radiation statistics. Measured mixture fraction statistics also were used to predict radiation statistics based on stochastic time series methods, the laminar flamelet approximation, and a narrow-band radiation model. Measured intensities of radiation fluctuations were in the range 10-40 percent, which causes mean radiation levels to be 1.1-4.2 times larger than estimates based on mean scalar properties in the flames. In contrast, stochastic predictions of mean and fluctuating radiation properties were generally in excellent agreement with measurements. An exception was the temporal integral scales of radiation fluctuations, where differential diffusion errors of the Mie scattering measurements were identified as the source of the discrepancies.

Roylu, U. 0 .

Koylu, U. O.; Sivathanu, Y. R.; Faeth, G. M.

Carbon Monoxide and Soot Emissions From Buoyant Turbulent

Diffusion Flames.

Michigan Univ., Ann Arbor

International Association for Fire Safety Scierce. Fire Safety Science. Proceedings. 3rd International symposium. July 8-12, 1991, Edinburgh, Scotland, Elsevier Applied Science, New York, Cox, G.: Langford, B., Editors, 625-634 pp, 1991 .

fire research; fire safety; fire science; carbon monoxide; combustion physics; toxic hazards; soot; turbulent flames; diffusion flames

Carbon monoxide concentrations and mixture fractions were measured in the fuel-lean (overfire) region of turbulent acetylene, propylene, ethylene, propane and methane diffusion flames burning in still air. Three burners (having exit diameters of 5,50 and $234 \mathrm{~mm}$ ) were used to study conditions ranging from buoyant jet flames to pool-like fires. Carbon monoxide generation factors (mass of $\mathrm{CO}$ emitted per unit mass of fuel carbon burned) were uniform throughout the overfire region for a given flame condition. Additionally, $c o$ generation factors of sooting fuels approached asymptotic values for flame residence times roughly an order of magnitude longer than the normal smoke point residence time, similar to earlier measurements of soot generation factors for similar conditions. Finally, processes of carbon monoxide and soot emission appear to be closely related due to the good correlation between their emission factors in the asymptotic regime: 0.34 (standard 
deviation of 0.09 ) $\mathrm{kg} \mathrm{co} / \mathrm{kg}$ soot. However, nonsooting methane/air flames still emitted low levels of $c 0$ so there there is a component of $C O$ emissions that is not associated with soot.

Kulkarni, A. K.

Kulkarni, A. K.; Kim, C. I.; Kuo, C. H. Turbulent Upward Flame spread for Burning Vertical Walls Made of Finite Thickness. Annual Report. August 15, 1989-August 14, 1990.

Pennsylvania state Univ., University Park NIST-GCR-91-597; 88 p. September 1991.

Available from National Technical Information Services PB92-112531

flame spread; masonite (trademark); mathematical models; polymethylmethacrylate; polyurethane foams; pyrolysis; textiles; wall fires; wood

Progress made during the second year of the NIST grant number 60NANB8D0849 for the period August 15, 1989 through August 14, 1990 is reported here. This report marks the eno of the first phase of the grant, for which the overall objective was to understand the basic mechanisms of upward flame spread and to develop a complete procedure to predict the flame spread on practical wall materials of finite thickness, appropriately verified by experiments. These objectives have been met. Specifically in the past year, several wall materials were tested in the upward flame spread apparatus, mathematical model development for predicting the upward flame spread was completed, and comparisons of data and predictions were made, in addition to completion of many other supporting tasks.

Levin, B. C.

Levin, B. C.: Paabo, M.; Braun, E.; Harris, R. H. , Jr. New Approach for Reducing the Toxicity of the combustion Products From Flexible Polyurethane Foam. National Institute of Standards and Technology, Gaithersburg, MD

Business Communications Co., Inc. (BCC). Recent Advances in Flame Retardancy of Polymeric Materials: Materials, Applications, Industry Developments, Markets. Annual Conference, 2nd. May 14-16, 1991, Stamford, CT, 1-6 pp, 1991.

polyurethane foams; flexible foams; toxicity; combustion products; copper; hydrogen cyanide; experiments;

flammability

Hydrogen cyanide (HCN) is one of the gases which is produced during the thermal decomposition of flexible polyurethane foams and which (in combination with carbon monoxide and other fire gases) contributes to the toxicity of the smoke. Flexible polyurethane foams treated with copper or various copper compounds produced significantly less HCN when thermally decomposed than the identical but untreated control foams. The effect was observed with copper levels as low as $0.1 \%$ by weight. The decreased atmospheric concentrations of $\mathrm{HCN}$ resulted in the reduction of the acute inhalation toxicity (as measured by lethality in Fischer 344 62 
rats) produced from exposure to this smoke. This reduction of HCN and toxicity occurred regardless of whether the copper or copper compound was added to the foam during its formulation (prior to the foaming process) or as a post-treatment (after formulation). In all these reported experiments, the foams were thermally decomposed under small-scale laboratory conditions in the cup furnace smoke toxicity method apparatus via a two phase procedure

previously shown to produce high concentrations of $\mathrm{HCN}$. The addition of $0.1 \%$ by weight of cuprous oxide (the most efficient of the tested copper compounds) did not affect the flammability characteristics of the foam, e.g.,

ignitability, heat release rate, smoke obscuration, rate of flame spread, heat of combustion, or $\mathrm{CO} / \mathrm{CO} 2$ ratios.

Levin, B. C.; Paabo, M.; Navarro, M.

Toxic Interactions of Binary Mixtures of NO2 and $\mathrm{CO}$, NO2, and $\mathrm{HCN}$, $\mathrm{NO} 2$ and Reduced $\mathrm{O} 2$, and $\mathrm{NO} 2$ and $\mathrm{CO} 2$.

National Institute of Standards and Technology, Gaithersburg, MD

Abstract 825 ;

Society of Toxicology. Annual Conference, 30th. Abstracts. Volume 11. Number 1. February 25-March 1, 1991, Abstract 825, Dallas, TX, $222 \mathrm{pp}, 1991$.

toxic gases; rats; exposure

A model to predict the toxic interactions of the major gases produced in fires is being developed at NIST and includes six gases-- $\mathrm{CO}, \mathrm{CO} 2, \mathrm{HCN}$, reduced $\mathrm{O} 2, \mathrm{HCl}$, and $\mathrm{HBr}$. The current objective is to add No2 to the model. The toxicity of individual gases, $\mathrm{CO}, \mathrm{CO} 2$, reduced $02, \mathrm{HCN}$, and $\mathrm{NO} 2$, in air as well as various two, three and four gas combinations have been examined in Fischer 344 male rats exposed for 30 min and observed for 14 days. LC50's for $\mathrm{HCl}$ and $\mathrm{HBr}$ were obtained from the literature. Deaths from NO2 in air occurred only in the post-exposure (PE) period and its LC50 is $200 \mathrm{ppm}$ (PE). Carbon dioxide has synergistic toxicological effects when combined with any of the other gases tested at NIST. The LC50 for NO2 in the presence of $5 \% \mathrm{CO} 2$ is $90 \mathrm{ppm}(\mathrm{PE})$. CO produces only within-exposure deaths (WE) and its $30 \mathrm{~min}$ LC50 is $6600 \mathrm{ppm}$. In the presence of $200 \mathrm{ppm}$ of $\mathrm{NO} 2$, the WE toxicity of CO increased. At the new LC50 of $\mathrm{CO}$, the PE toxicity of NO2 also increased. Deaths from HCN occur primarily during or within 24 hours following exposure and its LC50's are $200 \mathrm{ppm}$ (WE) and 150 ppm (PE). An antagonistic effect is observed with NO2 and $\mathrm{HCN}$; in the presence of $200 \mathrm{ppm}$ of NO2, 2.3 to 2.5 times the HCN LC50 is needed to produce one death within-exposure. Deaths from reduced 02 occur primarily within exposure and its $30 \mathrm{~min}$ LC50 is $5.4 \%$. In the presence of $200 \mathrm{ppm}$ of $\mathrm{NO} 2$, the WE LC50 of 02 and its toxicity increased. At this new LC50 of 02, the PE toxicity of NO2 increased. Thus NO2, and $\mathrm{PE}$ toxic gas, increases the toxicity of the WE toxic gases (except $\mathrm{HCN}$ ) and vice-versa. 
Levin, B. C.; Paabo, M.: Schiller, S. B.

Standard Reference Material for Calibration of the Cup Furnace Smoke Toxicity Method for Assessing the Acute

Inhalation Toxicity of Combustion Products.

National Institute of Standards and Technology,

Gaithersburg, MD

Journal of Research of the National Institute of Standards and Technology, Vol. 96, No. 6, 741-755, November/December

1991.

combustion products; inhalation; combustion; standard

reference materials; toxicity test method; rats

A standard reference material (SRM 1048) has been developed

for use with the cup furnace smoke toxicity method. This

$S R M$ is to be used to calibrate the apparatus and to enable

the user to have confidence that the method is being

conducted in a correct manner and that the equipment is functioning properly. The toxicological results from this SRM should not be used to compare with those of ther materials (i.e., to determine if the combustion products of a test material are more or less toxic than those from this SRM). SRM 1048 is an acrylonitrile-butadiene-styrene (ABS) and is the same as SRM 1007B which is used for calibrating the flaming mode of the smoke Density Chamber test method (ASTM E-662 and NFPA 258). For the purposes of calibrating the cup furnace smoke toxicity method, LC50 and N-Gas values plus their respective $95 \%$ confidence limits have been determined and certified for two combustion model (flaming and nonflaming) and two observation periods (for the $30 \mathrm{~min}$ exposure only and for the $30 \mathrm{~min}$ exposure plus a $14 \mathrm{~d}$ post-exposure period). The certified LC 50 values plus $95 \%$ confidence intervals (in $\mathrm{g} / \mathrm{m} 3$ ) are $27 \pm 3$ (30 min, flaming): $25 \pm 3$ ( $30 \mathrm{~min}+14 \mathrm{~d}$, flaming): $58 \pm 15$ ( $30 \mathrm{~min}$, nonflaming); and $53 \pm 12$ ( $30 \mathrm{~min}+14 \mathrm{~d}$, nonflaming). The certified $\mathrm{N}$-Gas values plus 95\% confidence intervals are $1.4 \pm 0.2$ (30 min, flaming); $1.5 \pm 0.2$ (30 min $+14 \mathrm{~d}$, flaming); $1.2 \pm 0.2$ (30 min, nonflaming); and $1.4 \pm 0.2$ (30 min $+14 \mathrm{~d}$, nonflaming). It is recommended that this $S R M$ be used with the N-Gas approach to calibrate the cup furnace smoke toxicity method rather than to determine the complete LC50 values. The N-Gas approach has the advantage of providing information on the gases responsible for the lethalities as well as the toxic potency of the smoke. In addition, the $\mathrm{N}-\mathrm{Gas}$ approach reduces the number of experimental animals, the time necessary to complete the calibration, and the expense.

Levine, R. S.

Levine, R. S.

Navy Safety Center Data on the Effects of Fire Protection Systems on Electrical Equipment.

National Institute of Standards and Technology,

Gaithersburg, MD

NISTIR 4620; 84 p. April 1991.

Available from National Technical Information Services PB92-108935

carbon dioxide; collateral damage; electrical equipment;

firex; halons; water; ships; submarines

Records of the Navy Safety Center, Norfolk, VA were reviewed to find data relevant to inadvertant operation of installed fire extinguishing systems in civilian nuclear power plants. 
Navy data show the incidence of collateral fire or other damage by fresh water on operating electrical equipment in submarines, and in shore facilities is about the same as the civilian experience, about $30 \%$. Aboard surface ships, however, the collateral damage incidence is much lower, about $15 \%$. With sea water, the collateral damage incidence is at least $75 \%$. It is concluded that the fire extinguisher water has to be contaminated, as by rust in sprinkler systems or deposited salt spray, for most collateral damage to occur. Reasons for inadvertant operation (or advertant operation) of firex systems at shore facilities, submarines, and surface ships resemble those for nuclear power plants. Mechanical or electrical failures lead the list, followed by mishaps during maintenance. Detector and alarm system failures are significant problems at navy shore facilities, and significant at nuclear power plants. Ships and submarines have few auotmatic firex systems, so this kind of failure is not significant. The Navy depends on trained firefighters to intervene. Prompt action with a portable $\mathrm{CO} 2$ extinguisher is usually effective. Fixed halon and $\mathrm{CO} 2$ systems in shore facilities cause no collateral damage. Lists of individual Navy incidents with water and with halon and carbon dioxide are included as appendices to this report.

Liu, S. T.

Liu, S. T.; Kelly, G. E.; Terlizzi, C. P.

Testing and Rating of an Atmospheric, Gas-Fired Furnace Equipped With a Burner Air Inlet Damper.

National Institute of Standards and Technology, Gaithersburg, MD

NISTIR 4717; 60 p. November 1991.

Available from National Technical Information Services PB92-126440

furnaces; burners; dampers; tracer tests; ANSI/ASHRAE 103; atmospheric burner; burner air inlet damper; DoE test procedure; flue draft factor; loss factor; off-cycle loss; optional procedure for power burner; tracer gas test

An atmospheric furnace with an integral draft diverter and an electro-mechanical burner box inlet damper was tested by the tracer gas method for the development of a test procedure. Tracer gas tests were conducted under two conditions: with the diverter open, and with the diverter sealed and the stack restricted. Test results indicated that the flue gas flow patterns inside the heat exchanger were different for the two conditions. There was reverse flow in one of the clam shells when the diverter was open, but no flow reversal when the diverter was sealed. The off-cycle sensible loss which was a measure of the effectiveness of the burner box inlet damper gave similar value for both conditions. Because of the change in flow pattern and the fact that the furnace normally operated in the field with the diverter open, a recommended test procedure was developed which requires that the tracer gas test should be conducted with the diverter open. A calculation procedure was developed to compute the annual fuel utilization efficiency for the type of furnaces that 
employ a burner box inlet damper or flue damper for off-cycle loss reduction.

Madrzykowski, D.

Madrzykowski, D.

Reduction in Fire Hazard in Corridors and Areas Adjoining

Corridors Provided by Sprinklers.

National Institute of Standards and Technology,

Gaithersburg, MD

NISTIR 4631; 90 p. July 1991.

Available from National Technical Information Services

PB91-222604

corridor tests; crib tests; large scale fire tests; life safety; refuge; room firs; sprinklers; tenability limits

A study was conducted for the General Services

Administration to investigate and quantify sprinklered fire exposure on an exit corridor and spaces adjacent to that corridor. The study compares the conditions in the test facility due to a 1 MW crib fire with those of a fire under control by a sprinkler. The effect of a sprinkler

positioned in the corridor, outside of the burn room, was also examined. The test facility consisted of a burn room, a target room and a corridor connecting the two rooms. The burn room was a $2.44 \mathrm{~m}$ square with a $2.44 \mathrm{~m}$ high ceiling. The corridor was $12.8 \mathrm{~m}$ long, $2.44 \mathrm{~m}$ wide and $2.44 \mathrm{~m}$ high. The target room consisted of an entry alcove and a rectangular room with a total volume of $15 \mathrm{~m}(3)$. The target room was protected using a simulated "standard door" (6 mm top cut, $6 \mathrm{~mm}$ side cut and a $13 \mathrm{~mm}$ undercut). Gas temperatures and concentrations of oxygen, carbon dioxide, and carbon monoxide were measured at selected points in the three rooms. Tenability was assessed using both temperature and gas toxicity criteria. This assessment showed that sprinklers maintained tenable conditions outside the room of fire origin.

Marsha11, R. D.

Marshall, R. D.

Lessons Learned by a wind Engineer.

National Institute of Standards and Technology,

Gaithersburg, MD

American Society of Civil Engineers. Hurricane Hugo One Year Later: Proceedings of a symposium and Public Forum. September 13-15, 1991, Charleston, SC, 109-169 pp, 1991. hurricanes; wind velocity; damage

Surface wind speeds during the passage of Hurricane Hugo

through the U. S. Virgin Islands and Puerto Rico are

described. Although damage to the affected areas was extensive, an assessment of relevant data indicates that the actual wind speeds were far lower than those reported by the news media. The consequences of overstating the wind speeds are examined and actions to improve the accuracy of measuring and reporting wind speeds are outlined.

Marshall, R. D.; Phan, L. T.; Celebi, M. 
Measurement of structural Response Characteristics of Full-scale Buildings: Selection of structures.

National Institute of standrds and Technology, Gaithersburg, MD

Geological Survey, Menlo Park, CA

NISTIR 4511; 24 p. February 1991.

Available from National Technical Information Services

PB91-167239

buildings; earthquakes; instrumentation; dynamic response;

field measurements; structural dynamics

This report describes the selection of existing building structures for subsequent field measurements of low-level ambient vibrations. By comparing measurement results with previously recorded high-level responses, it is anticipated that guidance can be developed for improved measurement practice. The buildings selected for this effort represent a cross-section of contemporary structural systems and materials, foundation types, and a range of building heights and aspect ratios. Each building was subjected to strong shaking during the Loma Prieta Earthquake of October 17, 1989.

Martin, J. W.

Martin, J. W.

Long Term Performance of Rubber in Seismic and Non-Seismic

Bearings: A Literature Review.

National Institute of Standards and Technology,

Gaithersburg, MD

NISTIR 4613; 29 p. June 1991.

Available from National Technical Information Services

PB91-206714

elastomeric bearings; isolation bearings; long-term

performance; materials; rubber bearings; seismic isolator

The use of seismic isolation bearings to decouple building:

and lifeline structures from strong ground motion has

received an increased amount of attention in recent years.

While several types of seismic isolation bearings have been

developed and proposed for use, the most common type is the

laminated rubber (elastomeric) bearing. Because the design

lifetime of these bearings is expected to be on the order of 50 to 100 years, the long-term performance of the rubber must be addressed. Therefore, a literature review was conducted to identify potential limits on the long-term performance of rubbers used in bearings. Several issues, including the need for consensus performance standards and for additional research on the effects of creep, aging, temperature, and high-energy radiaiton on the properties of rubber, were identified.

Martin, J. W.: Rossiter, W. J., Jr.; Embree, E.

Factors Affecting the Strength and Creep-Rupture Properties of EPDM Joints.

National Institute of Standards and Technology, Gaithersburg, MD

International Symposium on Roofing Technology, 3rd. April 17-19, 1991, Montreal, Canada, 63-71 pp, 1991. 
butyl adhesive; creep rupture life; EPDM; neoprene adhesive; peel strength; single-ply roofing; strain rate;

time-to-failure

The objectives of this research were: 1) to determine from a small but important set of material and fabrication variables (adhesive thickness, cure time, mechanical load, adhesive type and surface cleanness), those variables which are primarily responsible for causing joint failures; 2) to rank these experimental variables in the order in which the affect the strength and creep-rupture life of butyl-adhered EPDM joints; and 3) to determine the maximum peel stress as EPDM joint can sustain over its design life. From our results, cure time and level of cleanness of the EPDM rubber surface have the greatest effect on joint strength; while the thickness of the adhesive and the magnitude of the mechanical load have the greatest effect on the time-to-failure of a joint. It was further observed that the maximum stress that an EPDM joint can sustain over time is only a small fraction (less than 5 percent) of its short-time peel strength. It was concluded, therefore, that efforts should be made to ensure that the field-formed joints are not subjected to large peel loads.

Martin, J. W.; Rossiter, W. J., Jr.; Embree, E. Is Your Adhesive Layer Thick Enough?

National Institute of Standards and Technology, Gaithersburg, MD

Professional Roofing, Vol. 21, No. 5, 30-37, 1991. roofs; adhesives; seams; bonding; joint failures; strength; creep rupture; peel stress; stress (mechanics)

Research indicates that the lifetime of an EPDM roof may be prolonged significantly with a thicker layer of adhesive in the seams. The objectives of this research on the strength and creep-rupture properties of EPDM joints were: [*] To determine from a small but important set of material and fabrication variables (adhesive thickness, cure time, mechanical load, adhesive type and surface cleanness), those variables which are primarily responsible for causing joint failures; [*] To rank these experimental variables in the order in which they affect the strength and creep-rupture life of butyl-adhered EPDM joints; and [*] To determine the maximum peel stress an EPDM joint can sustain over its design life.

Martys, $\mathbf{N}$.

Martys, N. ; Robbins, M. O. ; Cieplak, M.

Scaling Relations for Interface Motion Through Disordered

Bond-Length Mismatch.

Johns Hopkins Univ., Laurel, MD

Polish Academy of Sciences, Warsaw, Poland

Physical Review B, Vol. 44, No. 22, 12/294-306, December 1, 1991.

scaling; scaling laws

We consider the critical transitions that occur as the force driving an interface through a random medium is increased. The total displacement of the interface, and the incremental advance after a small increase in force, diverage as the 
force approaches a critical depinning threshold. At the critical force there is a power-law distribution of growth sizes. General scaling relations are derived between the critical exponents associated with such transitions. These scaling relations are tested on a model system: fluid invasion of a two-dimensional porous medium. Critical exponents are determined from simulations using finite-size-scaling techniques. Two universality classes are identified: percolation and depinning. In both cases the calculated exponents obey the scaling relations.

Mathey, R. G.

Mathey, R. G. : Knab, L. I.

Uniaxial Tensile Tests to Measure the Bond of In Situ

Concrete Overlays.

National Institute of Standards and Technology,

Gaithersburg, MD

NISTIR 4648; $36 \mathrm{p}$. October 1991.

Available from National Technical Information Services

PB92-116300

tensile strength; concretes; test methods

The feasibility of two in situ tensile test methods for use in the field to measure the bond of concrete overlays was investigted in the laboratory. The two test methods used pneumatic and hydraulic loading apparatuses. The uniaxial tensile tests were conducted using partial-depth in situ cores drilled through overlay concrete and into previously cast slabs. Comparisons of the magnitude and repeatability of the tensile strength results for the two test methods indicated that they were comparable. The study demonstrated that both the pneumatic and hydraulic test methods are applicable for field use for measuring the tensile strength of the bond between a relatively thick overlay and its base concrete.

McKnight, M. E.

McKnight, M. E.

Feasibility of Using a Multiple Award Schedule for

Specifying Paints in Government Painting Contracts.

National Institute of Standards and Technology,

Gaithersburg, MD

NISTIR 4706; 18 p. November 1991.

Available from National Technical Information Services

PB92-126481

coatings; paints; facilities; multiple aware schedule; performance criteria

The Department of Defense is placing increasing emphasis on

the use of commercially available or branded products in

lieu of Military or Federal specification products in

building construction and maintenance. However, there are

few industry consensus specifications for paints and

coatings. Although non-government consensus coating specifications are being developed, a General Services

Administration Federal Supply Scheduel provides an additional mechanism through which Federal agencies can obtain commercially available coatings. Specifically, the use of a Multiple Award Federal Supply Schedule in a 
military painting contract is discussed in this report. Procedures for obtaining the lowest cost material that would meet the Government's minimum needs are addressed. A description of need based upon performance criteria for the specific end use, that would be included in a painting contract, is suggested. Advantages and disadvantages of using a Multiple Aware Schedule in painting contracts are enumerated. Advantages include providing a mechanism for using new coating technology, taking advantage of manufacturer's technical support and knowledge of regulatory issues, and decreasing the need for revising or preparing new coating specifications. Disadvantages include the additional effort needed to revise guide specifications, train both coating users and supplier in new procedures and the lack of performance criteria for some end uses. Despite the disadvantages cited, it is concluded that the advantages outweigh the disadvantages and that use of a Multiple Award schedule in painting contracts if feasible.

Milke, J.A.

Milke, J. A.; Bryan, J. L.

Development of a Technique to Assess the Adequacy of the Municipal Water Supply for a Residential Sprinkler system. Maryland Univ., College Park NIST-GCR-91-600; 82 p. November 1991. Available from National Technical Information Services PB92-123116

sprinkler systems; flow measurement; plumbing; residential

buildings; water supply; sprinklers

This research effort developed a technique to assess the adequacy of the municipal water supply for residential sprinkler systems installed in one- and two-family dwellings. This effort is a continuation of a recently completed project which investigated cost-effective techniques for alleviation deficiencies in the municipal water supply. In that effort, a need was identified to develop a technique to evaluate the adequacy of the municipal water supply. This report includes characterizing typical plumbing flow fixtures in residences to permit an analysis of the domestic water supply within a residence. Having characterized the residential flow devices, techniques to evaluate the domestic water supply are investigated. This investigation considers the feasibility of developing an inexpensive prototype apparatus with which to conduct the water supply evaluations. Based on the water supply evaluations, an assessment of the adequacy of typical domestic water systems are satisfying water demand requirements of residential sprinkler systems are documented. The water demand requirements for residential sprinkler systems were selected from the initial phase of this research which investigted techniques to alleviate water supply deficiencies.

Mitler, H. E.

Mitler, H. E.

Mathematical Modeling of Enclosure Fires. 
National Institute of Standards and Technology, Gaithersburg, MD

NISTIR 90-4294;

47 p. May 1991.

Available from National Technical Information Services

PB92-108976

computer models; fire models; mathematical models; modeling; numerical methods; room fires

After a brief description of the history and physicfs of enclosure fire modeling, two kinds of deterministic fire models are discussed: field models and zone models. The models consist of sets of coupled equations--differential, algebraic, or a mixture of the two. Special emphasis is placed on discussing some of the numerical techniques used to solve these equations. Although this is not a comprehensive review article, an attempt has been made to give a sufficiently complete reference section that the interested reader can follow up on any item.

Mitler, H. E.

Predicting the spread Rates of Fires on Vertical Surfaces. National Institute of standards and Technology,

Gaithersburg, MD

Combustion Institute, Symposium (International) on Combustion, 23rd. July 22-27, 1990, Orleans, France, Combustion Institute, Pittsburgh, PA, 1715-1721 pp, 1991.

combustion; flame spread rate; slabs (members); algorithms;

heat flux; pryolysis rate; equations; polymethylmethacrylate A model is developed for the upward spread rate of the pyrolysis front of a burning vertical slab. It is ignited with a flame from a line burner of user-specified strength. It can also be exposed to arbitrary, time-varying impinging external fluxes. It is assumed that the slab material has uniform, isotropic properties and that there is no lateral dirfusion of heat withing the slab. This model has been implemented as a computer program. The program has two options for the mass-loss rate. The first uses an algebraic submodel for the steady-state pyrolysis of simple, non-melting and non-charring materials. The second is based on Cone calorimeter data: the mass-loss rate data found via the cone at a given irradiance level is transformed into what the rate would be at those found during the actual experiment. The latter approach automatically includes the effects of charring, of transient heating, etc., to a first approximation. Expressions for the heating flux from the flame to the wall are found for all cases of interest. Runs were made assuming $2.5,5$, and $10 \mathrm{~kW} / \mathrm{m}$ igniting burners and with a square-root dependence on [equation] for the flame height, as well as with the usual $2 / 3$ power dependence. The results of each run were compared with the results of upward spread experiments on PMMA carried out in 1975 by orloff, et al. The results, using either mass-loss rate option, were in excellent agreement with experiment when the square-root dependence was used.

Morehart, J. H. Morehart, J. H.; Zukoski, E. E.; Kubota, T. 
Characteristics of Large Diffusion Flames Burning in a Vitiated Atmosphere.

California Institute of Technolgoy, Pasadena

International Association for Fire safety science. Fire Safety Science. Proceedings. 3rd International symposium. July 8-12, 1991, Edinburgh, Scotland, Elsevier Applied Science, New York, Cox, G.; Langford, B., Editors, 575-583 pp, 1991.

fire research; fire safety; fire science; laminar flames; diffusion flames; room fires; combustion products; flame length; extinction; fire models; natural gas; ethylene Experiments concerning properties of large diffusion flames burning steadily in a vitiated atmosphere under conditions similar to those which may arise in a room fire are described. The effects of vitiation on the products of combustion and flame lengths, and the extinction limits are described for natural gas and ethylene diffusion flames stabilied on 8.9-, 19- and 50-cm pool-type burners. As vitiation was increased and the flame extinction limit was approached, the flame length increased slightly. close to the limit, radiation from soot in the flame became imperceptible, leaving only a weakly luminous blue flame. Even with significant reductions in both the flame height and luminosity near the limit conditions, the hydrocarbon fuels were completely oxidized in the flame to water and carbon dioxide and no measurable concentrations of products of incomplete combustion were produced. A comparison of limiting oxygen concentrations and limiting flame temperatures for these experiments with the results of othe] investigations shows reasonably good agreement despite widely varying experimental techniques. These results are contrasted with those obtained in the unsteady situation which arises when a large buoyant diffusion flame burns in an enclosed space such that the upper part of the flame is in a strongly vitiated layer composed of a mixture of air and products of combustion, and the lower part in fresh air.

Mulholland, G. W.

Mulholland, G. W.: Benner, B. A., Jr.; Fletcher, R. A. ; steel, E.; Wise, S. A.; May, W. E.; Madrzykowski, D.; Evans, D. D.

Analysis of Smoke Samples From oil well Fires in Kuwait. Report of Test FR 3985.

National Institute of Standards and Technology, Gaithersburg, MD

Report of Test FR 3985; 15 p. June 20, 1991.

well fires; crude oil; smoke

This report describes results from a preliminary series of measurements concerning the smoke production from the Kuwait oil well fires. Detailed chemical analysis of the smoke is being carried out for determination of the fraction of ambient aerosol arising from the Kuwait oil well fires on a local, regional, and global scale. The overall goal is to characterize the amount of smoke particulate produced and its chemical makeup, as well as the amount of various gaseous species including SOx and PAHs from individual well fires. This information will be used together with the burning rates of a large number of oil well fires to 
estimate the total production of smoke and gases from all the fires in Kuwait. The source term information is essential for risk assessment in regard to health effects, environmental/climate impact, and visibility. Smoke samples were collected in the Al Maqwa oil field in Kuwait on May 15, 1991 from two locations illustrated on the map. The first set was collected about 3 meters above ground at an "ambient" location; that is, the sampling was not from a plume but was from the oil field region. These samples are indicated as ambient oil field samples. The second set of samples, denoted as plume samples, was collected in the plume of a combination jet-pool fire at a height of about 1 meter. The ground level plume consisted of whitish smoke, while black smoke was emanating from the flames. It was the whitish smoke that we were sampling. The particulate was collected on quartz filters, polytetrafluoroethylene (PTFE) filters, on stages of a cascade impactor, and on carbon coated transmission electron microscopy (TEM) grids. Volatile polycyclic aromatic hydrocarbons (PAHs) were collected downstream on XAD-2 sorbent and $\mathrm{CO}$ and $\mathrm{CO} 2$ were collected in PTFE sampling bags. The sampling procedures are described in more detail below. The smoke analysis included the determination of the mass of particulate on the filter, the relative amounts of organic and elemental carbon in the particulate, the $\mathrm{PAH}$ content of the particulate and gas, the chemical composition by laser microprobe mass spectroscopy (LMMS), and the particle size distribution by transmission electron microscopy and by cascade impactor. Gas chromatography was used to analyze the $\mathrm{CO}$ and $\mathrm{CO} 2$ concentration in the gas samples. Mulholland, G. W. : Janssens, M. ; Yusa, S.; Twilley, W. H. ;
Babrauskas, V.

Effect of Oxygen Concentration on $\mathrm{CO}$ and Smoke Produced by Flames.

National Institute of standards and Technology, Gaithersburg, MD

National Forest Products Assoc., Washington, DC

Building Research Inst., Ibaraki, Japan

International Association for Fire safety science. Fire Safety science. Proceedings. 3 rd International symposium. July 8-12, 1991, Edinburgh, Scotland, Elsevier Applied Science, New York, Cox, G.: Langford, B., Editors, 585-594 pp, 1991.

fire research; fire safety; fire science; carbon monoxide; cone calorimeters; heat release rate; methane; plastics; propane; smoke; wood

A modified cone calorimeter with an enclosure has been developed for measuring the yield of combustion products including $C O$ and smoke under vitiated conditions. The co yields of methane, propane, PMMA, ABS, polyethylene, and Douglas fir are found to increase by at least a factor of two as the oxygen concentration is decreased from $21 \%$ to $14 \%$, while the smoke yields are found to be insensitive to vitiation for the solid materials (less than $30 \%$ change). Results for air vitiated separately by nitrogen and by carbon dioxide suggest that the $c o$ yield for a given fuel in a free burn is mainly controlled by the flame temperature. 
For ambient conditions, the $c 0$ yields for the solid samples are about a factor of 2.3 smaller than the smoke yields for all the solid materials studied.

Nelson, H. E.

Nelson, H. E.

History of Fire Technology.

National Institute of Standards and Technology,

Gaithersburg, MD

Worcester Polytechnic Institute. Fire Safety Design in the

21 st Century Conference. May 8-10, 1991, 1-15 pp, 1991.

fire research; fire suppression; compartments; fire models

The history of fire technolgy is explored for clues to guide future fire technology efforts. Emphasis is placed on those factors that encourage, retarded, or restricted past efforts. The data were gathered from a series of interviews with persons involved in many of the past advances. Specific discussion is given to advances in the areas of risk appraisal, suppression, compartment fire modeling, and structural endurance.

Nelson, H. E. ; Deal, S. Comparing Compartment Fires With Compartment Fire Models. National Institute of standards and Technology, Gaithersburg, MD

International Association for Fire Safety Science. Fire Safety Science. Proceedings. 3rd International symposium. July 8-12, 1991, Edinburgh, Scotland, Elsevier Applied Science, New York, Cox, G.; Langford, B., Editors, 719-728 pp, 1991 .

fire research; fire safety; fire science; compartment fires;

fire models; fire tests; wood; plastics

An approach for appraising the expected performance of compartment fire models is presented. The approach involves comparing the results of well documented test data to selected outputs of the model. The paper applies this approach to four zone compartment fire models and offers a brief analysis of the results of that application. The test data was obtained from room fire tests involving both wood and plastic cribs reported by quintiere and McCaffrey in 1980. The models compared were FIRST9X, FAST, CCFM-VENTS, and FPETOOL.

Nelson, H. E.; Tu, K. M.

Engineering Analysis of the Fire Development in the

Hillhaven Nursing Home Fire, October 5, 1989.

National Institute of Standards and Technology, Gaithersburg, MD

NISTIR 4665; 56 p. September 1991.

Available from National Technical Information Services

PB92-112317

bedding; carbon monoxide; fire investigations; fire models;

fire tests; flashover; mattresses; nursing homes

This report presents the methods and results of an analysis of the development and spread of fire and smoke during the october 5, 1989 fire in the Hillhaven Rehabilitation and 
Convalescent Center, Norfolk, Virginia. The analysis uses data gathered from onsite visits, reports and information for other investigators, fire tests conducted at the National Institute of standards and Technology, and fire growth models and similar computations. The report details the procedure and data used, the reasons for those selected, and the results obtained. The analysis addresses mass burning rate; rate of heat release; smoke temperature; smoke layer depth; velocity, depth and temperature of the smoke front; oxygen concentration of smoke layer; carbon monoxide concentrations; and other factors. The areas of building analyzed include the room of fire origin, the corridor system exposed by that room, and other patient rooms on that corridor.

Nguyen, T.

Nguyen, T.; Byrd, E.; Lin, C.

spectroscopic Technique for In situ Measurement of Water at the coating/Metal Interface.

National Institute of Standards and Technology,

Gaithersburg, MD

Journal of Adhesion Science and Technology, Vol. 5, No. 9, 697-709, June 1991.

coatings; FT-IR; internal reflection spectroscopy; polymer/metal interface; water

A technique was developed based on Fouier transform infrared spectroscopy in the multiple internal reflection mode

(FTIR-MIR) for measuring in situ water at the coating/metal interface. The technique requires a direct application of a transparent or opaque polymer coating of any thickness to a Ge internal reflection element (IRE). A water chamber was attached to the polymer-coated IRE and water was introduced through the chamber inlet. FTIR-MIR spectra were taken automtically at specified time intervals without realignment or readjustment of the ATR accessory and without disturbing the specimens or the conditions of the experiment. The intensities of the water bands increased and those of the coating bands decreased initially and then leveled off as the exposure times increased. Calculations are presented to demonstrate that the technique can provide information on water at the coating/metal interface. The method may also provide a convenient means for measuring the diffusion of water in polymer coatings on metals.

Nguyen, T.; Byrd, E.; Lin, C.; Bentz, D.

Novel spectroscopic Technique for In-Situ studies of Water at the Interface Between a Metal and an opaque Polymeric Film.

National Institute of Standards and Technology, Gaithersburg, MD

Advanced Composite Materials, 1051-1060, 1991.

water; films; infrared spectroscopy; coatings; metals; FT-IR

A technique was developed based on Fourier transform infrared spectroscopy - multiple internal reflection (MIR-FTIR) for measuring water in situ at the coating/metal interface. The method requires direct application of a transparent or opaque polymeric coating of any thickness to 75 
a metal-free or metal-coated internal reflection element (IRE). A water chamber was attached to the organic coating side of the coated IRE and water was introduced through the chamber inlet. MIR-FTIR spectra were taken automatically at specified exposure time intervals without readjustment of the ATR accessory and without disturbing the specimens and conditions of the experiment. The method was found useful for determining the thickness of the water layer at the coating/metal interface and its change as a function of exposure time.

Nguyen, T.; Hubbard, J. B. ; McFadden, G. B. Mathematical Model for the Cathodic Blistering of Organic Coatings on steel Immersed in Electrolytes. National Institute of Standards and Technology, Gaithersburg, MD Journal of Coatings Technology, Vol. 63, No. 794, 43-52, March 1991.

steels; mathematical models; blisters; coatings; corrison A physical/mathematical model which describes blistering resulting from the corrosion of coated metals containing defects exposed to electrolytes has been developed. The model is based on the two-dimensional diffusion of cations through some arbitrary medium. Cations migrating along the coating/metal interface from the defect to the cathodic sites are assumed to be responsible for the formation of highly water-soluble corrosion products, leading to blistering. Solutions of the model were expressed in terms of dimensionless parameters. Concentration profiles between the blister and defect and cation flux into the blister as functions of time, blister size, distance between the blister and defect, ion diffusivity, and potential gradient were calculated. The predictions were related to available experimental data in the literature on cation uptakes and blistering rates for coated steel panels exposed to metal chloride solutions.

Nguyen, T.; Lin, C.

In-Situ Measurement of Chloride Ion at the Coating/Metal Interface.

National Institute of standards and Technology, Gaithersburg, MD

Journal of Adhesion, Vol. 33, 241-252, 1991. Ahesion Society, Inc. Annual Meeting, 13th. February 19-21, 1990, Savannah, GE, 1991.

corrosion; ion selective microelectrodes; analytical instrumentation; blister formation; steels; surfaces One of the main reasons for the lack of a complete understanding of corrosion and adhesion failures of a coated metal is the lack of analytical instrumentation to probe the behaviors of corrosive agents at the coating/metal interface. We have developed a procedure based on microelectrodes for studying in situ the behavior of chloride ions at a coating/metal interface. The procedure requires an attachment of a double-barreled cl ion-selective microelectrode at the coating/metal interface, thus allowing direct measurements of $\mathrm{Cl}$ concentration changes at localized 
areas under a coating. The procedure provided very useful information for mechanistic studies of corrosion under coatings, as well as for transport studies of $\mathrm{cl}$ ions through a coating. The procedure should also be useful for studying the roles of $\mathrm{Cl}$ in localized corrosion.

Norton, T. S.

Norton, T. S.: Smyth, K. C.

Laser-Induced Fluorescence of $\mathrm{CH}$ in a Laminar $\mathrm{CH} 4 / \mathrm{Air}$

Diffusion Flame: Implications for Diagnostic Measurements and Analysis of Chemical Rates.

National Institute of Standards and Technology,

Gaithersburg, MD

Combustion Science and Technology, Vol. 76, 1-20, 1991.

lasers; fluorescence; laminar flames; diffusion flames

Relative $\mathrm{CH}$ radical concentration profiels have been

measured in a laminar, co-flowing methane/air diffusion

flame using laser-induced fluorescence from the $(0,0)$ band

of the [equation] transition. $\mathrm{CH}$ has the narrowest profiel

of any species yet measured in this flame. The $\mathrm{CH}$ peak does

not coincide with the position of the $\mathrm{OH}$ and temperature

maxima, but appears on the fuel-rich side, between the peak concentrations of hydrogen atoms and methyl radicals. If $\mathrm{CH}$ fluorescnce is detected with a narrow bandpass dielectric filter, rather than using amonochromator, severe

interference attributed to fluorescence from polycyclic

aromatic hydrocarbons (PAH) is observed. The $\mathrm{CH}$

concentration decreased, while PAH fluorescence interference increases rapidly with height above the burner.

Implications for $\mathrm{CH}$ imaging experiments in turbulent diffusion flames are discussed. The net chemical

production/destruction rate of $\mathrm{CH}$ is determined as a

function of flame poisition at a height $\mathrm{H}$ of $9 \mathrm{~mm}$ above the burner. This $\mathrm{CH}$ production rate profile is used $t$ ) derive a relative mole franction profile for triplet methylene [equation]. The concentration ratio [equation] is found to be 13-300, where the major source of uncertainty is the reaction rate of [equation]. Maximum concentrations of the $\mathrm{CHx}$ radicals are not well established in this flame. However, if the derived [equation] ratio is combined with the calculated value of $25 \mathrm{ppm}$ for [equation] from puri et al. (1987), one estimates that the peak $\mathrm{CH}$ mole fraction lies between 0.08 and $2 \mathrm{ppm}$ at $\mathrm{H}=9 \mathrm{~mm}$.

Nyden, M. R.

Nyden, M. R.; Noid, D. W.

Molecular Dynamics of Initial Events in the Thermal

Degradation of Polymers.

National Institute of Standards and Technology,

Gaithersburg, MD

Oak Ridge National Lab., TN

Journal of Physical Chemistry, Vol. 95, 940-945, 1991.

thermal degradation; computers; simulation; kinetics;

stability; temperature: molecular weight

Computer simulations, based on molecular dynamics, were used to investigate the kinetic stability of model polymers as a function of temperature, secondary structure, and molecular 
weight. The rate constants for random scission of the carbon-carbon bonds were obtained from simulations starting from both planar zigzag and coiled conformations. The coiled polymers were found to be more stable than planar zigzag polymers with the same primary structure. The computer-generated rates correlated reasonably well with the functional predictions of the Rice, Ramsperger, and Kassel theory of unimolecular reactivity; however, deviations were observed for some of the short-chained polymers. Computer movies revealed pronounced coiling in the vicinity of dissociating bonds. This behavior was examined in light of proposed mechanisms for intramolecular hydrogen transfer.

Ohlemiller, T. J.

Ohlemiller, T. J.

Smoldering Combustion Propagation on Solid Wood.

Maryland Univ., College Park

National Institute of Standards and Technology,

Gaithersburg, MD

International Association for Fire Safety Science. Fire Safety Science. Proceedings. 3rd International Symposium. July 8-12, 1991, Edinburgh, Scotland, Elsevier Applied

Science, New York, Cox, G.; Langford, B., Editors, 565-574 pp, 1991 .

fire research; fire safety; fire science; smoldering combustion; wood; smoldering

Factors controlling the spread of smoldering combustion on solid wood (red oak, white pine) were examined in a configruation designed to enable self-sustained smolder. The sample was in the form of a U-shaped channel $74 \mathrm{~cm}$ long with $6.4 \mathrm{~cm}$ thick walls. A controlled flow of air was confined to the interior of the channel. Smoldering was initiated on the interior surface either of the upstream end of this channel (yielding forward smolder propagation), the downstream end (reverse smolder) or mid-length (coupled forward/reverse smolder). In separate tests the air flow velocity (referred to the initial cross section of the channel) was varied from about 9 to $22 \mathrm{~cm} / \mathrm{sec}$. At the low end of this range, the smoldering process was prone to extinction; at the high end it was increasingly likely to transition into flaming combustion. A simple energy balance model indicates a central role of radiative transfer in sustaining the smolder process.

Ohlemiller, T. J.; Villa, K. M.

Material Flammability Test Assessment for Space Station

Freedom.

National Institute of Standards and Technology, Gaithersburg, MD

NISTIR 4591; NASA CR-187115; 78 p. June 1991.

Available from National Technical Information Services PB91-216606

flame spread; flammability; ignition; microgravity; heat release rate; test methods; spacecraft; small scale fire tests

The NASA Upward Flame Propagation test, which measures response to a well-defined laminar flame at the bottom of a 
test sample, is currently used to screen for flammability all materials intended for use in the interior of manned spacecraft. The response of a series of materials was compared in this test and in the standard NIST Flammability Tests (Cone Calorimeter for rate of heat release and LIFT tests for ignitability and lateral flame spread). The goal was to see if these differing flammability assessment approaches provide comparable information on the potential hazards of a material. In the first phase of this study only one of the samples exhibited appreciable flame spread in the NASA test, yielding very limited data for comparisons with the NIST test results. The NIST tests, which employ a variable external radiant flux as an additional test parameter, revealed a widely varying response to this flux. In the second phase of the study, the NASA test was modified to include radiative pre-heating of the samples before they were exposed to the standard NASA ignitier in the standard manner. The response of the materials, as measured by the minimum pre-heat flux (or temperature) to yield upward spread, varied widely; for example, Nomex required very little pre-heating to yield full-length spread whereas Lexan 9034 was resistant. Rate of heat release behavior or lateral flame spread behavior alone did not appear to be predictive of behavior in the modified NASA test. A simplified upward flame spread model, which utilizes inputs derived from the NIST test, was employed in an attempt to predict the behavior in the modified NASA tests. The model greatly under-predicted the necessary pre-heat flux for some materials while doing the opposite for other materials. Thus, at the present, a firm relation between the behavior in the NASA test and in the NIST tests has not been established.

Oluokon, F. A.

Oluokon, F. A.; Burdette, E. G.; Deatherage, J. H.; Carino, N. J.

Early-Age Concrete Strength Prediction by Maturity--Another Look.

National Institute of Standards and Technology,

Gaithersburg, MD

ACI Materials Journal, Vol. 88, No. 5, 584-586,

September/October 1991.

concretes; equations; regression rate

The main thesis of the paper is that Plowman's function, Eq.

(2), is not an accurate representation of the relationship

between strength and maturity index at low maturity. Thus

the authors have suggested an alternative to Plowman's equations. The writer wishes to expand on some of the concepts mentioned in the paper and to suggest that there may be better functions than the proposed exponential

function [Eq. (3)].

Pagni, P. J.

Pagni, P. J.; Joshi, A. A.

Glass Breaking in Fires.

California Univ., Berkeley 
International Association for Fire safety science. Fire Safety science. Proceedings. 3rd International symposium. July 8-12, 1991, Edinburgh, Scotland, Elsevier Applied Science, New York, Cox, G.; Langford, B., Editors, 791-802 pp, 1991 .

fire research; fire safety; fire science; glass; compartment fires; windows; flashover; venting; thermal stresses: temperature

Glass breaking in compartment fires is an important practical problem since a window acts as a wall before breaking and as a vent after breaking. If sufficient excess pyrolyzates have accumulated in the hot layer, this sudden geometric change can lead to backdraft and flashover. As Emmons explained at the First symposium, window break in fires due to thermal stress from the differential heating of the central portion and the shaded edge. The focus of this paper is on quantifying the connection between the compartment fire and the glass temperature to predict the window breaking time. Techniques are presented for accurately calculating the history of the central glass temperature profile, for any fire exposure. Two-dimensional temperature histories, where $x$ is depth and $y$ is toward the center, and mean stress histories are also calculated. It is determined here that breaking occurs when the mean glass temperature difference is [equation] where [equation] is the maximum glass tensile strain, beta is the thermal coefficient of linear expansion and $g$ is a geometry factor of order one. Calculations suggest that the edge remains at its initial temperature so that [equation] when the shading is large [equation] and the heating is fast [equation], where $L$ is the glass thickness, $s$ is the shaded edge width and alpha is the glass thermal diffusivity.

\section{Parker, W. J.}

Parker, W. J.; Tu, K. M.; Nurbakhsh, S.; Damant, G. Chair Burns in the TB133 Room, the ASTM Room, the Furniture Calorimeter and the cone calorimeter.

National Institute of Standards and Technology,

Gaithersburg, MD

Bureau of Home Furnishings and Thermal Insulation, CA

International Association for Fire Safety Science. Fire

Safety science. Proceedings. 3rd International symposium. July 8-12, 1991, Edinburgh, Scotland, Elsevier Applied

Science, New York, Cox, G.: Langford, B., Editors, 699-708 pp, 1991.

fire research; fire safety; fire science; furniture;

furniture calorimeters; cone calorimeters; room burns; heat release rate; computer models

Ten sets of upholstered chairs were tested in the california Technical Bulletin 133 (TB133) room, in the proposed ASTM room and in the NIST furniture calorimeter. The chairs varied only in the type of fabric, type of foam, and whether or not there was a fiberglass interliner present. The rooms were instrumented to measure the total heat release rate of the chairs. A relationship was established between the peak heat release rate in the rooms and the temperature rise 25 $\mathrm{mm}$ below the ceiling above the chair. The combinations of fabric, fiberglass interliner and foam were also tested in 
the cone calorimeter. A correlation of the full scale and bench scale results for this set of chairs was obtained. Calculations were made of the upper layer temperature in the room, using Hazard 1 and the measured heat release rates.

Peacock, R. D.

Peacock, R. D. ; Babrauskas, V.

Analysis of Large-Scale Fire Test Data.

National Institute of Standards and Technology,

Gaithersburg, MD

Fire Safety Journal, Vol. 17, No. 5, 387-414, 1991.

large scale fire tests; calorimeters; room fires; data analysis; algorithms

Large-scale room fire testing has evolved from simple fire performance measurements such as intensity and duration of 'room fires' to sophisticated measurements to understand the properties which cause the fire. This paper provides a overview of typical calculations, based upon published research results, that are used at the center for Fire Research and elsewhere for the analysis of a large-scale room fire test. Analysis of large-scale fire test data requires the development of a series of algorithms that combine individual measurements to produce the desired physical quantity. A set of algorithms for the analysis of fire test data based upon published research results is described. Included are fire-specific calculations such as smoke and gas analysis, layer temperature and interface position, mass loss and flows, and rate of heat release. Examples of the application of the calculations are provided.

Peacock, R. D.; Breese, J. N.; Forney, C. L. User's Guide for RAPID, Version 2.3. National Institute of Standards and Technology, Gaithersburg, MD NIST SP 798; 112 p. January 1991. Available from Government Printing office computer programs; data acquisition; data reduction; fire tests

$* * * * *$ THIS REPORT SUPERSEDES NBS SP $722 * * * * *$

The voluminous amount of data that can be collected by automatic data acquisition systems during large scale fire tests requires the use of a digital computer for the reduction of data. RAPID is a stand-alone program specifically designed to convert raw instrument voltages collected during such tests into meaningful units. The reduced data can also be used alone or in combinations to obtain derived quantities. The program is written with the ability to accept data from a user defined data acquisition system and to check the correctness of data being anzlyzed. The data can be converted into meaningful scientific units and then presented in tabular or printer plot form, or stored for further processing. This guide provides detailed instruction for the use of the program. 
Peacock, R. D. ; Davis, S.; Babrauskas, V. Data for Room Fire Model Comparisons.

National Institute of Standards and Technology, Gaithersburg, MD

Journal of Research of the National Institute of Standards and Technology, Vol. 96, No. 4, 411-462, August 1991.

accuracy assessment; data analysis; experiments; fire models; fire tests; instruments

With the development of models to predict fire growth and spread in buildings, there has been a concomitant evolution in the measurement and analysis of experimental data in real-scale fires. This report presents the types of analyses that can be used to examine large-scale room fire test data to prepare the data for comparison with zone-based fire models. Five sets of experimental data which can be used to test the limits of a typical two-zone fire model are detailed. A standard set of nomenclature describing the geometry of the building and the quantities measured in each experiment is presented. Availability of ancillary data (such as smaller-scale test results) is included. These descriptions, along with the data (available in

computer-readable form) should allow comparisons between the experiment and model predictions. The base of experimental data ranges in complexity from one room tests with

individual furniture items to a series of tests conducted in a multiple story hotel equipped with a zoned smoke control system.

Peacock, R. D. ; Jones, W. W. ; Bukowski, R. W. ; Forney, C. L. Software User's Guide for the HAZARD I Fire Hazard

Assessment Method. Version 1.1. Volume 1. National Institute of Standards and Technology, Gaithersburg, MD

NIST HB-146/I; 297 p. June 1991.

Available from National Technical Information services

computer models; computer programs; evacuation; fire models;

hazard assessment; human behavior; toxicity

This report describes the first version of a method for predicting the hazards to occupants involved in a building fire. To implement the method, a personal computer software package called HAZARD I is provided. The software consists of modules which can predict the time varying environment within a building resulting from a specified fire; the locations and actions for a specified group of occupants as they. interact with the building, the fire, and each other; and the impact of the exposure of each of the occupants to the fire products in terms of whether the occupants successfully escape, are incapacitated, or are killed. NIST Handbook 146 consists of the Technical Reference Guide, the Software User's Guide, plus computer software supplied on six $51 / 4 "$ and three 3 1/2" disks.

Persily, A. K.

Persily, A. K. ; Dols, W. S.

Field Measurements of Ventilation and Ventilation

Effectiveness in an Office/Library Building. 
National Institute of Standards and Technology, Gaithersburg, MD

Indoor Air, Vol. 3, 229-245, 1991.

ventilation; office buildings; libraries; carbon dioxide;

air quality

Mechanical ventilation system performance involves the

provision of adequate amounts of outdoor air, uniform

distribution of ventilation air within the occcupied space,

and the maintenance of thermal comfort. Standard

measurement techniques exist to evaluate thermal comfort and air change rates in mechanically ventilated buildings;

procedures to evaluate air distribution or ventilation

effectiveness in the field are still being developed. This paper presents measurements of air change rates and

ventilation effectiveness in an office/library building in

Washington, DC. The tracer gas decay techniques was used to measure whole building air change rates. The air change rates during the measurement period were essentially constant at about 0.8 air changes per hour, somewhat below the design specification and above the minimum recommended in ASHRAE Standard 62-1989. Ventilation effectiveness was investigated at several locations within the building through the measurement of local tracer gas decay rate and mean local age of air. The ventilation effectiveness measurements serve as an investigation of the applicability of the measurement procedures employed, provding insight into the measurement issue of establishing initial conditions, the spatial variation in test results a building, and the repeatability between tests. The results of the ventilation effectiveness measurements are consistent with good distribution of the outdoor air by the ventilaiton system and good mixing within the occupied space.

Persily, A. K.; Dols, W. S. ; Nabinger, S. J.; Kirchner, S. Preliminary Results of the Environmental Evaluation of the Federal Records Center in Overland Missouri.

National Institute of Standards and Technology, Gaithersburg, MD

NISTIR 4634; 51 p. July 1991.

Available from National Technical Information Services PB91-240747

building diagnostics; building performance; carbon dioxide; carbon monoxide; formaldehyde; indoor air quality; office buildings; radon; ventilation; volatile organic compounds The National Institute of Standards and Technolgoy (NIST) is studying the thermal and environmental performance of new federal office buildings for the Public Buildings service of the General Services Administration (GSA). This project involves long-term performance monitoring both before occupancy and during early occupancy in three new office buildings. The performance evaluation includes an assessment of the thermal integrity of the building envelope, long-term monitoring of ventilation system performance, and the measurement of indoor levels of selected pollutants. This report describes the effort being conducted in the second of the three buildings, the Federal Records Center in Overland Missouri, and presents preliminary measurement results from the building. The 
infrared thermographic inspection of the overland Building did not reveal any significant thermal defects in the building envelope, though the existence of air leakage and thermal bridging was noted. The whole building pressurization test showed that the building is quite leaky compared to other modern office buildings. The measured radon concentrations were $2 \mathrm{pCi} / \mathrm{L}$ or less on the B2 level, and less than or equal of $0.5 \mathrm{pCi} / \mathrm{L}$ on the other levels. Formaldehyde concentrations ranged from 0.03 to $0.07 \mathrm{ppm}$, below the $0.1 \mathrm{ppm}$ guideline but above some levels of concern. The measured levels of voltile organic compounds were similar to those observed in other new office buildings, and the impact of building furnishings and construction activities on the Voc levels were noted. The carbon dioxide levels in the building have generally been low, as would be expected in a building with low levels of occupancy.

Petersen, S. R.

Petersen, S. R. ; Fanney, A. H.

Technical and Economic Analysis of CFC-Blown Insulations and Substitutes for Residential and Commercial Construction. National Institute of Standards and Technology, Gaithersburg, MD

Chapter 4;

Improved Thermal Insulation: Problems and Perspectives, Chapter 4, Technical Publishing Co., Inc., Lancaster, PA, 43-94 p., 1991.

insulation; rigid forms; construction; walls; housing; residential buildings; commercial buildings; economic factors

Rigid foam insulation blown with chlorofluorocarbons (CFCs) are among the most thermally efficient materials available for insulating walls and roofs of buildings. While they are more expensive than traditional insulating materials, their usage were space constraints dictate a more efficient insulator have become commonplace. Increasing concern about the effect of CFCs released to the atmosphere may result in restrictions on the availabiligy of these insulation materials. This report evaluates the thermal performance and economics of rigid foam insulating materials containing CFCs and alternative insulation materials that contain little or no CFC. Residential walls (wood-frame and masonry), commercial wall systems (frame, masonry, and curtain wall) and commercial low-slope roof systems are examined in a wide range of climates in the United States to determine the cost effectiveness of rigid foam insulation materials. Economic substitutes for insulation materials containing CFC exist; however, they are not compatible with all types of wall/window and roof systems and thus may make some wall and roof systems impractical.

Pitts, พ. M.

Pitts, W. M.

Effects of Global Density Ratio on the Centerline Mixing Behavior of Axisymmetric Turbulent Jets. 
National Institute of Standrds and Technology, Gaithersburg, MD

Experiments in Fluids, Vol. 11, 125-134, 1991.

axisymmetric jets; turbulent jets; mixing; light scattering; density effects

Measurements, utilizing Rayleigh light scattering, of

time-averged concentration and unmixedness have been made along the centerlines of axisymmetric turbulent jets formed from six pairs of jet and ambient gases. Jet to ambient density ratios range from 0.14 to 5.11 . Findings are compared with predictions of an approx. similarity analysis and with extensive previous literature measurements. It is shown that virtual origins for plots of inverse time-averaged concentration are strongly dependent on global density ratio. Unmixedness values first grow with increasing distance from the jet source and then achieve an asymptote. The flow distance required to reach this asymptote is a strong function of density ratio.

Pitts, W. M.

Large-Scale Turbulent structures and the Stabilization of Lifted Turbulent Jet Diffusion Flames.

National Institute of Standards and Technology,

Gaithersburg, MD

Combustion Institute, symposium (International) on

Combustion, 23rd. July 22-27, 1990, Orleans, France,

Combustion Institute, Pittsburgh, PA, 661-668 pp, 1991.

combustion; turbulent combustion; jet flames; diffusion

flames; turbulent flames

The physical mechanisms responsible for the stabilization of lifted axisymmetric turbulent jet diffusion flames remain uncharacterized. Flame stabilization has been shown to take place at radial locations in the corresponding isothermal jet where the flow has an intermittent character. Recently developed flow diagnostics capable of simultaneous multi-point concentration and velocity measurements are used to investigate the large-scale turbulent structures in the intermittent region of an isothermal jet of propane. The findings, in conjunction with earlier literature results, show that large-scale structures form as the result of organized turbulent motion during which strong outward ejections of fluid form central regions of the jet flow into the ambient surroundings. Once formed, the large-scale structures are convected downstream for long distances. The downstream edges of the structures are regions of significantly higher concentration gradients and shear than regions further upstream. Occasionally, the jet fluid loses its turbulent energy and is no longer transported by the flow. This fluid can be reentrained by the passage of later large-scale structures. It is concluded that the processes responsible for flame stabilization must occur in these large-scale turbulent structures. Flame extinction is most probable on the downstream edges of the structures while the ignition and stabilization of the flame is likely on the upstream sides. Reentrained fluid provides a possible mechanism for ignition of flammable mixtures on the upstream sides of the structures. 
Pitts, W. M.

Reynolds Number Effects on the Mixing Behavior of

Axisymmetric Turbulent Jets.

National Institute of Standrds and Technology, Gaithersburg, MD

Experiments in Fluids, Vol. 11, 135-141, 1991.

axisymmetric jets; turbulent jets; reynolds number; mixing; entrainment

Measurements of time-averaged jet fluid mass fraction and unmixedness are reported along the centerlines of

axisymmetric jets having Reynolds numbers ( $R e$ ) covering a range of 3,950-11,880. Jet gases investigated are propane, carbon tetrafluoride, and sulfur hexafluoride. The slopes for the fall off of inverse centerline mass fraction with distance are found to be independent of $\mathrm{Re}$ for moderate downstream distances, but virtual origins for the data for shown to move downstream with incresing Re. Unmixedness measurements show that flows with higher Re require longer flow distances to achieve asymptotic behavior. Results of other investigations reported in the literature are discussed which support the conclusions of this work. The relationship between the centerline mixing and entrainment behaviors of these flows is explored.

Pitts, W. M.

wind Effects on Fires.

National Institute of Standards and Technology,

Gaithersburg, MD

Progress in Energy and Combustion Science, Vol. 17, 83-134, 1991.

wind effects; urban fires; mass fires; fire storms; fire research; detonation; fire spread; fire brands; flame

whirls; fire behavior

Urban mass fires are relatively infrequent events which have historically resulted in immense losses of $l i f e$ and property. Mass fires often have occurred as the result of natural disasters or warfare. The development of nuclear weapons has increased the likelihood of urban mass fires due to the high level of thermal radiation generated by a nuclear detonation. There are a large number of wind-fire interactions which are important in the initiation, development and spread of these large fires. Dramatic examples include the extremely high winds and fire whirls which are often generated by such fires. Other effects such as wind-aided fire spread, fire brand spotting, and the effects of the atmospheric turbulent boundary layer can contribute significantly to the growth and behavior of mass fires. In this review characteristics of the two types of mass fire--fire storm and conflagration--are discussed. Brief histories of urban mass fire and research efforts on this topic are given. Models which have been developed to predict the initiation, development, spread, and behavior of mass fires following the detonation of a nuclear device in an urban environment are summarized. The current understanding of the fire processes which are believed to control mass fire behavior are reviewed. Particular emphasis is placed on the wind-fire interactions mentioned in the last paragraph. This discussion forms the basis for 
an analysis of the effectiveness of existing models for mass fire growth and behavior. It is concluded that the understanding of the important physical processes is incomplete and that models for mass fire development and behavior are likely to be subject to large and uncharacterized errors. The possibility of improving our understanding of the underlying physical and chemical processes utilizing reduced-scale experiemnts is assessed. This review is based upon a National Institute of standards and Technology internal report (NISTIR 89-4049, May 1989) entitled "Assessment of Need for and Design Requirements of a wind Tunnel Facility to study Fire Effects of Interest to DNA" which was prepared for the U. S. Defense Nuclear Agency.

Presser, C.

Presser, C.; Gupta, A. K.; Avedisian, C. T.; Semerjian, H. G.

Fuel Property Effects on the structure of Spray Flames. National Institute of Standards and Technology, Gaithersburg, MD

Combustion Institute, Symposium (International) on Combustion, 23rd. July 22-27, 1990, Orleans, France, Combustion Institute, Pittsburgh, PA, 1361-1367 pp, 1991. combustion; sprays; droplet size; fuels; velocity measurement; flame luminosity

The effect of fuel properties on the structure of swirling spray flames has been investigated. Droplet size, number density and velocity measurements have been carried out in pressure-atomized spray flames using phase/Doppler interferometry. Four fuels with different physical properties were studied, namely n-heptane, methanol, 50/50 methanol/1-dodecanol mixture, and kerosene. The results indicate that droplet mean size and velocity are influenced primarily by the fuel viscosity. No detectable trend could be attributed to changes in surface tension. Fuel volatility seems to have some effect on the spray flame structure, especially in the methanol flame. Flame luminosity is found to increase with increasing $\mathrm{C} / \mathrm{H}$ ratio and fuel heating value. Droplet size and velocity distributions near the nozzle are found to be quite broad, and include regions of negative velocities. Some evidence has also been found to indicate the occurrence of microexplosions in the methanol/dodecanol mixture flame.

Puri, R.

Puri, R.; Santoro, R. J.

Role of soot Particle Formation on the Production of Carbon Monoxide in Fires.

Pennsylvania State Univ., University Park

International Association for Fire Safety science. Fire Safety science. Proceedings. 3rd International symposium. July 8-12, 1991, Edinburgh, Scotland, Elsevier Applied Science, New York, Cox, G.; Langford, B., Editors, 595-604 pp, 1991.

fire research; fire safety; fire science; soot formation; carbon monoxide; diffusion flames; laminar flames 
A systematic study of the effects of soot formation on the production of carbon monoxide (CO) in laminar diffusion flames has been conducted. Increased amounts of soot have been observed to result in larger concentrations of $c o$ in the higher regions of the flames. Comparisons of $\mathrm{Co}$ state relationships as a function of local equivalence ratio show distinct effects as the local soot volume fraction is varied. Fuel rich regions exhibit lower co mole fractions as soot concentration increases, whereas higher co mole fractions are observed under fuel lean conditions. Radiativ quenching and competition between soot and $C O$ for $O H$ are examined. Competition for $O H$ is a plausible mechanism that can be responsible for the high $\mathrm{CO}$ emissions from fires.

Radiative quenching does not seem to play a significant role in fuel rich regions but can be important under fuel lean conditions.

\section{quintiere, J. G.}

Quintiere, J. G.

Transfer of Fire Research Into Practice.

Maryland Univ., College Park

Worcester Polytechnic Institute. Firesafety Design in the 21 st Century, Conference. May 8-10, 1991, Worcester, MA, 1-15 pp, 1991 .

fire research; fire protection engineering; fire protection; combustion; fluid flow; heat transfer; toxicity; tenability limits; people movement; human behavior; systems analysis; fire suppression

A discussion is presented of the role of research in the evolution of fire protection engineering. Views are presented on the status of fire protection in terms of its scientific components and the availability of analytical tools. It is concluded that the SFPE Handbook of Fire Protection Engineering is a significant transfer function for bringing research into practice, but that textbooks are also needed for effective education. Barriers to the effective transfer of research into practice are the lack of a sufficient research effort to continue to advance the knowledge base for fire protection engineering, and the adherence to the traditional prescriptive practices of the field.

Raufaste, N. J.

Raufaste, N. J.

NIST SP 820; September 1991.

U. S./Japan Natural Resources Development Program (UJNR) . Wind and Seismic Effects. Joint Meeting of the U. S./Japan Cooperative Program in Natural Resources Panel on Wind and Seismic Effects, 23rd. May 14-17, 1991, NIST SP 820 , Tsukuba, Japan, Raufaste, N. J., Editor, 636 pp, 1991. Available from Government Printing office

accelerograph; bridges; buildings; concretes; design criteria; disasters; disaster reduction; earthquakes; geotechnical engineering; ground failures; lifelines; liquefaction; masonry; repair and retrofit; risk assessment; seismic; soils; standards; storm surge; structural engineering; tsunamis; wind loads 
This publication is the proceedings of the 23 rd Joint Meeting of the U. S.-Japan Panel on Wind and Seismic Effects. The meeting was held at the Public Works Research Institute, Tsukuba, Japan, from May 14-17, 1991. The proceedings include the program, list of members, panel resolutions, task committee reports, and 42 technical papers. The papers were presented under seven themes: Wind Engineering, (II) Earthquake Engineering, (III) storm Surge and Tsunami, (IV) Joint Cooperative Research Program, (V) Performance of Nonstructural systems, (VI)

International Decade for Natural Disaster Reduction, and (VII) Summaries of Task Committee Workshop Reports (oral presentations only).

Raufaste, N. J.

Building and Fire Research Project Summaries 1991.

National Institute of Standards and Technology,

Gaithersburg, MD

NISTIR 4582; 154 p. June 1991.

Available from National Technical Information Services

PB91-216788

building controls; building research; coatings; combustion;

flammability; computer integrated construction; concretes;

earthquake engineering; fire dynamics; fire hazard; fire

physics; fire safety; heat and moisture transfer; indoor air

quality; lighting; quality assurance laboratories;

refrigeration; smoke dynamics; structural performance;

suppression; test procedures; toxicity

In early 1991, as part of an agency-wide reorganization, the National Institute of standards and Technology (NIST)

created the Building Technology and Fire Research Laboratory (BFRL) by merging its Centers for Building Technology and Fire Research BFRL's mission is to increase the usefulness, safety, and economy of constructed facilities, and reduce the human and economic costs of unwanted fires in buildings. This report summarizes BFRL's research for 1991. The report is arranged by its research programs: structural engineering, materials engineering, mechanical and environmental systems, fire science and engineering, and fire measurement and research. Each summary lists the project title, its research, the BFRL point of contact, sponsor, and results.

Rehm, R. G.

Rehm, R. G.; Baum, H. R.; Lozier, D. W.; Tang, H. C.; Sims, J. S.

Buoyant Convection in an Inclined Enclosure.

National Institute of Standards and Technology,

Gaithersburg, MD

International Association for Fire safety science. Fire Safety science. Proceedings. 3rd International symposium. July 8-12, 1991, Edinburgh, Scotland, Elsevier Applied

Science, New York, Cox, G.; Langford, B., Editors, 313-323 pp, 1991.

fire research; fire safety; fire science; boussinesq approximation; convection; fluid dynamics; finite difference theory; enclosures 
Equations for a Boussinesq model describing transient buoyant convection driven by a heat source in a rectangular enclosure are presented and solved by finite difference methods. Gravity is allowed to have an arbitrary direction relative to the enclosure so that the enclosure is inclined to horizontal. Computational results for three-dimensional dissipation-free flows and for two-dimensional flows with and without dissipation are presented. The hydrodynamics is based directly on the time-dependent Euler or Navier-stokes equations. No turbulence model or other empirical

parameters are introduced. The previous algorithms had been verified by comparisons with exact solutions to the equations in simple, special cases, and overall predictions of the model when the viscosity and thermal conductivity are zero have been compared with experimental results. The use of Lagranagian particle tracking allows one to visualize the flow patterns. The effects of a fire-induced flow in a corridor, and a stair well (or escalator) are examined.

Rehm, R. G.; Tang, H. C.; Baum, H. R.; Sims, J. S.; Corley, D. M.

Boussinesq Algorithm for Enclosed Buoyant Convection in Two Dimensions.

National Institute of Standards and Technology, Gaithersburg, MD

NISTIR 4540; 39 p. March 1991.

Available from National Technical Information Services

PB91-178848

algorithm; Boussinesq flow; computational fluid dynamics; gravity currents; stratified flow; trench effect

Approximate equations for a Boussinesq model with viscous dissipation and thermal conduction describing buoyant convection driven by a heat source in rectangular enclosure are derived. The finite-difference algorithm for computing transient solutions in two dimensions to these equations is presented. The algorithm allows the enclosure fluid to be stratified in a direction parallel to the enclosure walls initially, or for gravity to have an arbitrary direction relative to the enclosure (but with no initial

stratification). Computational results of transient, two-dimensional buoyant convection for very high resolution are presented. The hydrodynamics is directly based on the time-dependent Navier-stokes equations; the model is valid in the Boussinesq approximation. No turbulence model or other empirical parameters are introduced. There is no inflow or outflow at boundaries; this assumption, although rather restrictive, allows the mathematical problem to be properly formulated so that no other empiricism is introduced by specification of the algorithmic boundary conditions. A finite-difference scheme second-order in space and first-order in time is used to integrate the evolution equations, and an elliptic solver is used to solve the pressure equation. The algorithms have been verified by comparisons with exact solutions to the equations in simple, special cases, and predictions of the overall model when the viscosity and thermal conductivity are zero have been compared with experimental results. The use of Lagrangian particle tracking allows one to visualize the flow patterns. 
Robins, I. H.

Robins, L. H.; Tjossem, P. J. H.; Smyth, K. C.; Barnes, Y.;

Farabaugh, E. N.: Feldman, A.

Photoluminescence Excitation by Band-Gap Optical Absorption

in Chemical Vapor Decompositon Diamond Films.

National Institute of standards and Technology,

Gaithersburg, MD

Journal of Applied Physics, Vol. 69, No. 6, 3702-3708,

March 15, 1991.

vapors; films; luminescence

Photoluminescence excitation (PLE) spectra at photon

energies near the indirect band gap of diamond have been

obtained for diamond films grown by the filament-assisted

chemical vapor deposition (CVD) method. The PLE intensity

was observed to increase abruptly with photon energy above

$5.5 \mathrm{eV}$. This increase coincides with the onset of

phonon-emission-assisted interband absorption, which was

observed independently by diffuse transmittance

measurements. A lower-energy PLE threshold at approx. 5.25

$\mathrm{eV}$, which coincides approximately with the onset of

phonon-absorption-assisted interband absorption, was

observed in the spectrum of a gem-quality natural diamond,

but not in the spectra of the CVD-grown filsm. Emission

spectra of the luminescence excited by above-band-gap

photons have features similar to luminescence spectra of the

same specimens excited by $20-\mathrm{keV}$ electrons. The spectrally

integrated intensities of the luminescence excited by

above-band-gap photons and by electrons were found to vary

from specimen to specimen in a linearly related manner, suggesting that similar recombination processes occur in both cases.

Roby, R. J.

Roby, R. J.; Beyler, C. L.

Compartment Fire Combustion Dynamics. Annual Report. August

1, 1989-August 1, 1990.

Virginia Polytechnic Institute and state University,

Blacksburg, VA

Hughes Associates, Wheaton, MD

NIST-GCR-91-588; 39 p. May 1991.

Available from National Technical Information Services

PB92-156744

compartment fires; hexanes; polymethylmethacrylate;

polyurethanes; smoke generation; species concentrations;

toxic gases; wood

The interim findings of a planned three-year experimental

investigation are summarized. The investigation is designed

to determine the effect of realistic compartment fire flows

on species production rates and their correlation with

equivalence ratio and to establish major toxic gas and smoke generation rates for important fuels such as PMMA, wood and TDI-based polyurethane. The apparatus for the measurements is described and findings for a series of hexane fires over a range of equivalence ratio are described. Preliminary measurements using PMMA-fueled fires are also included. 
Roby, R. J.; Beyler, C. I. Compartment Fire Combustion Dynamics. Final Report. June 1 , 1988-September 1, 1991.

Virginia Polytechnic Institute and state University, Blacksburg, VA

Hughes Associates, Wheaton, MD

Final Report; 49 p. 1991.

compartment fires; hexanes; polymethylmethacrylate;

polyurethanes; smoke generation; species concentrations;

toxic gases; wood

A three year study has been completed which experimentally

(1) determined the effect of a realistic compartment fire

flows on species generation rates and their correlation with equivalence ratio, (2) established major toxic gas and smoke generaton rates for important fuels such as PMMA, wood and TDI-based polyurethane, and (3) determined the efficiency of external flames in destroying major toxic gses produced within the compartment under oxygen deficient compartment fire combustion. The apparatus that was used for this investigation includes a $1.2 \mathrm{~m} \times 1.2 \mathrm{~m} \times 1.5 \mathrm{~m}$ compartment with two ventilation paths; a normal window style exhaust vent, and a ducted air inlet vent. Separation of the two flows allows a relatively simple measurement of the air inflow, while leaving the exhaust flow dynamics undisturbed. Exhaust from the compartment is collected by a hood system

instrumented to allow the measurement of gas and smoke generation rates. This system allows direct measurement of air and fuel supply rates as well as speies generation rates. Correlations were developed between upper layer species yields and plume equivalence ratios and compared to correlations obtained for upper layers developed in an open hood. The study shows that the correlations developed for species yeilds in hood apparatus are qualitatively valid, but differ significantly from the correlations obtained for more realistic compartment fire environments. The work has shown that upper layer species yields in realistic

compartment fires are fairly independent of fuel but highly dependent on the fire dynamics; the ratio of the burning rate to the air entrainment rate (ie. the quivalence ratio) and the upper layer temperature. Simple equations are proposed for correlating the combustion efficiency and the major species yields with the plume equivalence ratio for two-layer compartment fires. The effect of external burning on $\mathrm{CO}$ and smoke yields from compartment fires was also investigated. A window-style exhaust vent was used for the external burning experiments and species yields were measured in the exhaust duct downstream of the compartment. The yields measured downstream of the exhaust vent were compared to yields measured in the compartment upper layer for similar fires. External burning of fuel rich exhaust gases significantly reduces the co yield to below life threatening levels. Fires with steady-state, average plume equivalence ratios greater than 2 were always observed to have sustained external burning.

Rosasco, G. J.

Rosasco, G. J.; Bowers, W. J., Jr.; Hurst, W. S.; Looney, J. P. : Smyth, K. C.; May, A. D. 
Simultaneous Forward-Backward Raman Scattering studies of D2 Broadened by D2, He, and Ar.

National Institute of standards and Technology,

Gaithersburg, MD

Toronto Univ., Ontario, Canada

Journal of Chemical Physics, Vol. 94, No. 12, 7625-7633,

June 15, 1991.

scattering coefficient; beams

Unavoidable beam crossings within a spherical-mirror,

multipass simulated Raman gain cell give rise simultaneously

to forward- and backward-scattering Raman signals. In the

Doppler-broadened/Dicke-narrowed regime of density, the

lineshape is a function of the momentum transfer in the scattering process and thus the observed spectra will have more complex lineshapes than those seen with simple forward or backward scattering geometries. The analyses necessary to quantitatively account for such forward-backward spectra are summarized. These spectra enable unique experimental tests of the lineshape functions used for the description of the Raman Q-branch spectrum under conditions. Where Doppler contributions and Dicke narrowing are significant. Results for the D2:D2 and D2:He systems support the well-known

Galatry, or soft collision, lineshape function. However, in the case of D2:Ar, our results suggest the need to employ the more general, complex soft collision function. In addition, these studies have provided data on linear-with-density line broadening coefficients (previously published) and line shifting coefficients (reported here) for these molecular systems.

Rosen, H. N.

Rosen, H. N.: Martin, J. W.

Sorption of Moisture on Epoxy and Alkyd Free Films and Coated steel Panels.

National Institute of standards and Technology,

Gaithersburg, MD

Journal of Coatings Technology, Vol. 63, No. 792, 85-93, January 1991.

films; steel panels; coatings; sorption; moisture; epoxy resins; equilibrium

sorption isotherm curves at $23 \mathrm{deg} C$ were determined for alkyd and epoxy free films and coated steel panels as well as for alkyd "pocket" panels, consisting of an unadhered free film surrounding and enclosing the steel panel. The isotherms consist of an increasing linear portion to about $75 \%$ relative humidity $(\mathrm{RH})$, followed by a rapidly rising nonlinear portion to $100 \% \mathrm{RH}$. A model assuming weak bonding forces between the paint film and water with microvoid condensation at high $\mathrm{RH}$ gave an excellent fit to the data. Transient sorption data on the approach to equilibrium conditions showed differences between alkyd and epoxy coatings. For alkyd films, surface boundary layer resistance was significant and sorption followed a Fickian model. For the epoxy coating, surface resistance was not significant and moisture movement was non-Fickian. 
Rossiter, W. J., JI.

Rossiter, W. J., Jr.

Data on Polymer-Modified Bitumen Membrane Materials. Letter Report.

National Institute of Standards and Technology, Gaithersburg, MD

Letter Report; 19 p. 1991.

bitumens; membranes: test methods; thermogravimetric analysis; thickness; tensile strength; elongation; strain energy; tear resistance; moisture content; low temperature: static puncture tests; dynamic puncture tests: coatings Modified Bitumen Test Specimens: Sample A: A two-ply composite consisting of a modified bitumen top sheet adhered by torch welding to a glass fiber base sheet. The two piles could not be readily delaminated, and consequently, the tests were generally conducted on the composite. An exception was the 2-year old sample which contained no base sheet when removed from the roof. This sample was then tested as a single-ply sheet. Sample B: A two-ply composite consisting of a modified bitumen top sheet adhered with hot air-blown asphalt to a glass fiber base sheet. The two plies could be readily delaminated, and consequently, the tests were conducted on the modified bitumen sheet alone. Sample c: A single-ply modified bitumen sheet that contained a spary-applied protective coating. The coating could note be readily removed from the modified bitumen sheet, and consequently, the tests were conducted on the modified bitumen with the coating in place. Rossiter, W. J., Jr.; Frohnsdorff, G.; Masters, L. W.:
Martin, J. W.

Performance Approach to the Development of Criteria for Low-Sloped Roof Membranes.

National Institute of Standards and Technology,
Gaithersburg, MD

NISTIR 4638; $\quad 36$ p. July 1991.

Available from National Technical Information Services PB

evaluation; low-sloped roofing; membranes; performance criteria; requirements: roof functions; roofs; seams; test methods; watertightness

This report outlines a performance approach for developing criteria for the selection and use of membranes in low-sloped roof applications. An overview of previous efforts for applying the performance approach to membrane roofing is also given. A fundamental aspect of the performance approach is that selection criteria are based on an understanding of the requirements necessary for the membrane system to perform acceptably in service. The availability of performance-based criteria would greatly assist in eliminating some of the defects that have plagued low-sloped roofing over the years. The approach consists of seven steps including identification of the key functions to be performed by a roof, identification of attributes essential to satisfactory performance, development of the requirements, criteria, and test methods, and putting in place a feedback mechanism to revise the criteria, if warranted, as new information becomes available on the performance of the system in service. Five key functions 
associated with the performance of the membrane in a low-sloped system are identified, and performance requirements for each function are proposed. These functions are watertightness, maintainability, health and safety, environmental impact, and appearance. of these five functions, watertightness is the one that directly affects the major problem (i.e., leaks) associated with low-sloped roof performance. As a consequence, the majority of the requirements recommended for membrane systems in past studies, as well as in the present report, emphasize this aspect of performance. It is recognized that considerable effort may be needed to develop criteria and test methods for the complete set of attributes. Consequently, the initial work should focus on those attributes of membrane roofing that have been associated with the most problems. Review of data from NRCA's Project Pinpoint indicated that seam defects in single-ply membranes have been the problems most frequently enountered for these types of roof systems. On this basis, it is further suggested that the application of the performance approach to membrane roofing begin with the subject of seams. As an initial step in this direction, an outline of the needed criteria is presented including attributes and suggested requirements. The development of criteria and test methods are reserved for future study.

Rossiter, W. J., Jr.; Nguyen, T. Cleaning of Aged EPDM Rubber Roofing Membrane Material for Patching: Analytical Techniques for Surface Characterization. National Institute of Standards and Technology, Gaithersburg, MD

NISTIR 4525; 22 p. February 1991.

Not Available from National Technical Information Services aged EPDM membrane; cleaning methods; contact angle; FT-IR; roofs; patching; roofing; scanning electron microscopy; seams; surface analysis; surface preparation methods; wettability

Proper seam formation is a critical parameter associated with the long-term performance of ethylene-propylene-diene terpolymer (EPDM) roofing systems. As time passes and the membrane weathers in service, patches and splices to an EPEM surface may be needed. A concern raised regarding the performance of EPDM roofing is whether weathering alters the rubber's surface characteristics such that successful bonding of the aged material becomes more difficult than with unaged rubber. This report describes the results of the preliminary phase of a study to investigate surface analysis techniques for ascertaining whether the surface of aged EPDM rubber is properly cleaned before patches are bonded to it. The intent of the investigations was to develop experimental procedures applicable to EPDM rubber based on existing analytical methods. The surface analytical techniques investigated were: 1) scanning electron microscopy, 2) electron probe microanalysis, 3) Fourier transform infrared spectroscopy, and 4) contact àngle (wettability) measurement. of the four methods, scanning electron microscopy, Fourier transform infrared

spectroscopy, and contact angle measurement were found to be 
useful for general laboratory analysis of EPDM rubber sheets. Experimental procedures were developed for this purpose. In the case of electron probe microanalysis, it was found that the technique offered little information thai could not be obtained by SEM analysis, unless it is desired to identify the elemental composition of the surface contaminants. Based on the results of the preliminary-phast investigations, it was recommended that research be continued on the application of the experimental procedures to analyze aged EPDM surfaces and to determine the effectiveness of different cleaning methods for removing surface contamination.

Rossiter, W. J., Jr.; Nguyen, T.; Byrd, W. E.; Seiler, J. F., Jr.; Lechner, J.A. Cleaning of Aged EPDM Rubber Roofing Membrane Material for Patching: Laboratory Investigations and Recommendations. National Institute of Standards and Technology,

Gaithersburg, MD

NISTIR 4544; 64 p. March 1991.

Not Available from National Technical Information Services aged EPDM membranes; cleaning methods; contact angle; creep rupture; FT-IR; low-sloped roofs; peel strength; roofing; scanning electron microscopy; seams; surface analysis: surface preparation methods; wettability

This study assessed the relative effectiveness of different surface cleaning methods used for preparing the surface of aged EPDM membranes for patching, and recommends procedures for use in the field. The effectiveness of the methods was evaluated using tests of short-term strength and long-term creep rupture in peel, and surface analytical techniques, namely, scanning electron microscopy (SEM), Fourier transform infrared (FTIR) spectroscopy, and contact angle measurements. A section of an aged, ballasted EPDM membrane, sampled from a roof after 10 years in service, was used in the study. The majority of the cleaning methods evaluated was selected based on a review of procedures used in the field to prepare the surface of aged EPDM rubber before patching. Cleaning the aged EPDM rubber surface removed the bulk of the contaminants and resulted in an increase of the exposed surface area of the EPDM rubber. This resulted in a decrease in the rubber's wettability by water, and a concomitant gain in the peel strengths of joints made with the cleaned rubber. All cleaning methods used in the study provided aged EPDM rubber surfaces that formed joints having peel strengths comparable to those of seams formed in the field between solvent-based adhesives and new EPDM rubber. Short-term strength and creep-rupture joints, prepared by tape-bonding the surface of

heptane-cleaned aged EPDM to a surface of well-cleaned new EPDM, failed at the interface between the tape and the new rubber. But, no relationships betwen contact angle and cleaning method were found. In particular, the contact angles measured using methylene iodide varied only slightly as a function of cleaning method. The FTIR technique could distinguish the uncleaned surface of the aged EPDM from those which were well-cleaned and/or coated during cleaning. No major differences between the FTIR spectra of the 
specimens cleaned using the various methods were observed. SEM analysis was the only technique that distinguished particle-free surfaces from those which retained particles after cleaning. The rate of spreading of dimethyl formamide (DMF) droplets on the surface of the aged EPDM rubber was found to relate to the degree of surface cleanness. Based on the results of this laboratory study on cleaning a section of an aged EPDM rubber membrane, it was conclued that such membrane materials may be suitably cleaned for patching. It was recommended that: (1) a number of cleaning methods may be used to prepare the surface of aged EPDM rubber membrane material before patching, and (2) the change in size over time of a droplet of DMF, placed on the aged EPDM rubber after cleaning, be used for preliminary assessment of the condition of the cleaned surface.

Rothfleisch, P.

Rothfleisch, P.; Didion, D. A.

Performance Evaluation of a Variable speed, Mixed

Refrigerant Heat Pump.

National Institute of Standards and Technology,

Gaithersburg, MD

NISTIR 4597; 58 p. June 1991.

Available from National Technical Information Services

PB92-143759

air conditioning; distillation; heat pumps; refrigerant

mixtures; refrigeration; zeotropic refrigerants

The performance of an innovative heat pump, equipped with a distillation column to shift the composition of a zeotropic refrigerant mixture, was evaluated. The results of the DoE rating tests and seasonal energy calculations are reported with the main cycle refrigerant compositions. No composition shifting of the circulating refrigerant mixture was observed. To demonstrate the potential value of composition shifting, an ideal vapor compression cycle computer program was used to predict what the system performance would have been had composition shifting occurred. Seasonal energy usage calculations based on the computer predictions demonstrated that the effect of composition shifting on HSPF was very small, increasing slightly with climate zone. However, the savings in auxiliary heat was found to be substantial. In cooling mode, computer predictions showed pure R2 2 to have a SEER approximately two percent higher than a mixture of $20 \%$ R131B1 and $80 \%$ R22 by weight.

Rubin, A. I.

Rubin, A. I.

Daylight Research Requirements--Workshop Proceedings.

National Institute of Standards and Technology,

Gaithersburg, MD

NISTIR 4639; 64 p. July 1991.

Available from National Technical Information Services

PB91-231563

building design; building fenestration; computer models;

daylight control; daylight delivery systems; daylight

design; energy savings; scale models; technolgoy 
This report summarizes the activities conducted at a workshop in Baltimore, Maryland during August 1990. The workshop was sponsored by the Electrical Power Research Institute and the Lighting Research Institute. Its purpose was to identify a research agenda concerned with daylight and energy use in buildings. The report contains a summary of the workshop proceedings, background papers, and a list of recommended research projects.

Rubin, A. I. Intelligent Building Technology in Japan. National Institute of Standards and Technology, Gaithersburg, MD

NISTIR 4546; 68 p. April 1991.

Available from National Technical Information Services PB91-187757

building systems; building technology; intelligent buildings; Japanese buildings; office automation

In May 1990, the author of this report visited Japan at the request of the Department of Commerce's Japan Technology Program, to assess Japanese experiences with 'intelligent building' design, construction and use. The state-of-the-art was determined by visiting advanced buildings, building complexes, and interviewing architects, engineers, and researchers and academics. Discussions also were conducted with organizations engaged in promoting the use and design of intelligent buildings. In general, Japanese experiences have paralleled those in the United states. In both countries, advanced building technologies have been employed to advance organizational effectiveness and personal productivity. A major problem shared by the two countries has been the lack of standardization of hardware and software (protocols), resulting in major difficulties in integrating equipment from different manufacturers, and in some instances, diverse products from the same manufacturer. Intelligent building design in Japan differs from that in the United States in several ways. They incorporate new systems and products into their buildings as soon as they become available. They stress the need for a high quality environment - amenity - more than the United states. The commitment for developing improved intelligent buildings includes active governmental involvement by two major ministries and other institutions such as banks.

Rubin, A. I.; Saraiji, R.; McCluney, R. : Huggins, M.; Emrich, C. Abstracts of Daylighting Research. National Institute of Standards and Technology, Gaithersburg, MD Florida Solar Energy Center, Cape Canaveral, FL NISTIR 4578; 119 p. May 1991. Available from National Technical Information Services PB91-206755

computer models; daylight; daylight design tools; energy savings design; fenestration; glare; response to light; scale models; sunlight delivery systems; daylight delivery systems 
This report is an annotated bibliography of Daylight research and practices. It is a compilation of two draft bibliographies, one compiled by the Florida solar Energy Center, and the other by the National Institute of standards and Technology. Both were the result of research projects conducted for the Electrical Power Research Institute. The topics covered are as follows: general treatments of daylight, energy saving design, research and design tools, control systems, computer, scale, and mathematical models, skylight research and applications, atria, fenestration systems and materials, shading devices, delivery systems--daylight and sunlight, and finally, the responses of people to light.

Santoro, R. J.

Santoro, R. J.

Fundamental Mechanisms for $\mathrm{CO}$ and Soot Formation in

Diffusion Flames. Annual Progress Report. May 1, 1990-June 30, 1991 .

Pennsylvania State Univ., University Park, PA

Annual Progress Report; 41 p. 1991.

diffusion flames; carbon monoxide; soot formation; hydroxyl radicals; sampling; laminar flames; probes

The following report summarizes the research efforts during the grant period May 1, 1990 through June 30, 1991 for the grant 60NANBOD1035, entitled "Fundamental Mechanisms for CO and Soot Formation in Diffusion Flames". This report also encompasses the progress during the fourth quarter of the grant and will serve as a quarterly report for that period as well. During the pase year, efforts have emphasized several areas including: (1) the mechanism of $C O$ formation and destruction in the presence of soot particles, (2) measurements of $\mathrm{CO}$ concentrations in underventilated diffusion flames, (3) measurements of hydroxyl radical concentrations in overventilated laminar diffusion flames in the presence of soot particles and (4) the development of a series of sampling probe techniques for obtaining some of the necessary measurements in these soot laden flames. In the following sections, progress made in each of these areas will be summarized. Since in some cases publications or papers in preparation for submission to journals have resulted, these are included as appendices and provide additional details.

\section{Schaenman, P.}

Schaenman, P.

Estimated Impact of the Center for Fire Research Program on the costs of Fire.

Tridata Corp., Arlington, VA

Fire Technology, Vol. 27, No. 4, 346-349, November 1991. NIST-GCR-91-591; 82 p. June 1991.

Available from National Technical Information Services PB91-217422

building codes; building design; costs; economic factors; fire detection; fire losses; fire models; fire research; fire suppression; fire tests; toxicity 
The Center for Fire Research (CFR) has had a huge impact on reducing casualties and losses from fires. It also has helped stimulate new industries, and saved industry enormous sums by engineering fire safety better, averting business disruption, reducing liability, and in a number of other ways. The dividends of the past continue; CFR's budget essentially has been "paid" through the Year 2100 by even the most conservative estimates of its impact. This was a first, brief effort to estimate the magnitude of the CFR impact, and how it is distributed across the major components of the total cost of fire. More work is needed on virtually every aspect of the estimation procedures used here. CFR's program has made a great contribution to life safety in the United states and has saved business billions of dollars in losses and unnecessary costs of fire. A much greater impact can be achieved with a few millions of dollars more investment in the CFR program each year--the enhanced program.

\section{silberstein, s.}

silberstein, s.

Proposed Standard Practice for Assessing the Performance of Gas-Phase Air Cleaning Equipment.

National Institute of Standards and Technology, Gaithersburg, MD

NISTIR 4523; 22 p. March 1991.

Available from National Technical Information Services

PB91-167353

activated carbon; gaseous contaminant removal equipment; air cleaning equipment; air contaminant; filter media; sorption

This proposed standard practice provides a general and flexible laboratory method for assesing the performance of equipment for controlling indoor concentrations of gas-phase air contaminants. Using a canister filled with adsorption media, a profile of breakthrough concentration over time is obtained during each test conducted at a fixed contaminant challenge concentration. Results of tests performed for different contaminants and different challenge concentrations can be used for estimating the useful life of air cleaning equipment, and for comparing equipment. This information will be useful to the engineer for the design and selection of such equipment.

Simiu, E.

Simiu, E.: Cook, G. R.

Chaotic Motions of Self-Excited Forced and Autonomous square Prisms.

National Institute of Standards and Technology, Gaithersburg, MD

Journal of Engineering Mechanics, Vol. 117, No. 2, 241-259, February 1991.

prisms; oscillators; equations; qualitative behavior;

numerical analysis

The motion of oscillators governed by the standard equations for the aerodynamic galloping of square prisms is studied

for two cases: a harmonically forced, single elastically mounted bar immersed in a uniform flow, and an autonomous, 
elastically coupled pair of such bars. It is shown that the behavior of the forced oscillator has similaritiesd to the behavior of the standard circle map. Thus it is possible to describe how locked-in oscillatory forms are organized within the forcing amplitude/frequency parameter space and to identify transitions from quasiperiodicity to chaos and turbulent intermittencies. For the coupled pair of oscillators, two stable attractors were identified on which the orbits are topologically similar, respectively, to the two normal modes of the associated linear system. Depending upon the system parameters, one of the attractors contains orbits that may be periodic, quasiperiodic, or chaotic.

Beyond a critical flow velocity this attractor vanishes. For the other attractor, only periodic orbits were identified. This work is the first stage of a numerical and experimental investigation aimed at assessing the potential role of chaotic dynamics in bluff body fluid elasticity, with a view to application in ocean engineering.

Simiu, E.; Cook, G. R.; Alibe, B. Algebraic Approximation of Attractors for Galloping Oscillators.

National Institute of Standards and Technology, Gaithersburg, MD

Journal of Sound and Vibration, Vol. 146, No. 1, 170-175,

1991.

oscillators; equations; numerical analysis

A constructive method for approximating attractors was recently developed in reference [1], where it was applied to systems with non-linearities due to bilinear operators. The purpose of this letter is to test the practical applicability of the method to autonomous galloping oscillators $[2,3]$, in which non-linearities are due to seventh degree polynomials. We summarize relevant results of reference [1], and give revised versions for two expression presented in reference [1] for approximating attractors and estimating approximation errors. We apply those results to galloping oscillators, and compare results obtained by algebraic approximation and by numerical integration. We tentatively assess some practical aspects of the method as applied to our systems.

Simiu, E.; Cook, G. R.; Alibe, B.

Chaotic Motions of Coupled Galloping Oscillators and Their Modeling as Diffusion Processes.

National Institute of Standards and Technology,

Gaithersburg, MD

Morgan State Univ., Baltimore, MD

CERRA, International Association for Civil Engineering Reliability and Risk Analysis. Applications of Statistics and Probability in Civil Engineering, 6th International Conference. CERRA-ICASP 6. 1991, Mexico City, Mexico, Esteva, L.; Ruiz, S. E., Editors, 993-1000 pp, 1991. oscillators; chaotic motions; diffusion processes; failure; equations; numerical analysis; tests

According to numerical investigations recently reported in the literature, certain types of compliant offshore 
structures may experience undesirable hydroelastic responses, including chaotic responses. The question arises whether such responses can be predicted reliably by using current fluidelastic models. We addressed this question in the specific case of a paradigmatic, strongly nonlinear hydroelastic oscillator consisting of two elastically restrained and coupled square prisms immersed in a uniform flow. Experiments showed that beyond a critical flow velocity the oscillator exhibits strongly chaotic behavior. Extensive numerical simulations suggest that by using conventional fluidelastic models the observed chaotic motions can be described qualitatively, at lease in certain instances; however, the windows of deterministic chaos, if they exist, are quite narrow, so that those motions cannot in general be predicted reliably. It is then shown that modeling the hydroelastic system as a nonlinear diffusion process helps to improve substantially the reliability of the predictions.

\section{Sivathanu, $\mathbf{Y} . \mathbf{R}$.}

Sivathanu, Y. R.; Kounalakis, M. E.; Faeth, G. M.

Soot and Continuum Radiation statistics of Luminous

Turbulent Diffusion Flames.

Michigan Univ., Ann Arbor

Combustion Institute, Symposium (International) on

Combustion, 23rd. July 22-27, 1990, Orleans, France,

Combustion Institute, Pittsburgh, PA, 1543-1550 pp, 1991.

combustion; soot; turbulent flames; diffusion flames;

luminous flames; statistics; propylene

The statistics of soot and spectral radiation intensities in the continuum were measured for horizontal radiation paths through the axis of highly-buoyant propylene flames burning in still air. Radiation statistics were also analyzed using a stochastic simulation of soot properties that matched soot statistics along the radiation path. Predictions and measurements of radiation statistics were generally in good agreement, aside from difficulties in predicting spikes of measured PDF's and temporal power spectra due to release of coherent structures near the source for low burner Reynolds numbers. Radiation fluctuation intensities up to 100 percent were obseved while temporal power spectra decayed proportional to the $-5 / 3$ power of frequency at high frequencies, suggesting strong turbulence/radiation interactions and a close relationship between turbulent mixing and continuum radiation statistics in turbulent flames.

Skelly, M. J.

Skelly, M. J.

Experimental Investigation of Glass Breakage in Compartment Fires.

Virginia Polytechnic Institute and State Univ., Blacksburg Journal of Fire Protection Engineering, Vol. 3, No. 1, $25-34,1991$.

NIST-GCR-90-578; $91 \mathrm{p}$. June 1990.

Available from National Technical Information Services 
PB90-244443

glass; compartment fires; windows; building fires; fire

tests: radiant heating

An experimental investigation has been completed which

studied the breaking of window glass by fire. The

experiments were carried out in a specially designed

compartment to achieve two-layer flows characteristic of

normal building fires. The experimental data was collected

from two test groups: the first for windows with their edges insulated from the fire (edge-protected) and the second for windows uniformly heated by the fire

(edge-unprotected). The results of the edge-protected

window tests indicated that the glass breakage was caused by a critical temperature difference between the central heated portion of the pane and the glass edge. The experimental work showed the critical value to be approximately $90 \mathrm{C}$. After the material properties of the glass were determined, the theoretical findings of Keski-Rahkonen were used to obtain a value of $70 \mathrm{C}$; the difference attributed to radiative heating. The test results also demonstrated a distinctive loss of integrity by the windows. When breakage occurred, the cracks spread throughout the glass, joined together and caused at least partial collapse of the pane. The results from the edge-unprotected window tests were quite different. There were relatively few cracks developed and almost no propagation across the glass. Consequently, there was no window collapse in any of these cases. The breakage did initiate at a consistent glass temperature value, however, the mechanism for these tests is not known.

Smith, R. I.

Smith, R. L.; Kashiwagi, T.

Expert Systems Applied to Spacecraft Fire Safety. Contractor

Report. Final Report.

National Institute of Standards and Technology,

Gaithersburg, MD

Journal of Applied Fire Science, Vol. 1, No. 2, 103-113, 1990-1991.

NASA CR-182266; NAS 1.26:182266; 12 p. June 1989.

Available from National Technical Information Services

PB89-231013

N89-23501

expert systems; artificial intelligence; spacecraft; space stations; fire detection; fire extinguishers; fire safety

Expert systems are problem-solving programs that combine a knowledge base and a reasoning mechanism to simulate a human "expert." The development of an expert system to manage fire safety in spacecraft, in particular the NASA Space Station Freedom, is difficult but clearly advantageous in the long-term. The report discusses some needs in low-gravity flammability characteristics, ventialting-flow effects, fire detection, fire extinguishment, and decision models, all necessary to establish the knowledge base for an expert system. 
Smyth, $\mathbf{K} . \mathbf{C}$.

Smyth, K. C. : Tjossem, P. J. H.

Relative $\mathrm{H}$-Atom and $\mathrm{O}$-Atom Concentration Measurements in a

Laminar, Methane/Air Diffusion Flame.

National Institute of Standards and Technology,

Gaithersburg, MD

Combustion Institute, Symposium (International) on

Combustion, 23rd. July 22-27, 1990, Orleans, France,

Combustion Institute, Pittsburgh, PA, 1829-1837 pp, 1991. combustion; diffusion flames; concentration measurement; laminar flames; methane; air

Relative $\mathrm{H}$-atom and o-atom concentration profiles have been measured in a laminar, co-flowing methane/air diffusion flame burning at atmospheric pressure. Multiphoton ionization $(2+1$ process at $243 \mathrm{~nm})$ has been used to detect $\mathrm{H}$ atoms, while laser-induced fluorescence at $845 \mathrm{~nm}$ excited by two-photon absorption at $226 \mathrm{~nm}$ was employed to observe 0 atoms. In both cases it was found that low photon

intensities were required in order to avoid the photolytic production of the species of interest. Doppler-free measurements were carried out using a retroreflected-beam geometry in order to provide sufficient signal levels. Under these experimental conditions it is necessary to correct the raw profile data for variations in collisional quenching and electron detection sensitivity as a function of flame position. Establishing absolute radical concentrations is discussed in terms of partial equilibrium considerations and detailed flame structure calculation.

Snell, J. E.

Snell, J. E.

Advances in Technology for Product Fire Safety Approval.

National Institute of Standards and Technology,

Gaithersburg, MD

Product Safety corporation. International conference on

Fire Safety, 16th. Volume 16. January 14-18, 1991,

Millbrae, CA, Product Safety Corp., Sunnyvale, CA, 1-6 pp, 1991.

fire safety

Product fire safety approval key questions: 1. What is it, and where, how and by whom will it be used? 2 . What is the potential role, if any, of it as a fire risk? Source of ignition? Fuse? Fuel? 3. What is the fire risk of the product (from above)? Scenario(s)? Involvement? Consequences/impacts? compare with similar products/uses? 5. What, if anything, needs to be done?

Snell, J.E.

Fire Research at NIST.

National Institute of Standards and Technology,

Gaithersburg, MD

SFPE Bulletin, 9-11, May/June 1991.

fire research; fire losses; costs; fire risk; fire safety:

fire hazards

A recent study of the total cost of fire presents a new alarming picture of the economic burden of fire--as much as $\$ 128$ billion annually, and that neglects most government 
fire safety losses and expenditures. The key to reducing fire losses and costs is to seek possibilities for quantum improvements under the assumption that business as usual will continue to bring forward worthy incremental

improvements, but that they collectively will continue to fall short even of halting the increasing rate of growth of the costs of fire. History suggests that major changes in the public's values and attitudes about fire safety are unlikely unless people are motivated by sound factual and effectively communicated information about fire risk and hazards. Moreover, quantum advances in fire safety technology are probably more likely and indeed may even help stimulate desired behavioral changes.

Snell, J. E.

International Fire Research.

National Institute of Standards and Technology, Gaithersburg, MD

Mapfre Seguridad, Vol. 11, No. 44, 91-94, 1991. International Association for Fire safety science. Fire Safety science. Proceedings. 3rd International symposium. July 8-12, 1991, Edinburgh, Scotland, Elsevier Applied Science, New York, Cox, G.; Langford, B., Editors, 149-163 pp, 1991 .

fire research; fire safety; fire science

This paper makes the case for international fire research, discusses the development and activities of the Forum for International Cooperation on Fire Research (FORUM) an informal association of heads of fire research organizations around the world, and suggests how the FORUM and IAFSS maY support one another.

Steckler, K. D.

Steckler, K. D.; Evans, D. D.; Snell, J. E.

Preliminary study of the 1991 Oakland Hills Fire and Its

Relevance to Wood-Frame, Multi-Family Building Construction.

National Institute of Standards and Technology,

Gaithersburg, MD

NISTIR $4724 ; \quad 53$ p. November 1991.

Available from National Technical Information Services

PB92-132992

urban fires; wildland fires; apartments; fire

investigations; residential buildings

The purpose of this study was to establish the relevance, if any, of the Oakland hills wildland and suburban fire that occurred on October 20, 1991, to the design of multi-family wood-frame housing in the United States (U.S.) and Japan. A group of fire scientists and experts in building practices from both countries studied the fire through inspections of the site and meetings with local fire and building officials. The high wind speed, proximity of flammable vegetation to structures, and the flammability of exterior construction materials were factors in the spread of the fire. The use of wood framing members in the construction of multi-family housing did not influence significantly the rate of spread or extent of the fire. The severity and duration of the exposure, from fires ignited both outside 105 
and inside of buildings, resulted in total destruction of most structures within the fire area, regardless of the type of construction.

Steckler, K. D.; Kashiwagi, T.; Baum, H. R.; Kanemaru, K. Analytical Model for Transient Gasification of Noncharring Thermoplastic Materials.

National Institute of Standards and Technology,

Gaithersburg, MD

Nagasaki Univ., Japan

International Association for Fire Safety Science. Fire Safety science. Proceedings. 3rd International symposium. July 8-12, 1991, Edinburgh, Scotland, Elsevier Applied

Science, New York, Cox, G.; Langford, B. , Editors, 895-904 $\mathrm{pp}, 1991$.

fire research; fire safety; fire science; gasification; polymethylmethacrylate; pyrolysis models; thermoplastics

An analytical model is presented for the one-dimensional transient gasification of a noncharring thermoplastic material subjected to a specified, time-dependent external radiant heat flux. The model provides for

temperature-dependent thermal properties and time-dependent radiative and convective heat losses from the surface. It assumes that the external radiant flux is absorbed only at the surface and that both the heat of vaporization and vaporization temperature can be specified and are constant. Calculated results are compared to experiments with poly (methylmethacrylate) (PMMA). Agreement between theory and experiment is much better for a high $(40 \mathrm{~kW} / \mathrm{m} 2)$ external radiant flux than for a low $(17 \mathrm{~kW} / \mathrm{m} 2)$ external radiant flux. Under the latter condition, sub-surface absorption and degradation processes play a significant role but are not represented in the current model. Variable thermal pioperties, however, are shown to be non-crucial provided an appropriate effective temperature is chosen for their evaluation.

Stone, W. C.

stone, W. C.; Taylor, A. W.

System Identification of Spirally Reinforced Circular Bridge Columns subjected to Cyclic Lateral Loading.

National Institute of Standards and Technology,

Gaithersburg, MD

NIST SP 820; September 1991.

U. S./Japan Natural Resources Development Program (UJNR) . Wind and Seismic Effects. Joint Meeting of the U. S./Japan Cooperative Program in Natural Resources Panel on Wind and Seismic Effects, 23rd. May 14-17, 1991, NIST SP 820, Tsukuba, Japan, Raufaste, N. J., Editor, 269-293 pp, 1991. Available from Government Printing office

columns; bridges (structures); failure modes; earthquakes; tests; system identification; regression rate

Problems relating to present procedures for the design of bridge columns to withstand seismic loads are discussed and a more rational design procedure is proposed. Central to the proposed analysis method is the requirement for an analytical capacity to predict the hysteretic behavior of 
reinforced concrete bridge columns when subjected to inelastic lateral loads up to and including failure. A three-parameter model with a nonsymmetric trilinear envelope was used in an initial effort to identify relationships between physical column properties and hysteretic model parameters. A digital database of load-displacement histories was established for circular, spirally reinforced bridge column tests. A system identification analysis was performed on each specimen in which the error in predicted cyclic absorbed energy was minimized. Three parameters, comprising a stiffness degrading coefficient, a strength degrading coefficient, and a pinching coefficient, were employed in this study. Subsequent multivariable least squares regression analyses were conducted to correlate the variation of the three failure model parameters with the specimens physical variables as well as cummulative absorbed energy. Conclusions are presented regarding the sensitivity of hysteretic behavior to certain physical characteristics of circular, sprially reinforced bridge columns.

\section{Stroup, D. W.}

Stroup, D. W. ; Evans, D. D.

Suppression of Post-Flashover Compartment Fires Using

Manually Applied Water Sprays.

National Institute of Standards and Technology,

Gaithersburg, MD

NISTIR 4625; 40 p. July 1991.

Available from National Technical Information Services

PB91-240770

crib tests; drop size measurements; extinguishment; fire

fighting: fire fighting equipment; fire suppression;

flashover; nozzles; room fires; sprinkler systems; water sprays

A series of four full scale fire tests were conducted to measure the effect of manual fire fighting efforts on post-flashover room fires. One objective of these tests was to generate data for evaluation of computer models of the fire suppression process. The tests were conducted in a room and corridor configuration consisting of a $2.44 \mathrm{~m}$ cube burn room connected to a $12.8 \mathrm{~m}$ long, $2.44 \mathrm{~m}$ wide, and 2.44 $\mathrm{m}$ high corridor. Hose nozzles with different water spray flow rates and median drop sizes were used in each of the four norminally identical wood crib fires. Gas temperatures, wall surface temperatures and concentrations of oxygen, carbon dioxide, and carbon monoxide were measured in the burn room. Specialized aspirated and shielded thermocouples were used to minimize the effects of the water sprays on gas temperature measurements. This study showed that a water spray flow of $36.51 / \mathrm{min}$ with volume median drop size of 930 microns was just able to control the post-flashover fire, the flow of $16.3 \mathrm{l} / \mathrm{min}$ with volume median drop size of 800 microns did not control the fire, while the $79 \mathrm{l} / \mathrm{min}$ flow with volume median drop size of 1040 microns definitely extinguished the fire. 
Stroup, D. W.; Madrzykowski, D.

Conditions in Corridors and Adjoining Areas Exposed to

Post-Flashover Room Fires.

National Institute of Standards and Technology,

Gaithersburg, MD

NISTIR 4678; 74 p. September 1991.

Available from National Technical Information Services PB92-156769

room fires; flashover; corridor tests; crib tests;

evacuation; fire doors; large scale fire tests; leakage;

life safety; office buildings; refuge; smoke hazards

This study, conducted for the General services

Administration, examined the effect of a post-flashover room fire on a corridor and attached target room. The burn room was a $2.44 \mathrm{~m}$ square with a $2.44 \mathrm{~m}$ high ceiling. The corridor was $12.8 \mathrm{~m}$ long, $2.44 \mathrm{~m}$ wide, and $2.44 \mathrm{~m}$ high. The target room was composed of two parts, a rectangular area, $2.6 \mathrm{~m}$ by $2.4 \mathrm{~m}$ and $2.2 \mathrm{~m} \mathrm{high,} \mathrm{and} \mathrm{an} \mathrm{entry} \mathrm{alcove,} 0.8 \mathrm{~m}$ long, $1.1 \mathrm{~m}$ wide and $2.0 \mathrm{~m}$ high. Gas temperatures, wall surface temperatures and concentrations of oxygen, carbon dioxide, and carbon monoxide were measured at selected points in the burn room, corridor, and target room. Various methods of protecting the target room from the effects of the post-flashover room fire were also examined. The target room and its doorway were protected using a simulated "standard" door (with a top cut, a side cut, and an undercut), a reduced leakage door (undercut only), and a commercial accordion fire door. In addition, the target room with the "standard" door was tested using mechanical pressurization. Pressurization of the target room and reduction of the amount of door leakage, below that of a standard door, into the target room were effective methods of combustion into the target room. Measurements from the study were used to examine a recently proposed model for predicting the flow velocity of the initial gravity wave dowr the corridor. The measured and predicted values agreed within the limits of uncertainty for the data.

stutzman, P. E.

Stutzman, P. E.

Cement clinker Characterization by Scanning Electron

Microscopy.

National Institute of Standards and Technology,

Gaithersburg, MD

Cement, Concrete and Aggregates, Vol. 13, No. 2, 109-114,

winter 1991.

cements; microscopy; cement clinker; clinker microstructure;

image analysis; petrography; phase analysis; scanning

electron microscopy: $x$-ray microanalysis

The scanning electron microscopy (SEM) is becoming

increasingly recognized as an important instrument for the study of portland cement clinker, cement, and concrete. Images of clinker surface topography are used to study particle size and shape, as well as fracture surface features. Microstructural features such as phase distribution and abundance are obtained by imaging polished surfaces. $\mathrm{X}$-ray microanalysis provides qualitative and quantitative elemental composition and images of element distribution. Computer-based image analysis systems are 
used to process microscopy images to enhance details (such as the separation of individual phases) and image analysis for the measurement of features (such as phase abundance). The linking of the SEM with $X$-ray microanalysis and image analysis under computer control will provide automated, quantitative, and consistent analysis of portland cement clinker.

Stutzman, P. E. Quantitative Phase Abundance Analysis of Three Cement Clinker Reference Materials by Scanning Electron Microscopy. National Institute of Standards and Technology, Gaithersburg, MD

National Institute of Standards and Technology and American Ceramic Society. Advances in Cementitious Materials.

Ceramic Transactions. Volume 16. July 22-26, 1990,

Gaithersburg, MD, Mindess, S., Editor, 199-210 pp, 1991.

cements; microscopy; portland cement

Three portland cement clinker reference materials are available from the standard Reference Materials Program at the National Institute of Standards and Technology. They are the first clinker reference materials for phase abundance analyses and were selected as representative of North American clinker production with respect to the range of phase abundance, grain size, and distribution. They are intended for use in the development and testing of methods for quantitative phase abundance analyses of portland cement clinker. Portland cement clinker microstructures were characterized by backscattered electron imaging in the scanning electron microscope. Clinker phases were identified on the basis of their brightness, grain morphology, occurrence within the clinker, and composition. Quantitative phase abundance analyses by point counting, and by image analysis of backscattered electron images and, for periclase, of $X$-ray maps, generally agreed with the

reference material values. Low contrast between belite and aluminate presented some problems for image analysis. $\mathrm{X}$-ray maps suitable for image processing require much longer collection times than backscattered electron images but worked well when elements unique to a phase (e.g., Mg for periclase) were mapped. With its capability to clearly image polished clinker sections at a wide range of magnifications, the scanning electron microscopy $\mathrm{X}$-ray analysis and with image analysis capabilities is a powerful tool for quantitative cement clinker microscopy.

Tank, R. C.

Tank, R. C. ; Carino, N. J.

Rate Constant Functions for strength Development of

Concrete.

National Institute of Standards and Technology,

Gaithersburg, MD

ACI Materials Journal, Vol. 88, No. 1, 74-83, January/February 1991.

Title 88-M11; 
concretes; construction; temperature; equivalent age; maturity; models; mortars (material); rate constant;

strength

The rate constant for strength development of a particular concrete mixture is the initial slope of the relative strength-versus-age curve at constant temperature curing. The form of the rate constant versus temperature funciton is needed to describe the combined effects of time and temperature on strength development. This study investigtes the relationship between the rate constant and curing temperature. Based on strength gain data for concrete and mortar specimens made with Type 1 cement and cured at 10, 23 , and $40 \mathrm{C}(50,73$, and $104 \mathrm{~F})$, the following conclusions are drawn: (1) strength gain can be represented by a three-parameter hyperbolic function: (2) the rate constant is a nonlinear function of curing temperature and a simple exponential function describes this relationship; (3) tests of appropriate mortar specimens provide the information needed to predict relative strength development of the corresponding concrete; and (4) the proposed rate constant model accurately describes the development of relative strength as a function of the equivalent age.

Todd, D. R.

Todd, D. R.

Guidelines and Procedures for Implementation of the

Executive order on Seismic Safety of New Construction. National Institute of Standards and Technology, Gaithersburg, MD NISTIR 4635: 27 p. July 1991. Available from National Technical Information Services PB

agency seismic safety coordinator; earthquake hazard; earthquakes; Executive Order on Seismic Słfety; Federal agencies; guidelines; new construction; seismic safety Executive Order 12699, "Seismic Safety of Federal and

Federally Assisted or Regulated New Building Construction", was signed by the President to further the goals of Public Law 95-124, the "Earthquake Hazards Reduction Act of 1977", as amended. These guidelines and procedures for

implementing the order have been prepared and endorsed by consensus of the Interagency committee on seismic safety in construction. The Executive order applies only to new construction. All buildings owned, leased constructed, assisted (through such methods as loans, grants, or guarantees of loans), or regulated by the Federal government must conform to the requirements of the order. Each Federal agency is independently responsible for ensuring that appropriate seismic design and construction standards are applied to new construction under its purview. These guidelines recommend that each agency name an agency seismic safety coordinator to serve as a focal point for the agency's seismic safety program. Guidelines for determining the adequacy of local building codes are provided. Recommended implementation procedures include requiring written acknowledgement of agency seismic design and construction requirements from the building architect, engineer, contractor, and/or owner. 
Treado, S. J.

Treado, S. J.

Lighting and HVAC: Heating, Ventilating, and Air

Conditioning Affect Lighting Efficiency.

National Institute of Standards and Technology,

Gaithersburg, MD

Lighting and Design Application, 18-23, July 1991.

lighting equipment; heating; ventilation; air conditioning

Lighting in commercial buildings is the single largest user

of electric energy, typically ranging from 25 to 50 percent

of total building electrical energy requirements. In 1980,

$2.8 \times 10(15)$ Btu of energy was used for lighting for a total cost of over $\$ 40$ billion annually. An overall increase in lighting efficiency of 1 percent would produce a savings of $\$ 400 \mathrm{million} / \mathrm{year}$.

Treado, S. J.

NIST Lighting and HVAC Interaction Test Facility.

National Institute of Standards and Technology,

Gaithersburg, MD

ASHRAE Journal, Vol. 33, No. 4, 47-50, April 1991.

test facilities; lighting equipment; energy transfer;

heating; ventilation; air conditioning

Lighting in commercial buildings is the single largest user

of electric energy, typically ranging from 25 to 50 percent

of total building electrical energy requirements. In 1980,

$2.8 \times 10(15)$ Btu of energy was used for lighting, for a

total cost of over $\$ 40$ billion annually. Therefore, an

overall increase in lighting efficiency of one percent would

produce a savings of $\$ 400$ million a year.

Treado, S. J.; Bean, J.W.

Measurement and Evaluation of Iighting/HVAC Interaction.

National Institute of Standards and Technology,

Gaithersburg, MD

NISTIR 4429; 54 p. May 1991.

Available from National Technical Information Services

PB91-206706

air flow; cooling; energy; lighting; load calculation;

ventilation

The interaction of building lighting and HVAC systems and

the effects on cooling load and lighting system performance

are being evaluated using a full-scale test facility at the National Institute of Standards and Technology (NIST). The test facility and measurement methodology are described, along with sample test data and performance evaluation results. The implications of measurement uncertainty on results are discussed.

Tu, K. M.

$\mathrm{Tu}, \mathrm{K} . \mathrm{M}$.

Experimental Study of Top Vented Compartment Fires.

National Institute of standards and Technology,

Gaithersburg, MD

NISTIR 4499; 33 p. February 1991. 
Available from National Technical Information Services PB91-167254

ceiling vents; compartment fires; density differential; fire models; flow rate; pressure differential; vents

In a top vented compartment fire, both density difference and pressure difference across the horizontal ceiling vent control the vent flow. This research work pursued

experimental studies and investigations of exchange flows through a horizontal ceiling vent as related to solely top vented compartment fire situations. A cubic box with inside dimensions of $0.43 \times 0.43 \times 0.43 \mathrm{~m} \mathrm{high} \mathrm{(17 \times 17 \times 17} \mathrm{in)}$ and walls of $0.025 \mathrm{~m}$ ( 1 in) thick Kaowool was employed for the compartment fire tests. For compartment fires of various horizontal ceiling vent sizes: (1) the fuel mass burning rates were measured, and (2) the air and combustion-flue-gas exchange flow rates were estimated based on [i] available theories and [ii] gas concentrations in the fire compartment.

Tu, K. M.; Quintiere, J. G.

Wall Flame Heights With External Radiation.

National Institute of standards and Technology,

Gaithersburg, MD

Maryland Univ., College Park

Fire Technology, Vol. 27, No. 3, 195-203, August 1991.

walls; flame height; radiation; flame spread;

polymethylmethacrylate; particle boards; energy transfer;

heat release rate; interior finishes

An existing flame heat transfer fire testing apparatus was used to study the upward flame spread potential of two kinds of wall materials: (1) PMMA (Polymethylmethacrylate) and

(2) Douglas Fir Particle Board. PMMA is noncharring whereas Douglas Fir Particle Board is a charring material. Various levels of external radiant heat flux rangirig from 1.8

$\mathrm{W} / \mathrm{cm}(2)$ to $3.4 \mathrm{~W} / \mathrm{cm}(2)$ were imposed onto the wall samples in order to measure the flame heights as a function of energy release rate. Flame height measurements were established visually by a review of video recordings. The results for these wall flames correlate flame height to the $2 / 3$ power of energy release rate per unit sample width. The wall results are generally higher than data from gas burner line fires against a wall for a range of 10 to $200 \mathrm{kw} / \mathrm{m}$.

Tzeng, L.

Tzeng, L.; Atreya, A.

Theoretical Investigation of Piloted Ignition of Wood. Michigan State Univ., East Lansing, MI NIST-GCR-91-595; 230 p. August 1991. Available from National Technical Information Services PB92-112432

diffusion flames; equations; pilot ignition; premixed flames; wood

A theoretical model for piloted ignition of a flame in the gas phase above a vaporizing or pyrolyzing solid has been developed. Using this model it has been found that (i) The postulated simplified governing equations adequately explain the pre-ignition flashes that are often observed 
experimentally; (ii) A rational criterion for positioning the pilot flame exists; (iii) The heat losses to the surface play an important role, indicating that the fuel evolution rate by itself is insufficient for predicting the onset of piloted ignition. In this investigation, a numerical integration scheme is developed that accounts for the often vastly different rates between chemical reaction and convection or diffusion processes in the equations of combustion theory. This new numerical scheme is found to be very efficient for the piloted ignition problem, which involves both pre-mixed and diffusion flames. Finally, a numerical model for piloted ignition of wood which includes transient solid-phase decomposition has been developed. It has been found that the activation energy for the combustion of the evolved fuel is $49 \mathrm{Kcal} / \mathrm{mole}$.

Vaezi-Nejad, H.

Vaezi-Nejad, H.; Hutter, E.; Haves, P.; Dexter, A. L.;

Kelly, G.; Nusgens, P.; Wang, S.

Use of Building Emulators to Evaluate the Performance of Building Energy Management Systems.

CSTB, France

Oxford Univ., UK

National Institute of Standards and Technology,

Gaithersburg, MD

Liege Univ., Belgium

Building Simulation Conference. August 20-23, 1991, Nice,

France, 1-6 pp, 1991.

emulators; energy management systems; building control systems; simulation; emulation; field testing; heating; ventilation; air conditioning

Three complementary approaches may be used in the evaluation of the performance of building control systems - simulation, emulation and field testing. In emulation a real-time simulation of the building and HVAC plant is connected to a real building energy management system (BEMS) via a hardware interface. Emulation has the advantage of allowing controlled, repeatable experiments whilst testing real devices that may contain proprietary algorithms. Building emulators have been developed by the authors in the context of IEA Annex 17, which is concerned with the use of simulation to evaluate the performance of BEMS. The paper discusses different approaches to the design of building emulators and describes the different architectures, hardware and software used by the authors. The problem of evaluating the overall performance of BEMS is discussed and results are presented that illustrate the use of emulators to investigate the influence of the tuning of local loop controls on building performance.

Villa, K. M.

Villa, K. M.; Babrauskas, V.

Cone Calorimeter Rate of Heat Release Measurements for

Upholstered Composites of Polyurethane Foam.

National Institute of Standards and Technology,

Gaithersburg, MD 
NISTIR 4652; 39 p. August 1991.

Available from National Technical Information Services

PB92-108984

composite materials; cone calorimeters; heat release rate; melamine; nylon (trademark); polyolefins; polyurethane foams: polyvinyl chloride; upholstered furniture Certain regulatory authorities have recently banned or restricted the use of furniture upholstered with a combination of polyvinyl chloride (PVC) covering and a melamine-treated polyurethane foam padding. Thus, it was endeavored to determine if quantitative measurements would reveal; any special hazards associated with this particular combination. The work represents the testing of nine different upholstered composites, made of fabric coverings and polyurethane foam, tested at three different irradiance levels in the National Institute of Standards and Technology Cone Calorimeter. Additional combinations using a polyester batting interbarrier were also used. The composite bench-scale specimens were tested at $25 \mathrm{~kW} / \mathrm{sq} \cdot \mathrm{m}, 35 \mathrm{~kW} / \mathrm{sq} \cdot \mathrm{m}$ and $50 \mathrm{~kW} / \mathrm{sq} \cdot \mathrm{m}$ irradiance levels. For most variables describing fire hazard, the performance of the combination of melamine-treated polyurethane foam and PVC fabric covering was not found to behave in an unusual manner. Only by considering the time period of 15 seconds after ignition was this combination numericaly worse than all other combinations tested.

Worthey, J. A.

Worthey, J.A.

Dealing with Obvious Issues in Iighting.

National Institute of Standards and Technology,

Gaithersburg, MD

Lighting Design and Application, Vol. 21, No. 8, 15,17-19,

August 1991.

Iighting equipment

In an article last month, I listed six reasons why theory is important for lighting research and practice: 1 . Theory is what engineers do. For instance, all electrical engineers must understand circuit theory. 2. It's hard to vary light source size. Theory can isolate the effects of source area. Experiments to vary size while controlling other parameters would be hard. 3. It's also hard to vary spectral power distribution. 4. Optics is not controversial. Much of the theory need for the discussion of lighting quality is simple optics as applied to the interaction of light and objects. 5. Theory guides experiment. Theory helps in the design of experiments. 6. More speculative theories may also have a place. Theory lets you move forward from the simple to the complicated. These six reasons for the use of theory all come down to this: Iighting is complicated, but theory can help you to understand it step by step. In this article, I want to look at one more rationale for the use of theory. In a final article, I'll talk about the payoffs that a more theoretical approach to lighting may give. I believe that better use of theory may lead to solid, advances in the design of luminaires and systems, but that's for next time. 
Worthey, J. A.

Lighting Research and Theory Can Create Business Prospects.

National Institute of Standards and Technology,

Gaithersburg, MD

Lighting Design and Application, Vol. 21, No. 9, 14-17,

September 1991.

lighting equipment; luminescence; thermodynamics

The first article in this series 1 isted six reasons for the use of theory in lighting. These reasons all relate to the complexity of lighting and the need to approach it systematically, as a physicist would. The second article addressed the curious fact that theory helps us to deal with things that are obvious. While the lighting engineer can control light source area over a wide range, controlled experiments with a wide variation of obvious lighting features are had to design. It is easier to design an experiment in which the independent variable is something subtle. In the theoretician's orderly universe, it is normal to state the obvious, to work with it, and to calculate things from it. The topic of this final article is: What benefits can come from a more theoretical approach to lighting research and design? The answer proposed will be this: Better theory can give better lighting system designs and, in particular, new and better luminaires.

Worthey, J. A.

Role of Theory in Lighting Research and Design.

National Institute of Standrds and Technology, Gaithersburg, MD

Lighting Design and Applications, 15-17, July 1991.

lighting equipment; light source; optics

It is a truism that theory needs to be tested in the

laboratory and many lighting experiments remain to be done.

Nonetheles, an important question is, "What is the importance of theory in lighting research?" In recent years, much has been written by historians of science about the role of theory in the development of science and the interplay of theory and experimentation. For instance, in stating that heavy objects fall no faster than light ones, Galileo was not reportint on an experiment in which he dropped a feather and a stone from the Tower of Pisa. He experiemented with metal balls rolling down inclined planes. He then made a theoretical statement that extrapolated to the idealized cased of objects falling without air resistance. With today's vacuum pumps, one could do the idealized experiment; Galileo could not. If it seems trival today that gravity and air resistance are separate effects, we can thank Galileo for his theory of falling objects, which lets us move ahead to other problems. This article does not trace the history of science, but lists some specific reasons that theory is important in lighting research and design. In doing this, I am not promoting a particular comprehensive theory of lighting, but the appropriate use of analytical methods from optics, visual science, and elsewhere. 
Wright, $R . N$.

Wright, R. N.

Activities of the Interagency committee on seismic safety in Construction.

National Institute of standards and Technology,

Gaithersburg, MD

Federal Construction Council. Retrofitting Buildings for

Seismic safety (Summary of a Symposium). Technical Report

No. 109. November 20, 1990, Washington, DC, National

Academy of Sciences, Washington, DC, 26-32 pp, 1991.

construction: safety: earthquakes

The Interagency comittee on seismic safety in construction

(ICSSC) assists federal agencies involved in construction to develop and incorporate earthquake hazards reduction

measures in their ongoing programs. ICSSC proposed an executive order for seismic safety in construction that became the basis for Executive order 12699, "Seismic Safety of Federal and Federally Assisted or Regulated New Building Construction", dated January 5, 1990. The National

Earthquake Hazards Reduction Program Reauthorization Act of October 20, 1990, calls for ICSSC to provide standards for existing federal and federally assisted buildings by 1994. ICSSC will participate in cooperative activities with the private sector to develop nationally recognized voluntary standards suitable for federal use in the assessment of the seismic resistance of existing buildings and the

strengthening of those inadequately resistant.

Wright, R. N.

Competing for Construction in the World Arena.

National Institute of Standards and Technology,

Gaithersburg, MD

Construction Business Review, Vol. 1, No. 3, 36-39,

May/June 1991.

construction

Buildings and other facilities shelter and support most

human activities. The quality of those facilities affects

the competitiveness of the country's industry, and the

safety and welfare of its people. Moreover, construction

quality strongly affects national wealth. over five-eights

of our fixed, reproducible wealth is invested in constructed

facilities, not including land or mineral deposits. And the industry itself is one of the nation's largest. In 1991, alone, new construction put in place amounted to $\$ 445$ billion--8.1 percent of the GNP--and provided employment for 6.7 million workers.

Wright, R. N.

Research and Technology for Structural Engineering

Productivity.

National Institute of Standards and Technology,

Gaithersburg, MD

American Society of civil Engineers. Structures Congress

' 91 Compact Papers. Structures Congress, 9th. April 29-May

1, 1991, Indianapolis, IN, 1-7 pp, 1991.

structural engineering 
Wright, R. N. : Gross, J. G.

Research for Standards and Conformity Assessment.

National Institute of standards and Technology,

Gaithersburg, MD

RILEM International Seminar on Direct Transfer of Research

Results to Industry. November 4-6, 1991, Buenos Aires,

Argentina, 1-20 pp, 1991.

standards; building products; regulations; public awareness standards are a major mechanism for communication between buyers and sellers of building products and services and the basis for regulations protecting public health, safety and welfare. Therefore, standards provide the principal vehicle for the transfer of knowledge from research to building practice. Research for standards includes research to improve the performance of building products and services and research to improve the development and use of standards and regulations. Trends for research for standards and conformity assessment are described in the context of $U$. S. and international activities.

Wright, R. N.; Watson, G. H.; Fisher, J. W. Construction Materials.

National Institute of Standards and Technology,

Gaithersburg, MD

Chapter 4;

Japanese Technology Evaluation Center Panel Report on

Construction Technologies in Japan, Chapter 4, Loyola

college, Baltimore, MD, 43-54 p., 1991.

construction materials; steel structures; concretes;

composite materials

The JTEC panel's interactions with offices of Japanese government and industry, public and private laboratories, and construction sites have provided substantial information for this chapter on materials for structures, earthworks, and foundations. Topics not covered include materials and components for mechanical systems, exterior enclosure materials, and interior finishes and furnishings. Examples of new techniques and products developed or licensed in Japan, including all the above areas, are given inReference 4.1. A recent study by the U. S. Air Conditioning and Refrigeration Institute (Ref. 4.2) describes Japanese research and development on alternatives to the refrigerants that contribute to the greenhouse effects and loss of the ozone layer. The panel did not study this important topic.

Tu, s. T.

Wu, S. T.: Clifton, J. R.

Computational Models Developed for the Corrosion of

Prestressing steel.

National Institute of Standards and Technology,

Gaithersburg, MD

NISTIR 4455; 19 p. March 1991.

Available from National Technical Information Services

PB91-167304

concretes; fracture energy; fracture mechanics; general

corrosion; modeling; prestressing steel; stress corrosion;

cracking 
Stress corrosion cracking and general corrosion are the two major processes potentially responsible for corrosion failures in prestressed concrete. Modeling for the purpose of estimating the corrosion rates of steel in prestressed concrete are discussed in the paper. For steel in concrete, localized corrosion processes are not well understood. It is premature at present to develop a sophisticated but still incomplete mathematical model. Instead, a simplified approach is proposed for the quantitative evaluation considerations of diffusion processes and electrochemical reactions. The dominant chemical factors, such as the concentration of oxygen at the electrodes, are treated as primary variables in the differential equations. Two approaches which have been frequently used to treat stress corrosion cracking are briefly described. The first approach is based on a conventional engineering approach by estimating the stress intensity factors under various environments. In the second approach, the surface energy at grain boundaries is estimated along the crack path. It is suggested that the chemical potentials and concentratons of the important absorbed species be included in the energy expression.

Yancey, C. W. C.

Yancey, C. W. C.; Fattal, S. G.; Dikkers, R. D.

Review of Research Literature on Masonry Shear Walls.

National Institute of Standards and Technology,

Gaithersburg, MD

NISTIR 4512; 99 p. February 1991.

Available from National Technical Information Services

PB91-167189

code requirements; design; full scale tests; lateral

loading; masonry shear walls; research; shear strength;

standards; test methods

A review of the technical literature on masonry shear wall tests was conducted to determine the range and depth of available research and to identify areas in need of additional research. The review covers documents published from 1976 to 1989 and includes approximately seven hundred masonry wall tests. Both U.S. and foreign research was included in the review. U.S. code and standard requirements for the design of masonry shear walls are discussed. Some of these requirements are highlighted in tabular and graphic form. Technical information regarding experimental studies is tabulated for easy reference. A selected number of test programs are examined in greater detail to present the objective and scope, test variables and major findings. Experimental data from comparable research studies are combined and analyzed to determine the influence of key design parameters on the performance of shear walls to in-plane lateral loading. Also included is a comparison of two experimentally-derived shear strength formulae with the shear strength provisions of the 1988 edition of the Uniform Building code. The findings of the review are summarized and specific research needs are identified. 
Zarx, R. R.

Zarr, R. R.

Intra-Laboratory Comparison of a Line-Heat-Source Guarded

Hot Plate and Heat-Flow-Meter Apparatus.

National Institute of Standards and Technology,

Gaithersburg, MD

Insulation Materials: Testing and Applications. 2nd

Volume. ASTM STP 1116, Am. Soc. for Testing and Materials,

PA, Graves, R. S.: Wysocki, D. C., Editors, 502-519 pp,

1991.

heat sources; thermal conductivity; thermal insulation;

thermal resistance; heat flow meter; heat flux meter; heat

flux transducer; intra-laboratory comparison; guarded hot

plate; line heat source; precision

The apparent thermal conductivity and thermal resistance of several building insulaitons were determined at the National Institute of standards and Technology (NIST) using three apparatus. Reference values were determined with NIST's I-metre Line-Heat-Source Guarded Hot Plate (GHP). The other two apparauts were heat-flow-meter (HFM) apparatus calibrated with a standard Reference Material of fibrous-glass board. The apparatus - NIST's 1-metre GHP; the $610 \mathrm{~mm}$ HFM; and the $305 \mathrm{~mm}$ HFM - were operated at a mean temperature of $24 \mathrm{deg} C$ and temperature difference of 22 deg $C$ across the thickness of the specimen. Measurements of thermal conductivity were determined for individual specimens nominally $25 \mathrm{~mm}$ thick, covering a range of thermal conductivity from 0.02 to $0.16 \mathrm{~W} / \mathrm{m} \mathrm{K}$ ). The thermal resistance of thick specimens of cellular plastics, fibrous and loose-fill insulation was also determined. Deviations from reference values of the GHP were calculated for the HFM apparatus. For the $610 \mathrm{~mm}$ HFM, the majority of deviations were within $\pm 3 \%$ of the GHP. Substantial improvement was achieved by calibrating the $305 \mathrm{~mm}$ HFM as a function of thickness; however, deviations ranged from +1.5 to $+9.2 \%$ from the GHP. The apparatus, test procedure, and analysis of the deviations are described in the paper.

Zarr, R. R.

Summary of Low-Density Glass-Fiber Reference Materials at NIST: 1980-1989. Temperature.

National Institute of Standards and Technology,

Gaithersburg, MD

Journal of Thermal Insulation, Vol. 14, 211-220, January 1991.

glass fibers; calibrated transfer specimens; glass-fiber insulation; proficiency testing; standard reference material; thermal insulation

This paper reviews three programs at the National Institute of Standarás and Technology (NIST) that provide specimens of low-density glass-fiber insulation as reference materials. The National Voluntary Laboratory Accreditation Program (NVLAP) provides specimens as Proficiency Test Materials; the Standard Reference Materials Program (SRMP), as Standard Reference Materials; and the Center for Building Technology (CBT), as Calibrated Transfer specimens. The programs of SRMP and CBT are summarized for the years 1980 to 1989. The paper includes a catalogue of NIST publications covering the 
technical development of the low-density glass-fiber insulation used in the programs of NVLAP, SRMP and CBT.

Zarr, R. R. i Licitra, B. A.

Calibration at 24 deg $C$ of a Heat-Flow-Meter Apparatus Having $610 \mathrm{~mm}$ Square Plates.

National Institute of Standards and Technology,

Gaithersburg, MD

NISTIR 4539; 35 p. May 1991.

Available from National Technical Information Services PB9 1-206730

calibration; computer; data-acquisition-system; guarded hot plate; heat-flow-meter; heat-flux-transducer; standard

Reference Material

Results are summarized for 38 individual calibration measurements conducted at 24 deg $C$ and atmospheric conditions for a heat-flow-meter apparatus having $610 \mathrm{~mm}$ square plates. The apparatus was calibrated using a 26.2-mm-thick specimen of fibrous-glass board having a density of $139 \mathrm{~kg} / \mathrm{m} 3$. The specimen was selected from an internal $\log$ (Lot 1970) of standard Reference Material (SRM) similar to SRMs 1450, 1450a, and 1450b. Values of apparent thermal conductivity were predicted using a regression equation developed for this lot of fibrous-glass insulation. Calibration measurements varied $\pm 0.4 \%$ with a small drift of $0.4 \%$ over 250 days. The apparent thermal conductivity of the calibration specimen was also measured using the National Institute of Standards and Technology's one-metre Line-Heat-Source Guarded Hot Plate. Agreement between measurements of thermal conductivity of the guarded hot plate and predicted values were within +0.2 to $-0.3 \%$ at 24 deg $C$. The report describes the heat-flow-meter apparatus and the computer data-acquistion-system used to collect data from the apparatus.

Zarr, R. R.; Somers, T. A.; Ebberts, D. F. Room Temperature Thermal Conductivity of Fumed-Silica

Insulation for a standard Reference Material.

National Institute of Standards and Technology,

Gaithersburg, MD

Improved Thermal Insulation--Problems and Perspectives. Chapter 5, Technomic Publishing Co., Inc., Lancaster, PA, 97-119 p., 1991 .

silica; insulation; temperature; thermal conductivity; standard reference materials

Thermal conductivity of fumed-silica insulation board was measured using the National Institute of Standards and Technology 1-meter Guarded Hot Plate. Measurements were conducted for the following range of parameters: bulk density, 304.5 to $325.4 \mathrm{~kg} \mathrm{~m}(3)$; mean temperature 283.1 to $311.0 \mathrm{~K}:$ and barometric pressure 97.5 to $103.43 \mathrm{kPa}$. The effect of moisture content on room-temperature measurements was minimized by prior conditioning of the specimen at 100 deg $C$ for 24 hours. Seventy-five samples (600 by 600 by $25.4 \mathrm{~mm}$ ) were transferred to the office of standard Reference Materials in Gaithersburg, Maryland, USA. The 
material is offered as a standard Reference Material having a low thermal conductivity at room temperature.

Zhou, L.

Zhou, L.; Fernandez-Pello, A. C.

Turbulent Burning of a Flat Fuel surface.

California Univ., Berkeley

International Association for Fire Safety science. Fire Safety Science. Proceedings. 3rd International Symposium. July 8-12, 1991, Edinburgh, Scotland, Elsevier Applied

Science, New York, Cox, G.; Langford, B., Editors, 415-424 pp, 1991.

fire research; fire safety; fire science; turbulent burning; velocity; turbulence; regression rate; solid fuels; air

flow; burning rate; equations

Experiments have been conducted to study the effect of flow velocity and grid-generated turbulence intensity on the surface regression rate of thick PMMA sheets burning in a forced air flow. All the tests are carried out in a laboratory-scale combustion tunnel with flow velocities ranging from $1 \mathrm{~m} / \mathrm{s}$ to $4 \mathrm{~m} / \mathrm{s}$ and turbulence intensities from $1 \%$ to $20 \%$. It is found that for all turbulence intensities, the regression rate decreases with the distance from the fuel sheet upstream edge, and increases with the flow velocity, in agreement with boundary layer analyses of the process. It is also found that flow turbulence has a strong influence on the surface regression rate due primarily to an enhancement of the heat transfer from the flame to the fuel that is caused by turbulence generated flame fluctuations. It is shown that the experimental data can be correlated in terms of a non-dimensional mass burning rate that is approximately linearly proportional to the turbulent flow parameter. The good correlation of the data in terms of these parameters indicate the potential predictive capabilities of theoretical models of the process that incorporate the flow turbulence through an eddy viscosity, and thermal and mass diffusivities. Explicit expressions for the laminar and turbulent mass burning rates in terms of the solid fuel and flow properties are reported. 


\section{Author Index}

Abu-Zaid, M. 2

Alibe, B. 1, 101

Ames, S. 1

Apte, V. B. 2

Atreya, A. 2, 112

Avedisian, C. T. 87

Babrauskas, V. $3,4-7,73,81$, 82,113

Barnes, Y. 91

Barnett, J. P. 56

Batts, M. E. 12

Baum, H. R. 9, 33, 36, 89, 90, 106

Bean, J. W. 111

Benner, B. A., Jr. 9, 72

Bentz, D. $10,11,12,41,75$

Beyler, C. L. 91,92

Bilger, R. W. 2

Bowers, W. J., Jr. 92

Braun, E. 5-7, 12, 62

Breese, J. N. 81

Brown, J. E. 13

Bryan, J. L. 70

Bryner, N. P. 9, 13, 57

Bukowski, R. W. 7, 14-16, 82

Burch, D. M. 16-17, 37

Burdette, E. G. 79

Bushby, S. T. 18

Byrd, E. 75

Byrd, W. E. 96

Carino, N. J. $19,79,109$

Celebi, M. 19, 66

Chen, Y. 20

Cheok, G. S. 21, 22

Chwalowski, M. 22

Cieplak, M. 68

Cleary, T. G. 23, 55

Clifton, J. R. 19, 24, 53, 117

Collins, B. L. $\quad 25-26$

Cook, G. R. 1, 27, 100-101

Cooper, L. Y. 28-31
Corley, D. M. 90

Daisey, J. M. 48

Damant, G. 4, 80

Damasceno, G. S. 31

Danner, W. F. 31

Davis, S. 12

Davis, W. D. 31-32

Day, A. R. 42

Deal, S. 74

Dentherage, J. H. 79

Dexter, A. L. 113

Didion, D. A. 55, 97

Dietenberger, M. A. 32

Dikkers, R. D. 33, 118

diMarzo, M. 33

Dobbins, R. A. 34

Dols, W. S. 82-83

Domanski, P. A. $31,34-35$

Ebberts, D. F. 120

Embree, E. 67, 68

Emrich, C. 98

Evans, D. D. 9, 33, 35-36, 42, $72,105,107$

Faeth, G. M. 61,102

Fanney, A. H. 37, 84

Farabaugh, E. N. 91

Fattal, S. G. 38,118

Feldman, A. 91

Fernandez-Pello, A. C. 121

Fields, B. A. 38

Fields, R. J. 38

Fingas, M. F. 9, 35

Fisher, J. W. 117

Fletcher, R. A. 72

Forney, C. L. $16,81,82$

Forney, G. P. 32, 39

Frendi, A. 20-21

Frohnsdorff, G. 39, 94

Fuller, S. K. 40

Gann, R. G. $5,6,12$ 
Garboczi, E. J. $10,11,24,41-42$

Getachew, T. 60

Ghoniem, A. 36

Gingold, D. 11

Goldschmidt, V. W. 31

Goodin, P. J. 26

Gore, J. P. 9, 42-44, 49

Gould, J. R. 35

Graves, R. S. 44

Green, A. R. 2

Griffiths, P. R. 45

Gross, D. 45, 46

Gross, J. G. 46, 47, 117

Grot, R. A. 48

Gupta, A. K. 87

Hagen, D. E. 49

Hamins, A. 44, 49

Harris, R. H., Jr. 5-6, 50, 62

Haves, P. 113

Heskestad, G. 51

Hodgson, A. T. 48

Hubbard, J. B. 76

Huggins, M. 98

Hurst, W. S. 92

Hutter, E. 113

Janssens, M. 73

Jason, N. H. 15, 51, 52

Jennings, H. M. 11

Jones, W. W. 7, 16, 82

Joshi, A. A. 52, 79

Kaetzel, L. J. 53

Kanemaru, K. 106

Kao, J. Y. 54

Kashiwagi, T. 44, 49, 55, 103, 106

Kedzierski, M. A. 55

Kelly, G. 113

Kelly, G. E. 56, 65

Kim, C. I. 62

Kinney, P. D. 57

Kirchner, S. 83

Klassen, M. E. 43-44, 49

Klote, J. H. 12, 32, 57-59

Knab, L. I. 24, 69

Kokkala, M. 59
Koseki, H. 36, 59-60

Kostreva, M. M. 60

Kounalakis, M. E. 61,102

Koylu, U. O. 61

Kubota, T. 71

Kulkarni, A. K. 62

Kuo, C. H. 62

Lawson, J. R. 35-36

Lechner, J. A. 96

Levin, B. C. $5-6,12,62-64$

Levine, R. S. 64

Lew, H. S. 21, 22

Li, K. 9

Liao, Y. 33

Licitra, B. A. 120

Lin, C. 75,76

Liu, S. T. 65

Lobb, C. J. 11

Looney, J. 92

Lozier, D. W. 89

Madrzykowski, D. $\quad 66,72,108$

Marshall, R. D. 19,66

Martin, J. W. 12, 67-68, 93, 94

Martys, N. 68

Masters, L. W. 39, 94

Mathens, L. R., Jr. 37

Mathey, R. G. 69

May, A. D. 72,92

McCaffrey, B. J. 42

McCluney, R. 98

McElroy, D. L. 44

McFadden, G. B. 76

McKnight, M. E. 69

Milke, J. A. 70

Miller, R. G. 44

Mitler, H. E. 70, 71

Morehart, J. H. 71

Mulholland, G. W. 9, 13, 35-36, $57,59-60,72-73$

Nabinger, S. J. 83

Navarro, M. 63

Nelson, H. E. 74

Newman, H. M. 18

Nguyen, T. 75-76, 95-96

Noid, D. W. 77 
Norton, T. S. 77

Nubakhsh, S. 4,80

Nusgens, P. 113

Nyden, M. R. 77

Ohlemiller, T. J. 78

Oluokon, F. A. 79

Paabo, M. 5-6, 12, 50, 62-64

Pagni, P. J. 52, 79

Park, C. 56

Parker, W. J. 1, 80

Peacock, R. D. 6-7, 16, 81-82

Persily, A. K. $\quad 48,82-83$

Petersen, S. R. 84

Phan, L. T. 19,66

Pitts, W. M. 84-86

Presser, C. 87

Puri, D. Y. H. 57

Puri, R. 87

Quintiere, J. G. 2, 23, 88, 112

Raufaste, N. J. $\quad 88,89$

Rehm, R. G. 9, 89-90

Richardson, L. 7

Robbins, M. O. 68

Robins, L. H. 91-92

Roby, R. J. 91

Rooke, S. 31

Rosasco, G. J. 92

Rosen, H. N. 93

Rossiter, W. J., Jr. 67-68, 94-96

Rothfleisch, P. 97

Rubin, A. I. 97, 98

Sanford, D. T. 31

Santoro, R. J. $34,87,99$

Saraiji, R. 98

Schaenman, P. 99

Schiller, S. B. 64

Seiler, J. F., Jr. 96

Semerjian, H. G. 34,87

Sibulkin, M. 20, 21

Silberstein, S. 100

Simiu, E. 1, 27, 100-101

Sims, J. S. $\quad 89-90$

Sivathanu, Y. R. $\quad 61,102$
Skelly, M. J. 102

Skinner, S. M. 44

Smith, R. L. 103

Smyth, K. C. 77, 91-92, 104

Snell, J. E. 104, 105

Sommers, T. A. 120

Steckler, K. D. 105-106

Steel, E. 72

Stone, W. C. 106

Stroup, D. W. 107-108

Struble, L. J. 53

Stutzman, P. E. 108,109

Tamura, G. T. 58, 59

Tang, H. C. $\quad 89-90$

Tank, R. C. 109

Tartarini, P. 33

Taylor, A. W. 106

Tebeau, P. A. 35

Tennyson, E. J. 35-36

Terlizzi, C. P. 65

Tewari, S. S. 20-21

Thomas, W. C. 17, 37

Tjossem, P. J. H. 91, 104

Todd, D. R. $\quad 38,110$

Treado, S. J. 111

Tu, K. M. 74, 80, 111-112

Twilley, W. H. 73

Tzeng, L. 112

Vaezi-Nejad, H. 113

Villa, K. M. 78, 113

Walton, W. D. 36

Wang, S. 113

Watson, G. H. 117

Wiecek, M. M. 60

Wise, S. A. 9, 72

Worthey, J. A. 114, 115

Wright, R. N. 116-117

Wu, S. T. 117

Xiong, L. X. 24

Yancey, C. W. C. 118

Yang, Y. 31

Yarbrough, D. W. 44

Yusa, S. 6, 73 
Zarr, R. R. $17,44,119-120$

Zhou, L. 121

Zukoski, E. E. 71 


\section{Keyword Index}

A

absorption 91, 106

adhesives 96

aggregates 34

air $1-3,17,19,22,23,31,35$, $37,42,44-46,48$, $49,54,55,57,58$, $61-63,65,72,73$, $77,78,83,84,89$, $92,94,97,100$, $102,104,111-113$,

$115,117,121$

air conditioning 111,113

air flow 46,78

air quality 83

algorithm 30,32

algorithms $39,56,81$

anisothermal tests 39

arrows 26

ASHRAE $16,18,31,35,37,48$, $56,58,65,83,111$

assets 33

\section{B}

\section{BACnet 18}

bedding 74

bonding $68,93,95,96$

bridges 88,106

building automation 18

building automation system 54

building codes 8

building construction 48

building control 113

building control systems 113

building materials 49,53

building technology $51,52,119$

buildings 67,105

burners $61,65,71,72$

burning rate 59

buses 12

cables 7 calibration 12,120

calorimeters 4

carbon dioxide 21,49

carbon monoxide $49,75,88$

ceiling jets 31

cellulose 20

cement paste 10,11

cements $10-12,25,41,108,109$

certification 46

char $20,21,55$

cleaning methods 96

coatings 94

collateral damage 65

color $14,25-27$

columns 21, 22, 27, 106, 107

combustibility 4

combustion $12,20,21,28,36$, $37,46,49,62,113$

combustion products 37,73

composite materials 117

computer $3,13,28-30,39,42$, $53,57,78$

computer models $14,31,53,80$

computers 59

concretes $11,21,41$

conductance 42,45

conductivity 33,45

conformance 18

connected porosity fraction 12

connections 22

construction $17,47,48,105,116$

contact angle 95,96

control $3,17,18,34,36,45,46$, $50,54-59,62,66$, $82,86,97,99$, $107,109,112,113$, 115

cooling $33-35,51,56,97,111$

copper 62,63

corrison 76

costs $40,60,89,99,100,104$, 105

cracking 117 
creep $39,67,68,96$

crude oil 49

cylindrical holes 12

\section{D}

damage $14,64-66$

dampers 65

damping 20, 28

data acquisition 81

data analysis 34,43

daylight $97-99$

death $6,7,41,50,63$

density effects 85

design $1,8,19,22,23,27,33$, $35,38,46-48,54$, $55,57-60,67,68$, $74,83,87,88$, $97-100,105,106$, $110,111,113-115$, 118

diffusion $17,25,77,85,88,102$, 104

diffusion flames $61,72,77$

direct digital control 54

doors $45,46,58,59,108$

$\mathbf{E}$

earthquakes 116

EC $92 \quad 47$

effectiveness 83,98

egress $15,25,26,60$

EMCS 18,56

emissions 43

emulators 113

enclosures 89

energy $2,18,20-22,24,43,49$, $56,67,78,85,86$, 91, 94, 97-99, 107,

entrainment 86 $111-113,117,118$

EPDM 67, 68, 95-97

equations $4,27,35,38,100,121$

equilibrium 93

ethylene 72

evacuation 60

evaluation $111,113,118$

exit $25,26,61,66$ experiments 32,49

exposure 63

F

facilities 47

failure $22,65,68,101,106,107$

fenestration 99

films $75,91,93$

fire behavior 86

fire growth 32

fire hazard 16,82

fire hazards 104

fire models 3,74

fire protection $14,26,59,64$

fire research $36,51,52,59,100$, 105

fire safety 103-105

fire science 105

fire suppression 88

firex 64,65

flame height 72

flame luminosity 87

flame spread 79

flame spread rate 55

flame velocity 2

flammability 23, 62, 79

flashover 7

fluorescence 49

fly ash 11,25

fog 49

formulations 33,38

FT-IR $\quad 45,75,95,96$

fuels $9,21,33,43,44,49,61$, $72,87,91,92,121$

furniture $1,5,80,114$

G

gasification 20, 21

glare 98

glass $52,53,79,80,94,102$, $103,119,120$

guarded hot plate 119

guide specification 54

guidelines 33

gypsum $13,14,37,38$ 


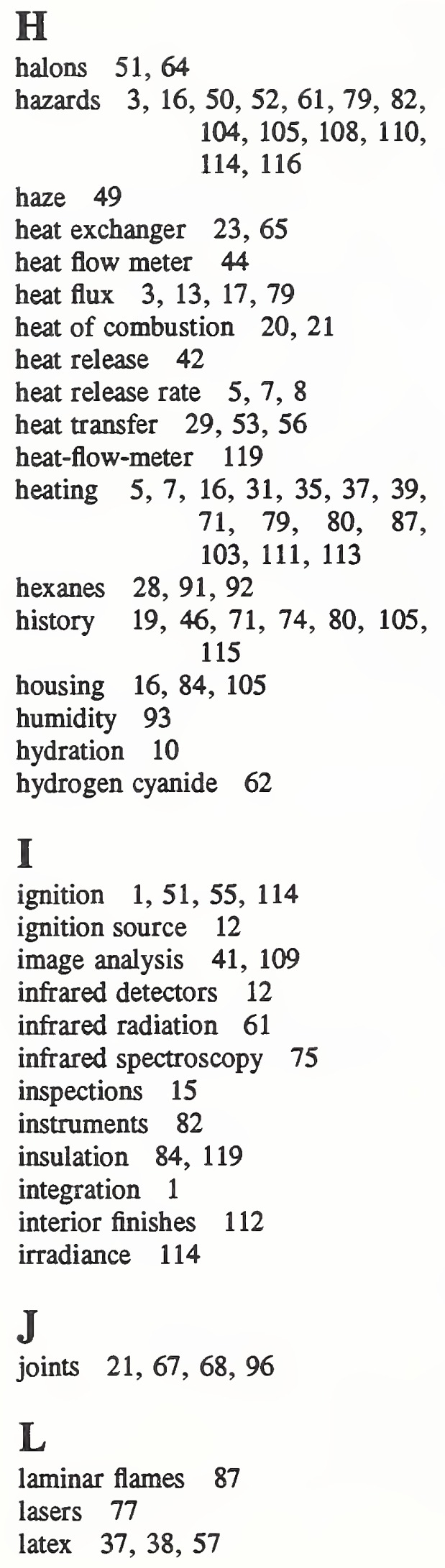

leakage $17,45,46,48,58,84$,

life safety 26

light scattering 34

lighting 115

lighting equipment 114

linings 4,24

luminescence 91

$\mathbf{M}$

maintenance 40

manuals 52, 57

masonry $38,84,88,118$

materials $8,19,45,49,53,64$, $73,84,117,120$

mathematical models 9,40

maturity 19

metals 75,76

methane $28,30,42-44,61,62$, $73,77,104$

microscopy $73,96,108$

mineral admixtures 25

mixing $9,44,83-86,102$

mixture $9,19,22,23,37,61,71$, $72,87,97,110$

modeling 29, 53

models $3,4,7,9,10,12,14,16$, $22,27-32,39,40$, $51-53,58,60,62$, $71,72,74-76,80$, $82,86,87,97-99$, $102,103,106,107$, $110,112,117,121$

moisture content 37,38

moisture transfer 38

molecular weight 77

moment resistant 22

multizone analysis 48

N

nonazeotropic 22

nozzles 107

NTU 22, 23

numerical analysis $39,100,101$

numerical simulations 27

nursing homes 74 
office automation 98

optics 114,115

ozone 55,117

$\mathbf{P}$

paints 37,69

parameters 13, 114

particle size 57

PDES 31

performance criteria 69

period $8,20,62-64,83,99,114$

periodic motion 27

physical security 33

piston effect 58,59

plastics 74

polycyclic aromatic hydrocarbons

73

polymethylmethacrylate 2,71

polyvinyl chloride 114

pool fires 60

portland cement 41,109

post-tensioning 22

precast concrete 22

precision 119

prisms 100,102

probes 99

product approval 47

profile $22,77,80,100,104$

propane $61,73,85,86$

propylene 102

protocol 6,18

public awareness 117

pumps $31,35,97,115$

pyrolysis $2,20,21$

R

radiant heating 103

radiation $39,53,61,102$

radiative heat loss 44

radon $49,83,84$

rate constant 110

rats $50,63,64$

refrigerants 97,117

refuge $46,66,108$

regression rate 79,106 requirements 118

research $36,40,51,52,59,89$, $98,100,105,117$

research facilities 47

residential buildings 105

response time 36

risks 40

roofing $67,68,94-96$

roofs $51,68,84,94-96$

room fires 24,71

rooms $1,28,30,32,39,66,75$, 80

$\mathbf{S}$

safety $2,3,5,12,15,21,23,24$, $26,29,33,36,40$, $44,46,47,51,57$, $59-61,64,66$, $72-74,78,80,81$, $87,89,95,100$, 103-106, 108, 110, $116,117,121$

scaling $36,68,69$

scaling laws 68

scanning electron microscopy 96 ,

seals 46

seams $68,94-96$

seats 12

seismic $20,22,67,88,89,106$, 110,116

seismic isolator 67

seismic safety 110,116

service life 25

shear strength 38

ships $15,16,64,65$

sign $25-27$

silica $10,11,25,120$

simulation 11,41

smoke $3,7,9,10,13-15,23,25$, $29,30,32,36,37$, $39,40,45,46,50$, 52, 57-64, 72-75, $81,82,89,91,92$, 108 
smoke control 58,82

smoke detectors 15

smoke hazards 108

smoke movement 58

smoke toxicity 7,50

smoldering 78

software documentation 53

soils 88

soot $34,43,44,52,55,61,62$, $72,87,88,99,102$

sorption 100

spontaneous combustion 46

sprays $51,87,107$

sprinklers 70

stairwells 57

standard reference material 64 , 120

standards $18,36,40,48,57,64$, $82,87,99,117$

statistics 51,101

steels 76

STEP $4,9,18,31,52,95,114$

strength $19,38,68,69,107,110$

stress $38,39,53,68,80,98$, 117,118

stress (mechanics) 68

structural dynamics 67

structural engineering 116

structures 19

submarines 64

substrates 12

sulfate attach 24

suppression 88

surface reaction 10

surfaces 39,76

\section{T}

technolgoy 59, 83, 97

temperature $19,28,30,34,66$, $77,80,103$

tenability limits 66

tensile strength 69

test methods $7,17,69,95,118$

testing $4,5,7,12,18-20,23,24$,

$35,40,45-48,65$,

$81,109,112-114$,

119 tests

$3,5-8,12,13,18-20,22$,

$23,36,39,43,45$, $55,65,66,69,74$,

$75,78,79,81-83$,

93, 94, 96, 97,

99-101, 103, 106-1-

$08,110,112,118$,

121

thermal conductivity 33,45

thermal insulation 119

thermal properties 2

thermodynamics 55,115

thermoplastics 106

thickness $30,45,59$

threats 33

time-to-failure 68

tolune 43

toxic gases 32,63

toxicity $3,7,16,45,50,52,62$,

tracer gas test 65

$63,82,89,99$

trench effect 90

turbulent flames 85

U

ultimate load 38

upholstered furniture 114

upholstery 1

V

validation 6

vapors 91

variable air volume system 54

velocity $2,78,87$

ventilation $82,83,111$

venting 31,80

vents $29,31,32,52,74,112$

visibility 25,26

volatile organic compounds 49,83

W

walls $17,28,29,32,38,46,62$, $78,84,90,112$, 118 
water $3,9-12,17,19,21,24,25$, $27,29,30,36,37$, $42,43,51,59,60$, $64,65,70,72,75$, $76,93,96,107$

water vapor diffusion 17

watertightness 94

wettability 95,96

wind loads 88

wind velocity 2

windows $16,80,102,103$

wires 7

wood $2,5,6,13,14,17,21,62$, $73,74,78,84,91$, $92,105,107,112$, 113

\section{$\mathbf{X}$}

$\mathrm{x}$-ray microanalysis 108

$\mathbf{Z}$

zeotropic refrigerants 97

zone models $28-30,32$ 



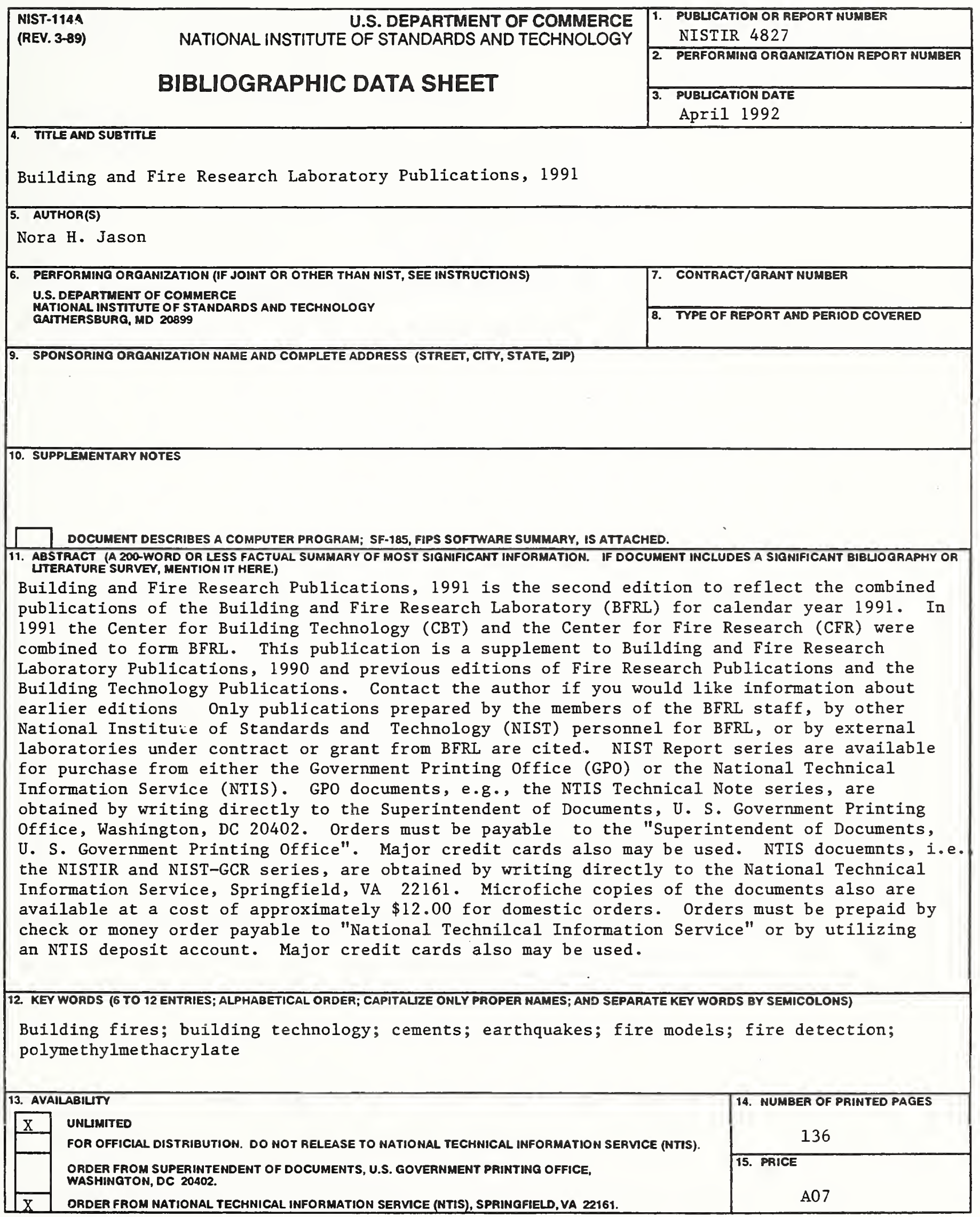



